\title{
ELETRO-OXIDAÇÃO OSCILATÓRIA DE MOLÉCULAS ORGÂNICAS PEQUENAS: PRODUÇÃO DE ESPÉCIES VOLÁTEIS E DESEMPENHO CATALÍTICO
}

Tese apresentada no Instituto de Química de São Carlos da Universidade de São Paulo como parte dos requisitos para a obtenção do título de doutor em ciências.

Área de concentração: Físico-Química

ORIENTADOR: PROF. DR. HAMILTON VARELA

\author{
Exemplar revisado \\ $\mathrm{O}$ exemplar original encontra-se em \\ acervo reservado na Biblioteca do IQSC-USP
}

São Carlos, 2016 

Aos meus pais, Cleide e Emilio, a minha irmã Andrea, a minha namorada Thaís e à memória de minha tia Luzia. 


\section{AGRADECIMENTOS}

Primeiramente, agradeço ao meus pais, Emilio e Cleide, a minha irmã Andrea, e a minha namorada Thaís, pelo apoio, paciência e compreensão imensuráveis.

Agradeço especialmente ao Prof. Hamilton Varela por sua dedicação profissional exemplar, e, acima de tudo, por sua imprescindível orientação, extremamente confiável e que me guiou em busca de novos conhecimentos de forma bastante desafiadora.

Fico muito grato ao Raphael e ao Melke, cujas contribuições foram significativas para o desenvolvimento desta tese. Ao Prof. Fábio Lima e ao seu ex-aluno Daniel, pelos seus esforços dedicados ao aprimoramento da técnica de espectrometria de massas do IQSC-USP, sem os quais a obtenção de resultados desta tese não seria possível. Não poderia deixar de reconhecer o envolvimento do Nickson com este trabalho, ajudando-me bastante durante todo o tempo, principalmente em meus primeiros passos em um laboratório de eletroquímica.

Tenho ciência de que este trabalho não seria possível sem a participação direta ou indireta de incontáveis pessoas que, ao menos em algum momento, dedicaram parte de suas vidas ao desenvolvimento das mais diferentes atividades alinhadas aos interesses do Instituto de Química de São Carlos da Universidade de São Paulo, contribuindo para o estabelecimento da elevada qualidade do ensino e da pesquisa desta instituição. Diante disso, registro a seguir, de modo limitado, lembrança e gratidão a todas essas pessoas: Elton, Eduardo (Spin), Bruno Batista, Graziela, Jéssica, Fabian, Emerson, Manuel, Alana, Bruno Previdello, Caroline, Débora, Cristiane, Murilo, Loriz, Otávio, Elenice, Thairo, Edvan, Amanda, Bott, Adriana, Patrícia, Maurinho, Jonas, Valdecir, Wanderson, Gabriel, Pedro, Nycolas, Rafael, Julia, Amaury, Rashida, Guilherme, Drielly, Vanessa, Fábio, Pietro, Jairo, Anielli, Waldemir, Pablo, Ayaz, Martin, Liliane, João, Herbert (Perereca), Watson, Tiago (Jeca), Daniel Angeli, Thiago Segato, Matias, Fabi, Maurinha, Vanderson, Edinho (vidraria), Miltinho (vidraria), Alex (mecânica), Toninho (mecânica), Ednelson (mecânica), Márcio (Central de Análises), Andreia (Serviço de Pós-Graduação), Gustavo (Serviço de Pós-Graduação), Silvia (Serviço de Graduação), Vilma (Setor de Limpeza), Aparecida (irmã da Vilma), Prof. Ernesto, Prof. Ticianelli, Prof. Germano, Prof ${ }^{a}$. Joelma, Prof. Carrilho, Prof. Sérgio Machado.

Por fim, agradeço ao CNPq pelo apoio financeiro, projeto No. 160511/2011-9, à FAPESP pelo auxílio financeiro dado ao Grupo de Eletroquímica do IQSC e à Universidade de São Paulo. 


\section{RESUMO}

A emergência frequente de oscilações de corrente e potencial durante a eletro-oxidação de moléculas orgânicas pequenas tem implicações mecanísticas importantes, como por exemplo, na conversão reacional global e, portanto, no desempenho de dispositivos práticos de conversão de energia. Orientado nesse sentido, este trabalho desenvolveu-se por meio de duas frentes relacionadas: (a) utilizando-se medidas obtidas por meio do acoplamento de uma célula eletroquímica a um espectrômetro de massas, estudou-se a dinâmica da produção de espécies voláteis durante a eletro-oxidação oscilatória de ácido fórmico, metanol e etanol. Além da apresentação de resultados experimentais ainda não relatados, introduz-se o uso de regressão linear multivariada para se comparar a corrente faradaica total estimada, com a proveniente da produção de espécies voláteis detectáveis: dióxido de carbono para ácido fórmico, dióxido de carbono e metilformiato para metanol e, dióxido de carbono e acetaldeído para etanol. A análise fornece a melhor combinação das correntes iônicas detectadas para se representar a corrente global ou a máxima contribuição faradaica possível devido à produção de espécies voláteis. Os resultados foram discutidos em conexão com aspectos do mecanismo reacional de cada molécula. A incompatibilidade entre a corrente faradaica total estimada e a obtida pela melhor combinação das correntes parciais provenientes da produção de espécies voláteis foi pequena para ácido fórmico, quatro e cinco vezes maior para etanol e metanol, respectivamente, evidenciando, nestes dois últimos casos, o aumento do papel desempenhado por espécies solúveis parcialmente oxidadas; (b) investigou-se características gerais da eletro-oxidação de formaldeído, ácido fórmico e metanol sobre platina em meio ácido, com ênfase na comparação do desempenho eletrocatalítico global sob condições estacionária e oscilatória. A comparação procedeu-se por meio da interpretação de resultados tratados de diferentes formas e generalizada pela utilização das mesmas condições experimentais em todos os casos. Para todos os sistemas, o baixo potencial alcançado durante as oscilações evidenciou uma considerável diminuição do sobrepotencial associado à reação anódica, se comparado com o obtido na ausência de oscilações. Além do mais, o processo de reativação superficial do catalisador que ocorre durante as oscilações amplia o desempenho de todos os sistemas em termos de atividade eletrocatalítica. Por fim, também são discutidos alguns aspectos do mecanismo reacional das moléculas estudadas. 


\begin{abstract}
The frequent emergence of current/potential oscillations during the electrooxidation of small organic molecules has implications on mechanistic aspects such as, for example, on the overall reaction conversion, and thus on the performance of practical devices of energy conversion. In this direction, this work is divided in two parts: (a) by means of on line Differential Electrochemical Mass Spectrometry (DEMS) it was studied the production of volatile species during the electrooxidation of formic acid, methanol and ethanol. Besides the presentation of previously unreported DEMS results on the oscillatory dynamics of such systems, it was introduced the use of multivariate linear regression to compare the estimated total faradaic current with the one comprising the production of volatile detectable species, namely: carbon dioxide for formic acid, carbon dioxide and methylformate for methanol and, carbon dioxide and acetaldehyde for ethanol. The introduced analysis provided the best combination of the DEMS ion currents to represent the total faradaic current or the maximum possible faradaic contribution of the volatile products for the global current. The results were discussed in connection with mechanistic aspects for each system. The mismatch between estimated total current and the one obtained by the best combination of partial currents of volatile products was found to be small for formic acid, 4 and 5 times bigger for ethanol and methanol, respectively, evidencing the increasing role played by partially oxidized soluble species in each case; (b) it was investigated general features of the electro-oxidation of formaldehyde, formic acid and methanol on platinum and in acid media, with emphasis on the comparison of the performance under stationary and oscillatory regimes. The comparison is carried out by different means and generalized by the use of identical experimental conditions in all cases. In all three systems studied, the occurrence of potential oscillations is associated with excursions of the electrode potentials to lower values, which considerable decreases the overpotential of the anodic reaction, when compared to that in the absence of oscillations. In addition, the reactivation of catalyst surface benefits the performance of all systems in terms of electrocatalytic activity. Finally, some mechanistic aspects of the studied reactions are also discussed.
\end{abstract}




\section{LISTA DE FIGURAS}

Figura 1 - Visão esquemática da eletro-oxidação de moléculas orgânicas pequenas sobre platina em diferentes regimes: (a) curva de polarização estacionária para um sistema em que $\mathrm{R}_{\mathrm{T}}<\mathrm{R}_{\mathrm{C}}$, (b) Cronoamperometria, (c) curva de polarização estacionária para um sistema em que $R_{T}>R_{C}$,

(d) Cronoamperometria para uma corrente aplicada de modo que o potencial do eletrodo sofra oscilações temporais espontâneas.[2] Ver texto para mais detalhes.

Figura 2 - Circuito equivalente simplificado representando uma célula eletrolítica conectada à um potenciostato, em que, C: capacitância; $Z_{\mathrm{F}}$ : impedância faradaica; $\mathrm{R}_{\mathrm{T}}$ : resistência ôhmica total; I: corrente total; $\mathrm{I}_{\mathrm{F}}$ : corrente faradaica; $\mathrm{I}_{\mathrm{C}}$ : corrente capacitiva; U: potencial aplicado; E: potencial do eletrodo de trabalho vs. eletrodo de referência (omitido na figura).

Figura 3 - Gráficos das funções $\mathrm{I}(\mathrm{E})$ e $\mathrm{I}_{\mathrm{F}}(\mathrm{E})$ em um mesmo plano cartesiano. Retas $\mathrm{I}(\mathrm{E})$ obtidas pela equação $\mathrm{I}(\mathrm{E})=(\mathrm{U}-\mathrm{E}) / \mathrm{R}_{\mathrm{T}}$, para diferentes valores dos parâmetros de controle $\mathrm{U}_{\text {e }} \mathrm{R}_{\mathrm{T}}$ : (a) $\mathrm{U}_{1} \mathrm{e}$ $\mathrm{R}$; (b) $\mathrm{U}_{1}$ e 10R; (c) $\mathrm{U}_{2}$ e 10R; (d) $\mathrm{U}_{3}$ e 10R. Retratos de fase para cada uma dessas condições estão esquematizados paralelamente ao eixo E, na parte inferior de cada figura. Ver texto para mais detalhes. $[1,14,16]$ 24

Figura 4 - Curvas de polarização estacionárias obtidas pela resolução numérica da equação (7),

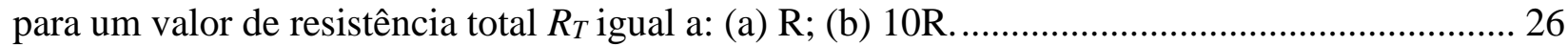

Figura 5 - Gráficos mostrando uma síntese da dinâmica do modelo unidimensional determinado pela equação (7): (a) diagrama de estabilidade.[19] (b) diagrama de bifurcação.[14, 17] A sigla sn em (a) e (b) marca a posição dos pontos fixos sela-nó, os quais delimitam a região de biestabilidade.

Figura 6 - Ilustração da existência de soluções periódicas obtidas pela resolução numérica das equações (15) e (16): (a) linhas finas azul e preta são as isóclinas de e e de c, respectivamente. Intersecção entre essas isóclinas determinam um ponto fixo instável do sistema. Linhas grossas em preto e vermelho são soluções obtidas por integração numérica das equações acopladas (15) e (16). (b) soluções periódicas para e em função do tempo. (c) soluções periódicas para c em função do tempo.[16, 18, 20] 36

Figura 7 - Análise do comportamento matemático das variáveis e e c: linhas azul e preta são as isóclinas de e e de c, respectivamente. Intersecção entre essas isóclinas determinam um ponto fixo instável do sistema. Os sentidos das trajetórias das soluções nas vizinhanças desse ponto são indicados pelos sinais das derivadas.[13, 14, 19].

Figura 8 - Análise da dinâmica de e e de c durante um ciclo oscilatório: (a) linhas azul e preta são as isóclinas de e e de c, respectivamente. Intersecção entre essas isóclinas determinam um ponto fixo instável do sistema, em torno do qual é mostrado um ciclo limite estável, em vermelho.[13, 14] (b) oscilações de potencial em função do tempo.[16]. 39

Figura 9 - Diagrama mostrando a região dos parâmetros $\rho$ e u onde o sistema bidimensional N-NDR exibe oscilações e biestabilidade.[10] Figura modificada a partir da referência 10........ 41 
Figura 10 - Gráficos ilustrando algumas propriedades do modelo HN-NDR: (a) constante de velocidade em função do potencial do eletrodo. b) isoterma de adsorção de uma espécie inibidora. (c) Curva de polarização estacionária corrente vs. potencial em preto e oscilações em regime galvanostático em vermelho.[19]

Figura 11 - Ciclos de retroalimentação positivo e negativo dos modelos N-NDR e HN-NDR. Nesses mecanismos matemáticos, o sinal positivo indica ativação e o negativo, inibição.[10, 14]

Figura 12 - Diagrama mostrando as regiões dos parâmetros $\rho$ e u onde o sistema bidimensional HN-NDR exibe oscilações e biestabilidade.[10] Figura modificada a partir da referência 10.... 46

Figura 13 - Medidas simultâneas de (a) VC e (b) VCEM para a corrente iônica $\mathrm{m} / \mathrm{z}=44$, durante a eletro-oxidação de ácido fórmico sobre um eletrodo de platina. $[\mathrm{HCOOH}]=1,0 \mathrm{~mol} \mathrm{~L}^{-1}$, $\left[\mathrm{H}_{2} \mathrm{SO}_{4}\right]=0,5 \mathrm{~mol} \mathrm{~L}-1$ e $\mathrm{T}=20^{\circ} \mathrm{C}$. Velocidade de varredura $=0,01 \mathrm{~V} \mathrm{~s}^{-1}$. Setas indicam o sentido da varredura de potencial.

Figura 14 - Medidas simultâneas de: (a) VC; VCEM para as correntes iônicas (b) $\mathrm{m} / \mathrm{z}=44$, (c) $\mathrm{m} / \mathrm{z}=60$, durante a eletro-oxidação de metanol sobre um eletrodo de platina. $\left[\mathrm{CH}_{3} \mathrm{OH}\right]=2,0 \mathrm{~mol} \mathrm{~L}^{-1},\left[\mathrm{HClO}_{4}\right]=0,5 \mathrm{~mol} \mathrm{~L}^{-1} \mathrm{e} \mathrm{T}=20^{\circ} \mathrm{C}$. Velocidade de varredura $=0,01 \mathrm{Vs}^{-1}$. Setas indicam o sentido da varredura de potencial. Dados brutos foram publicados nas ref. 3 e 34 .

Figura 15 - Medidas simultâneas de (a) VC, VCEM para as correntes iônicas de (b) m/z = 44, (c) $\mathrm{m} / \mathrm{z}=15$ e (d) $\mathrm{m} / \mathrm{z}=29$, durante a eletro-oxidação de etanol sobre nanopartículas de platina (platina black). $\left[\mathrm{CH}_{3} \mathrm{CH}_{2} \mathrm{OH}\right]=1,0 \mathrm{~mol} \mathrm{~L} \mathrm{~L}^{-1},\left[\mathrm{H}_{2} \mathrm{SO}_{4}\right]=0,5 \mathrm{~mol} \mathrm{~L}-1$ e $\mathrm{T}=20{ }^{\circ} \mathrm{C}$. Velocidade de varredura $=0,01 \mathrm{Vs}^{-1}$. Setas indicam o sentido da varredura de potencial. 61

Figura 16 - Evolução temporal (a) do potencial do eletrodo de trabalho, U e (b) da corrente iônica $\mathrm{m} / \mathrm{z}=44, \mathrm{j}_{\mathrm{m} / \mathrm{z}=44}$, durante a eletro-oxidação oscilatória de ácido fórmico a j $=0,44 \mathrm{~mA} \mathrm{~cm}^{-2}$. $[\mathrm{HCOOH}]=1,0 \mathrm{~mol} \mathrm{~L}^{-1},\left[\mathrm{H}_{2} \mathrm{SO}_{4}\right]=0,5 \mathrm{~mol} \mathrm{~L}^{-1} \mathrm{e} \mathrm{T}=20^{\circ} \mathrm{C}$. Para informações adicionais, ver seção Experimental.

Figura 17 - Séries temporais normalizadas: (a) derivada primeira do potencial do eletrodo experimental a j =0,44 mA.cm ${ }^{-2}$, dU/dt (linha preta), acompanhado pela derivada primeira do potencial do eletrodo predita, dUp/dt (linha azul); (b) derivada primeira do potencial residual, o erro $\varepsilon$. $[\mathrm{HCOOH}]=1,0 \mathrm{~mol} \mathrm{~L}^{-1},\left[\mathrm{H}_{2} \mathrm{SO}_{4}\right]=0,5 \mathrm{~mol} \mathrm{~L}^{-1} \mathrm{e} \mathrm{T}=20^{\circ} \mathrm{C}$. Dados mostrados em (a) foram obtidos a partir dos resultados mostrados na Figura 16. Como foi normalizada, a escala no eixo horizontal está ausente: tem a sua origem no zero e termina em 1.

Figura 18 - Análise de covariância para as séries temporais normalizadas resultantes da eletro-oxidação oscilatória de ácido fórmico (a) derirada primeira do potencial do eletrodo experimental, dU/dt; (b) covariância populacional entre $\varepsilon$ and dU/dt, Cov ( $\varepsilon, \mathrm{dU} / \mathrm{dt}$ ); (c) corrente

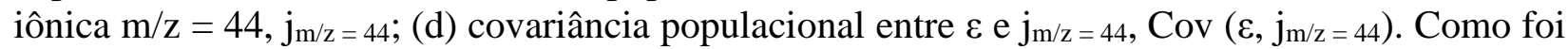
normalizada, a escala no eixo horizontal está ausente: tem a sua origem no zero e termina em 1. 
Figura 19 - Evolução temporal (a) do potencial do eletrodo de trabalho, U, e das correntes iônicas de (b) $\mathrm{m} / \mathrm{z}=44, \mathrm{j}_{\mathrm{m} / \mathrm{z}=44}$ e (c) $\mathrm{m} / \mathrm{z}=60, \mathrm{j}_{\mathrm{m} / \mathrm{z}=60}$, durante a eletro-oxidação oscilatória de metanol a $\mathrm{j}=0,35 \mathrm{~mA} \mathrm{~cm}{ }^{-2}$. $\left[\mathrm{CH}_{3} \mathrm{OH}\right]=1,0 \mathrm{~mol} \mathrm{~L}^{-1},\left[\mathrm{HClO}_{4}\right]=0,5 \mathrm{~mol} \mathrm{~L}^{-1} \mathrm{e} \mathrm{T}=20^{\circ} \mathrm{C}$. Para informações adicionais, ver Seção Experimental. Dados brutos foram publicados nas ref. 3 e 34 .

Figura 20 - Séries temporais normalizadas: (a) derivada primeira do potencial do eletrodo experimental a $\mathrm{j}=0,35 \mathrm{~mA} \mathrm{~cm} \mathrm{~cm}^{-2}, \mathrm{dU} / \mathrm{dt}$ (linha preta), acompanhado pela derivada primeira do potencial do eletrodo predita, $\mathrm{dU}_{\mathrm{p}} / \mathrm{dt}$ (linha azul); (b) derivada primeira do potencial residual, o erro $\varepsilon$. $\left[\mathrm{CH}_{3} \mathrm{OH}\right]=1,0 \mathrm{~mol} \mathrm{~L}^{-1},\left[\mathrm{HClO}_{4}\right]=0,5 \mathrm{~mol} \mathrm{~L}^{-1} \mathrm{e} \mathrm{T}=20{ }^{\circ} \mathrm{C}$. Dados apresentados em (a) foram obtidos a partir daqueles mostrados na Figura 19. A escala no eixo horizontal é omitida pois foi normalizada.

Figura 21 - Análise de covariância para as séries temporais normalizadas resultantes da eletrooxidação oscilatória de metanol (a) derirada primeira do potencial do eletrodo experimental, dU/dt; (b) populacional corariência entre $\varepsilon$ e dU/dt, $\operatorname{Cov}(\varepsilon, \mathrm{dU} / \mathrm{dt}$ ); (c) corrente iônica $\mathrm{m} / \mathrm{z}=44, \mathrm{j} / \mathrm{z}=44$;

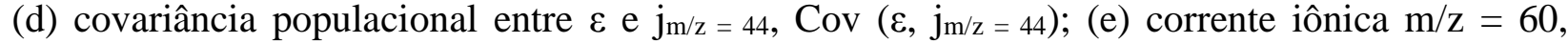
$\mathrm{j}_{\mathrm{m} / \mathrm{z}=60}$; (f) covariância populacional entre $\varepsilon$ e $\mathrm{j}_{\mathrm{m} / \mathrm{z}=60}$, $\operatorname{Cov}\left(\varepsilon, \mathrm{j}_{\mathrm{m} / \mathrm{z}=60}\right)$. A escala no eixo horizontal está omitida, pois foi normalizada.

Figura 22 - Evolução temporal (a) do potencial do eletrodo de trabalho, U, e das correntes iônicas de (b) $\mathrm{m} / \mathrm{z}=44, \mathrm{j} / \mathrm{z}=44$, (c) $\mathrm{m} / \mathrm{z}=15, \mathrm{j} \mathrm{m} / \mathrm{z}=15$ e (c) $\mathrm{m} / \mathrm{z}=29, \mathrm{j} \mathrm{m} / \mathrm{z}=29$ durante a eletro-oxidação oscilatória de etanol a j $=0,043 \mathrm{~mA} \mathrm{~cm}^{-2}$. $\left[\mathrm{CH}_{3} \mathrm{CH}_{2} \mathrm{OH}\right]=1,0 \mathrm{~mol} \mathrm{~L}^{-1},\left[\mathrm{H}_{2} \mathrm{SO}_{4}\right]=0,5 \mathrm{~mol} \mathrm{~L}^{-1} \mathrm{e}$ $\mathrm{T}=20^{\circ} \mathrm{C}$. Para informações adicionais, ver Seção Experimental. 73

Figura 23 - Séries temporais normalizadas: (a) derivada primeira do potencial do eletrodo experimental a j $=0,043 \mathrm{~mA} \mathrm{~cm}^{-2}, \mathrm{dU} / \mathrm{dt}$ (linha preta), acompanhado pela derivada primeira predita do potencial do eletrodo, $\mathrm{dU} / \mathrm{pt}$ (linha azul); (b) derivada primeira do potencial residual, $\varepsilon$. $\left[\mathrm{CH}_{3} \mathrm{CH}_{2} \mathrm{OH}\right]=1,0 \mathrm{~mol} \mathrm{~L}^{-1},\left[\mathrm{H}_{2} \mathrm{SO}_{4}\right]=0,5 \mathrm{~mol} \mathrm{~L}^{-1}$ e $\mathrm{T}=20^{\circ} \mathrm{C}$. Dados mostrados em (a) foram obtidos a partir daqueles mostrados na Figura 22, ver texto para maiores detalhes. A escala no eixo horizontal está omitida, pois foi normalizada. 74

Figura 24 - Análise de covariância para as séries temporais normalizadas resultantes da eletrooxidação oscilatória de etanol (a) derivada primeira do potencial do eletrodo experimental, dU/dt; (b) populacional covariância entre $\varepsilon$ e dU/dt, $\operatorname{Cov}\left(\varepsilon, \mathrm{dU} / \mathrm{dt}\right.$ ); (c) corrente iônica $\mathrm{m} / \mathrm{z}=44, \mathrm{j}_{\mathrm{m} / \mathrm{z}=44}$;

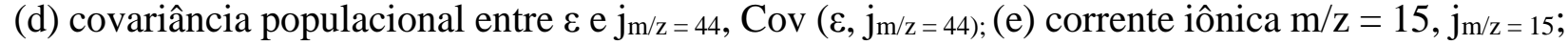
(f) covariância populacional entre $\varepsilon$ e $\mathrm{j}_{\mathrm{m} / \mathrm{z}=15}$, $\operatorname{Cov}\left(\varepsilon, \mathrm{j}_{\mathrm{m} / \mathrm{z}=15)}\right.$; (g) corrente iônica $\mathrm{m} / \mathrm{z}=29, \mathrm{j}_{\mathrm{m} / \mathrm{z}=29}$; (h) covariância populacional entre $\varepsilon$ e $\mathrm{j}_{\mathrm{m} / \mathrm{z}=29}$, $\operatorname{Cov}\left(\varepsilon, \mathrm{j}_{\mathrm{m} / \mathrm{z}=29}\right)$. A escala no eixo horizontal está omitida, pois foi normalizada.

Figura 25 - Esquema simplificado do mecanismo de eletro-oxidação de (a) ácido fórmico, (b) metanol e (c) etanol sobre platina. Espécies em azul são as detectadas pelo DEMS on line e em vermelho, espécies solúveis parcialmente oxidadas que não são detectáveis.

Figura 26 - Curvas potenciodinâmicas (linhas pretas) obtidas durante uma varredura lenta $\left(\mathrm{dU} / \mathrm{dt}=0.002 \mathrm{~V} \mathrm{~s}^{-1}\right)$ do potencial de eletrodos de platina imersos em 0,5 mol L-1 de (a) HCHO, (b) $\mathrm{HCOOH}$, (c) $\mathrm{CH}_{3} \mathrm{OH}$, contidos em uma solução aquosa de $\mathrm{H}_{2} \mathrm{SO}_{4} 0,5 \mathrm{~mol} \mathrm{~L}^{-1}$. Da esquerda 
para a direita, curvas galvanostáticas (linhas vermelhas) obtidas sob as seguintes correntes aplicadas: (a) $2.6 \mathrm{~mA} \mathrm{~cm}^{-2}$, (b) $2.7 \mathrm{~mA} \mathrm{~cm}^{-2}$, (c) $0.77 \mathrm{~mA} \mathrm{~cm}^{-2}$. O potencial médio a cada ciclo é dado pelos pontos em verde. $\mathrm{T}=25^{\circ} \mathrm{C}$.

Figura 27 - Curvas de densidade de potência vs. densidade de corrente para a eletro-oxidação de farmaldeído sob regimes galvanodinâmico (vermelho) e potenciodinâmico (preto). $\mathrm{d} / \mathrm{dt}=5 \mu \mathrm{A} \mathrm{s}^{-1}$. Demais condições são idênticas às descritas na Figure 26................................ 85

Figura 28 - dU/dt versus U (parte inferior) e U versus tempo (parte superior) para um ciclo oscilatório. Dados extraídos da Figure 26 para (a) e (d) formaldeído, (b) e (e) ácido fórmico e, (c) e (f) metanol. 


\section{LISTA DE TABELAS}

Tabela I - Dados termodinâmicos para as reações de oxidação de $\mathrm{H}_{2}$, formaldeído, ácido fórmico, metanol e etanol sob condições padrão a $25^{\circ} \mathrm{C}$.............................................................. 17

Tabela II -Máxima velocidade dU/dt e $U_{p}$ para um ciclo oscilatório, amplitude $(\Delta U)$, o tempo para o potencial atingir o seu valor máximo ( $\mathrm{t}_{\mathrm{Umax}}$ ) e frequência (f) para um ciclo oscilatório 


\section{SUMÁRIO}

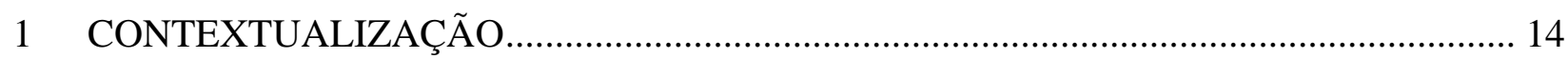

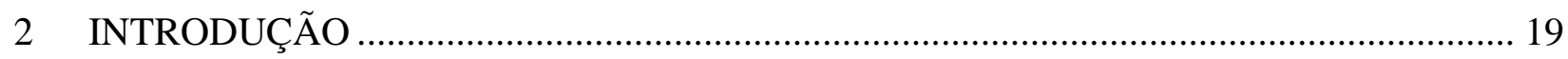

2.1 Resistência Diferencial Negativa ......................................................................... 19

2.2 Modelo Protótipo Unidimensional: Biestabilidade........................................................... 21

2.3 Estabilidade Linear para o Sistema Unidimensional ..................................................... 31

2.4 Sistema Bidimensional N-NDR: Oscilações Periódicas Simples.................................... 33

2.5 Sistema Bidimensional HN-NDR: Oscilações Periódicas Simples .................................. 41

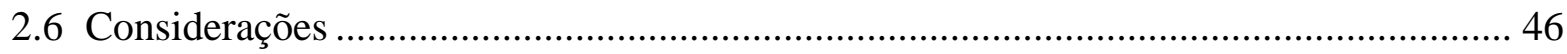

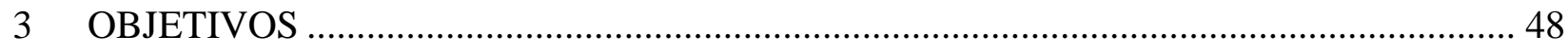

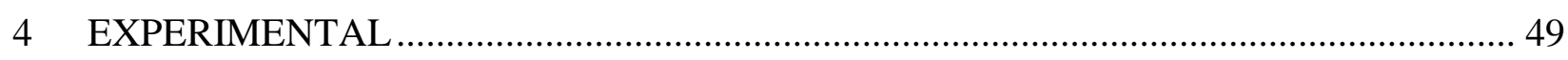

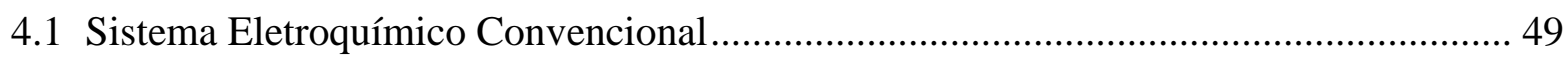

4.2 Célula Eletroquímica Acoplada à um Espectrômetro de Massas: Detecção de Produtos

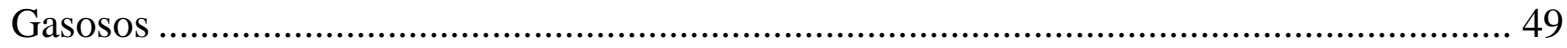

4.3 Procedimento de Limpeza......................................................................................... 51

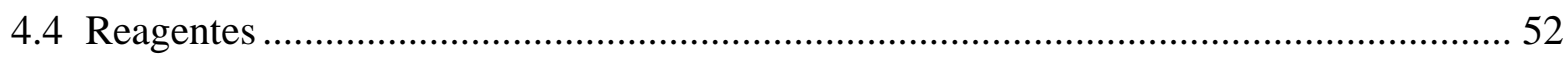

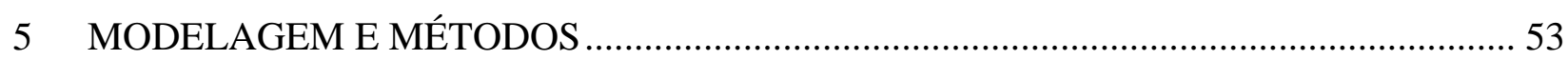

5.1 Descrição Algébrica do Modelo de Regressão Linear Multivariada ............................... 53

5.2 Breves Descrições Algébrica e Matricial do Método dos Mínimos Quadrados .............. 55

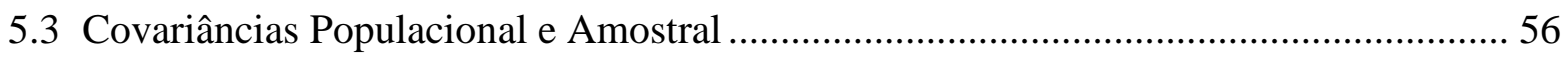

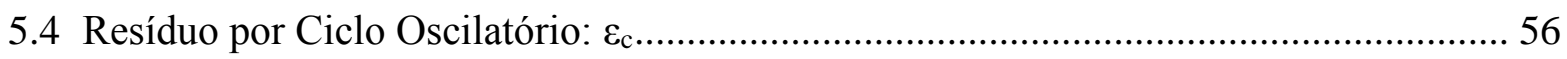

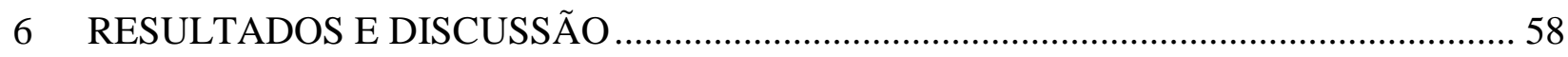

6.1 Produção de Espécies Voláteis Fundamentada por um Modelo de Regressão Linear

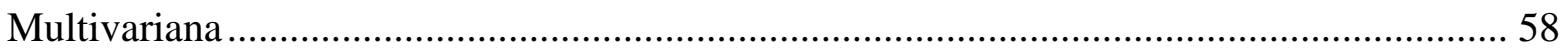

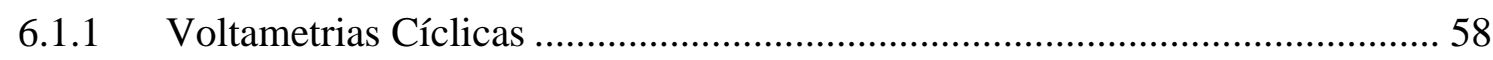

6.1.2 Regressão Linear Multivariada: Resultados Obtidos para Ácido Fórmico...... 62

6.1.3 Regressão Linear Multivariada: Resultados Obtidos para Metanol................. 66

6.1.4 Regressão Linear Multivariada: Resultados Obtidos para Etanol..................... 72

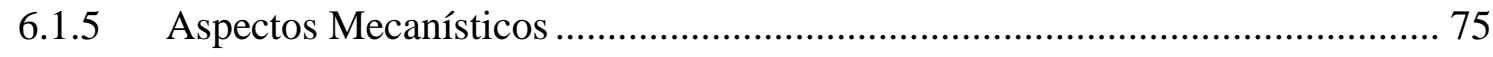

6.2 Desempenho Eletrocatalítica durante a Oxidação de Moléculas Orgânicas Pequenas em

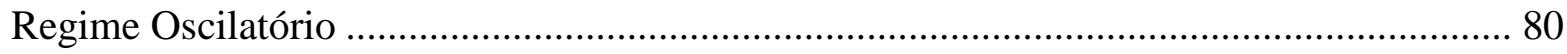

6.2.1 Eficiência em Termos de Sobrepotencial......................................................... 81 
6.2.2 Eficiência e Mecanismo Reacional ...................................................... 85

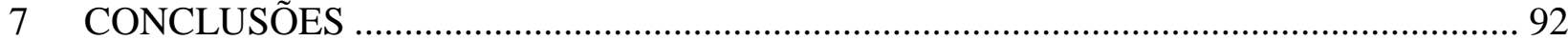

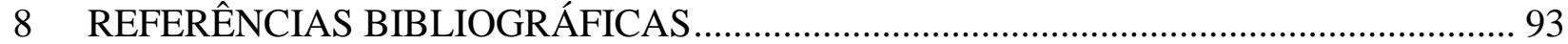




\section{CONTEXTUALIZAÇÃO}

Os mecanismos de reação de diversas moléculas orgânicas pequenas apresentam características em comum que tornam os seus processos de eletro-oxidação susceptíveis a instabilidades dinâmicas. Varela e Krischer[1] realizaram uma sistematização dessas características. Primeiro, existe ao menos um intermediário fortemente adsorvido que inibe a reação de oxidação global em baixos valores de potencial ou cuja lenta cinética de oxidação limita a velocidade reacional. Segundo, em potenciais mais elevados, espécies oxigenadas adsorvidas sobre o eletrodo apresentam um caráter dual: ao mesmo tempo que reagem com os intermediários citados anteriormente, também inibem a reação de oxidação global de modo a originar, em uma curva de polarização estacionária corrente $v s$. potencial, uma região de resistência diferencial negativa parcialmente escondida.

A Figura 1 ilustra de forma esquemática alguns aspectos da eletro-oxidação dessas moléculas em eletrodos de platina ou a base deste metal.[2] Em (a) é mostrada uma curva de polarização estacionária corrente $v s$. potencial com seu formato característico, desde que o sistema eletroquímico tenha uma resistência total $\mathrm{R}_{\mathrm{T}}$ abaixo de um valor crítico $\mathrm{R}_{\mathrm{C}}$. Devido à lenta cinética de oxidação do intermediário fortemente adsorvido sobre o eletrodo, a corrente é desprezível em uma ampla faixa de potenciais e daí resulta os altos sobrepotenciais encontrados para esses sistemas. $\mathrm{O}$ aumento abrupto da corrente coincide com a rápida intensificação da velocidade de formação de espécies oxigenadas a partir da água, as quais reagem com o intermediário que bloqueia a superfície do eletrodo em baixos valores de potencial. Todavia, a corrente prontamente diminui de modo a gerar um pico ou ombro, indicando que outro processo deve acontecer concomitantemente à essa reação de oxidação. De fato, com o aumento do potencial, ocorre o fortalecimento da interação entre espécies oxigenadas e a superfície do eletrodo, dando origem a um processo de inibição: a adsorção de espécies oxigenadas compete com a adsorção das moléculas orgânicas, reduzindo a velocidade da reação global e dando origem à resistência diferencial negativa, parcialmente escondida. 
Figura 1 - Visão esquemática da eletro-oxidação de moléculas orgânicas pequenas sobre platina em diferentes regimes: (a) curva de polarização estacionária para um sistema em que $\mathrm{R}_{\mathrm{T}}<\mathrm{R}_{\mathrm{C}}$, (b) Cronoamperometria, (c) curva de polarização estacionária para um sistema em que $R_{T}>R_{C}$,

(d) Cronoamperometria para uma corrente aplicada de modo que o potencial do eletrodo sofra oscilações temporais espontâneas.[2] Ver texto para mais detalhes.

(a)
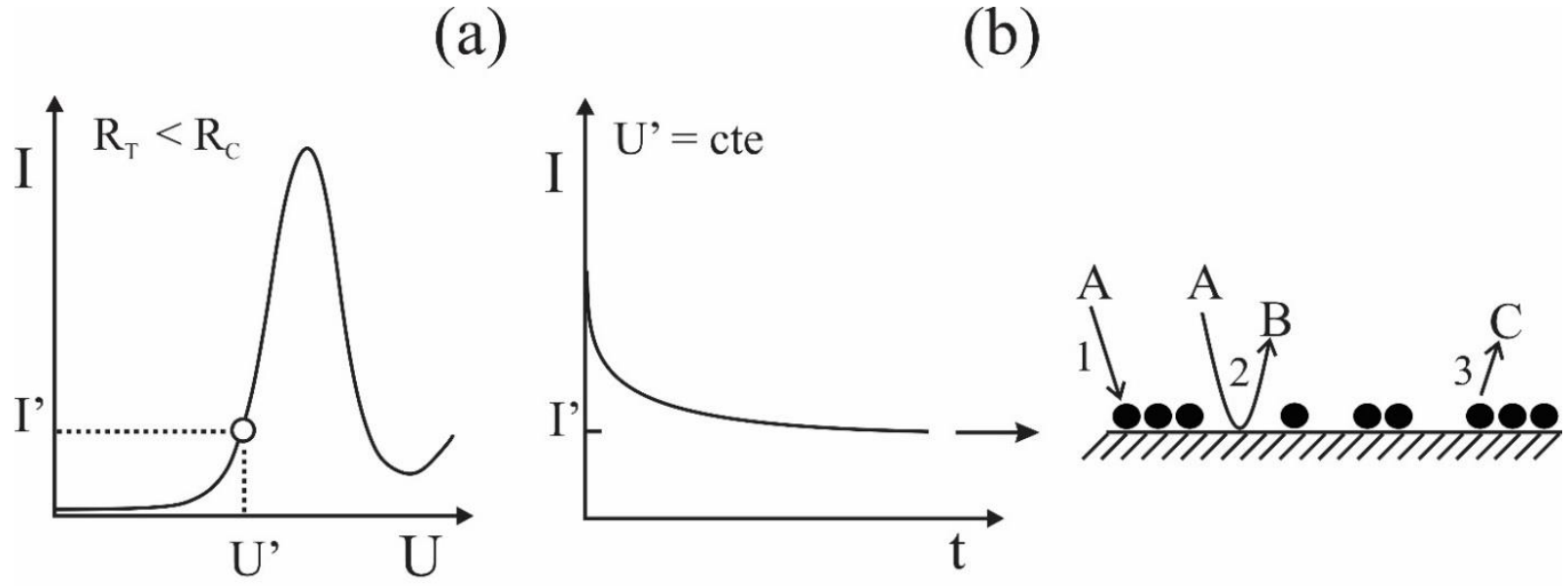

(c)

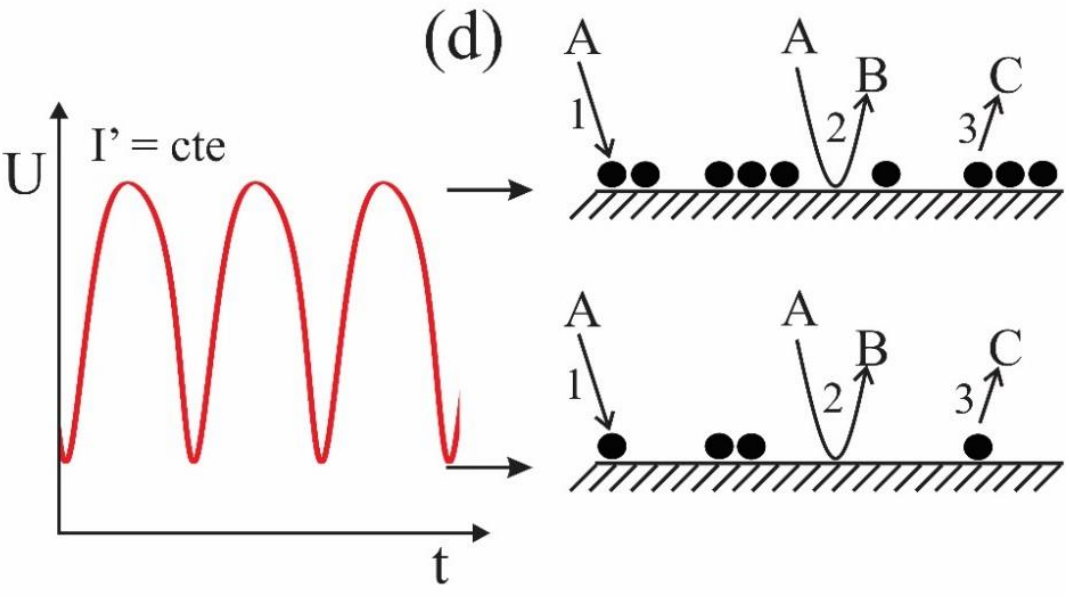

Supondo-se, por exemplo, que o valor de potencial U' ilustrado na Figura 1 (a) seja aplicado ao sistema eletroquímico contendo a molécula orgânica pequena. A variação da corrente total medida em função do tempo pode ser representada pela Figura 1 (b). Depois de um transiente inicial, a corrente tende para um valor estacionário em que as velocidades das etapas reacionais e, evidentemente, o potencial do eletrodo e o recobrimento de diferentes intermediários adsorvidos tornam-se independentes do tempo. O painel ao lado da Figura 1 (b) esboça essa situação em termos de um eletrodo parcialmente bloqueado por um intermediário fortemente adsorvido P (círculos pretos) e de reações envolvendo espécies A, B e C. Nessa notação, A refere-se à molécula orgânica, 
B a produtos solúveis parcialmente oxidadas e $\mathrm{C}$ ao produto solúvel da oxidação final do intermediário P. A reação 1 representa a formação desse intermediário a partir de A, a 2 a oxidação parcial de A para B e a 3 a etapa reacional em que o intermediário adsorvido P é completamente oxidado. Mais adiante é apresentado um exemplo para ilustrar a natureza química dessas espécies.

Por outro lado, se a corrente de magnitude I' for imposta através da interface, a resistência total do sistema $\mathrm{R}_{\mathrm{T}}$ excede o valor crítico $\mathrm{R}_{\mathrm{C}}$ devido a infinita resistência externa inerente ao regime galvanostático. A Figura 1 (c) enfatiza que a região de resistência diferencial negativa torna-se instável quando o sistema se encontra sob esse modo de controle e que apenas os estados estacionários representados pela linha contínua podem ser acessados experimentalmente nessa condição. Aplicada a corrente, depois de certo transiente, o processo de eletro-oxidação pode estabelecer-se em um estado estacionário estável ou evoluir para um estado oscilatório, em que o potencial do eletrodo oscila no transcorrer do tempo, como demonstrado na Figura 1 (d). A evolução temporal dessas oscilações pode ser compreendida como descrito abaixo.

Ao redor da região de resistência diferencial negativa escondida, o potencial do eletrodo sofre sucessivos aumentos, os quais são amplificados pela queda ôhmica do sistema até que acontece um aumento abrupto. Com um certo atraso, a reação entre o intermediário adsorvido P e espécies oxigenadas provoca um aumento da corrente faradaica, suprimindo o aumento do potencial em um primeiro momento. E, posteriormente, provocando sucessivos decréscimo de potencial, que amplificados, resultam em uma brusca diminuição. O painel ao lado da Figura 1 (d) ilustra a situação de mínimo e máximo recobrimento da espécie P. O recobrimento desta espécie (e de outros adsorbatos), bem como a velocidade de todas as etapas reacionais envolvidas variam entre dois valores limites.

A natureza química das espécies A, B, C e P representadas na Figura 1 pode ser discutida em termos do mecanismo de uma reação de eletro-oxidação particular. Assumindo-se o metanol como sendo a molécula orgânica de partida A, o seguinte conjunto de reações pode ser descrito. A reação 1 é a formação da espécie $\mathrm{P}$, isto é, do monóxido de carbono adsorvido $\mathrm{CO}_{\mathrm{ad}}$ a partir de uma molécula de metanol (A):

$$
\mathrm{Pt}+\mathrm{H}_{3} \mathrm{COH} \rightarrow \mathrm{PtCO}+4 \mathrm{H}^{+}+4 e^{-}
$$


Na reação 2, a espécie solúvel parcialmente oxidada do metanol (A), por exemplo, resulta em ácido fórmico dissolvido $\mathrm{HCOOH}(\mathrm{B})$ :

$\mathrm{Pt}+\mathrm{H}_{3} \mathrm{COH}+\mathrm{H}_{2} \mathrm{O} \rightarrow \mathrm{Pt}+\mathrm{HCOOH}+4 \mathrm{H}^{+}+4 e^{-}$.

Finalmente, a oxidação do $\mathrm{CO}_{\mathrm{ad}}(\mathrm{P})$ a dióxido de carbono, $\mathrm{CO}_{2}(\mathrm{C})$, é dada por,

$\mathrm{PtCO}+\mathrm{PtO} \rightarrow 2 \mathrm{Pt}+\mathrm{CO}_{2}$

As reações listadas nesse exemplo não são etapas elementares. Para um esquema mais realístico da eletro-oxidação do metanol, ver o mecanismo proposto por Nagao et al.[3].

A Tabela I permite a comparação de dados termodinâmicos para as reações de oxidação de gás hidrogênio e de algumas moléculas orgânicas: formaldeído, ácido fórmico, metanol e etanol. $\Delta G^{o}$ é a energia livre e $n$ o número de elétrons envolvidos na reação global. $U_{c e l}^{o}$ e $E^{o}{ }_{a n o d o}$ representam o potencial de circuito aberto termodinâmico para a célula e o potencial padrão teórico do ânodo, respectivamente.[2, 4]

Tabela I - Dados termodinâmicos para as reações de oxidação de $\mathrm{H}_{2}$, formaldeído, ácido fórmico, metanol e etanol sob condições padrão a $25^{\circ} \mathrm{C} .[2,4,5]$

\begin{tabular}{ccccc}
\hline Reações Globais & $\begin{array}{c}\Delta \mathbf{G}^{\mathbf{0}} \\
\left(\mathbf{k J ~ m o l} \mathbf{- 1}^{-1}\right)\end{array}$ & $\mathbf{n}$ & $\begin{array}{c}\mathbf{U}^{\mathbf{o}} \text { cel } \\
(\mathbf{V})\end{array}$ & $\begin{array}{c}\mathbf{E}^{\mathbf{0}} \text { anode } \\
(\mathbf{V})\end{array}$ \\
\hline $\mathrm{H}_{2}+1 / 2 \mathrm{O}_{2} \rightarrow \mathrm{H}_{2} \mathrm{O}$ & -237.3 & 2 & 1.23 & 0.00 \\
\hline $\mathrm{CH}_{2} \mathrm{O}+\mathrm{O}_{2} \rightarrow \mathrm{CO}_{2}+\mathrm{H}_{2} \mathrm{O}$ & -521.7 & 4 & 1.35 & -0.12 \\
\hline $\mathrm{HCOOH}+1 / 2 \mathrm{O}_{2} \rightarrow \mathrm{CO}_{2}+\mathrm{H}_{2} \mathrm{O}$ & -285.5 & 2 & 1.48 & -0.25 \\
\hline $\mathrm{CH}_{3} \mathrm{OH}+3 / 2 \mathrm{O}_{2} \rightarrow \mathrm{CO}_{2}+2 \mathrm{H}_{2} \mathrm{O}$ & -702.7 & 6 & 1.21 & 0.02 \\
\hline $\mathrm{CH}_{3} \mathrm{CH}_{2} \mathrm{OH}+3 \mathrm{O}_{2} \rightarrow 2 \mathrm{CO}_{2}+3 \mathrm{H}_{2} \mathrm{O}$ & -1327 & 12 & 1.14 & 0.09 \\
\hline
\end{tabular}

Nessa tabela, nota-se que os potenciais de circuito aberto termodinâmicos para todas as moléculas orgânicas são bastante similares ao do gás hidrogênio. Contudo, as reações de oxidação dessas moléculas só acontecem de forma considerável em potenciais muito maiores do que seus potenciais padrão teóricos, resultando, então, em altos sobrepotenciais.[4] Tão logo o mecanismo reacional dessas moléculas é posto em questão, fica imediatamente claro que a frequente ocorrência de caminhos paralelos levando a produção de subprodutos podem significativamente reduzir a completa conversão dessas moléculas orgânicas à $\mathrm{CO}_{2}$, cujo caminho reacional resulta no maior 
número de elétrons transferidos. De fato, baixa eficiência de potencial e baixa eficiência de corrente são limitações que inviabilizam a aplicação dessas moléculas como combustíveis líquidos em dispositivos de conversão de energia.[5]

Poucos trabalhos científicos têm abordado a compreensão de fenômenos não-lineares em sistemas eletroquímicos sob uma perspectiva mais abrangente do mecanismo reacional de moléculas orgânicas pequenas. Por exemplo, para a oxidação oscilatória de metanol e etanol, não existem estudos especificamente tratando da contribuição da produção de espécies parcialmente oxidadas para a corrente global. Na verdade, nosso trabalho parece ter sido o primeiro, pois parte dos resultados apresentados nesta tese já foram publicados no seguinte periódico: Delmonde et al.: J. Phys. Chem. C 2014, 118, 17699-17709. Tem sido relatado que células combustíveis com membrana polimérica alimentada com $\mathrm{H}_{2}$ contaminado por $\mathrm{CO}$ apresentam um aumento de performance quando operam em regime oscilatório.[6-8] Mas é desconhecido até o presente momento qualquer trabalho relatando um estudo sistemático comparando a performance da eletro-oxidação oscilatória de combustíveis líquidos orgânicos.

Portanto, a fim de contribuir com novos conhecimentos no contexto evidenciado no parágrafo imediatamente anterior, a eletro-oxidação oscilatória de algumas moléculas orgânicas foi investigada com foco na produção de espécies voláteis, bem como na comparação do desempenho global desses sistemas operando em regime regular e oscilatório. Como a investigação se baseia na análise dos perfis dos ciclos oscilatórios, torna-se importante estabelecer de forma um pouco mais formal a origem dos mecanismos matemáticos e físicos pelos quais se dão tais perfis. Portanto, a seguir é apresentada uma introdução à dinâmica não-linear em conexão com sistemas eletroquímicos. Na parte final dessa seção, retorna-se ao esboço dado pela situação apresentada na Figura 1, mas então, baseando-se em novos conceitos apresentados, discute-se algumas considerações de fundamental importância para esta tese. A partir daí o texto está organizado na seguinte sequência: objetivos, experimental, modelagem e métodos, resultados e discussão, conclusões e referências bibliográficas. 


\section{INTRODUÇÃO}

Para sistemas eletroquímicos operando longe do estado de equilíbrio termodinâmico, instabilidades relacionadas ao potencial do eletrodo possibilitam a emergência de padrões temporais auto-organizados, ou seja, de oscilações ao longo do tempo. O mecanismo matemático que descreve o comportamento não-linear das variáveis que determinam a morfologia dessas oscilações de potencial são comuns em diversas áreas do conhecimento: química, biologia, astronomia, etc.[9, 10] Exemplos de variáveis para um sistema envolvendo a eletro-oxidação de moléculas orgânicas pequenas são o potencial do eletrodo e o grau de recobrimento do monóxido de carbono.

A seguir, com o intuito de se demonstrar a inter-relação entre essas variáveis e o seu impacto na morfologia de um ciclo oscilatório, primeiramente é apresentada a origem física e química da região de resistência diferencial negativa e depois, parte-se para a discussão de alguns aspectos importantes, também associados ao circuito eletroquímico. Posteriormente, discute-se o mecanismo matemático e físico relacionado às oscilações de dois modelos protótipos de osciladores eletroquímicos. Por fim, algumas considerações são realizadas dando-se ênfase ao último modelo apresentado, cujas características são mais compatíveis com o surgimento de oscilações durante a eletro-oxidação de moléculas orgânicas pequenas e que, portanto, pode ser utilizado para orientar a discussão de alguns aspectos elencados sobre a morfologia das oscilações.

\subsection{Resistência Diferencial Negativa}

Instabilidades cinéticas são extremamente comuns em sistemas eletroquímicos operando longe do equilíbrio termodinâmico e frequentemente acontecem associadas com processos faradaicos que resultam em uma curva de polarização corrente vs. potencial em formato de "N". Mais precisamente, tais instabilidades surgem em conexão com o ramo central dessa curva, caracterizada por apresentar uma resistência à transferência de carga negativa ou simplesmente, NDR, do inglês Negative Differential Resistence.[1, 11, 12]

As possíveis origens da NDR foram deduzidas por Koper e Sluyters[13]. Por exemplo, supondo-se, por simplicidade, um processo de transferência de elétrons ocorrendo irreversivelmente, ou seja, em um único sentido.[14] Neste caso, a dependência existente entre a 
corrente faradaica $I_{F}$ e o potencial do eletrodo $E$ pode ser expressada pela relação geral dada pela equação (4), em que, $n$ é o número de elétrons transferidos, $F$ a constante de Faraday, $A$ a área do eletrodo disponível, $k(E)$ a constante de velocidade e $\mathrm{c}(0)$ é a concentração da espécie eletroativa no plano reacional.[1]

$$
I_{F}(E)=n F A k(E) c(0)
$$

A partir dessa equação, a resistência a transferência de carga $R_{t c}$ ou, equivalentemente, a impedância faradaica $Z_{F}$ pode ser definida como:[12]

$$
Z_{F}^{-1}=R_{t c}^{-1}=\frac{d I_{F}(E)}{d E}=n F\left(c(0) k(E) \frac{d A}{d E}+A c(0) \frac{d k(E)}{d E}+A k(E) \frac{d c(0)}{d E}\right)
$$

A análise dessa equação mostra a existência de pelo menos três causas possíveis para a origem da NDR: (1), $d A / d E<0$; (2), $d k(E) / d E<0 ;(3), d c(0) / d E<0$, todas baseadas em evidências experimentais[13]:

1. processos faradaicos, em decorrência de alguma inibição, podem ser simultaneamente acompanhados por uma diminuição da área do eletrodo à medida que a polarização aumenta. Isso provoca um decréscimo da corrente faradaica, o qual é sucessivamente intensificado com o aumento do sobrepotencial de transferência de carga. Um exemplo típico é a completa passivação da superfície de eletrodos devido a formação de camadas de óxido durante a dissolução de metais.[14]

2. a diminuição da constante de velocidade com o aumento da polarização do eletrodo pode ser causada pela adsorção de alguma espécie que não chega a inibir completamente a reação, como descrito no item 1, mas que é suficiente para aumentar a energia de ativação do processo de transferência de carga de tal modo que a NDR é originada.[1, 10] Outra causa é a perda de catalisador. Um exemplo desse caso é a eletro-redução de In(III) sobre $\mathrm{Hg}$ catalisada por ânions $\mathrm{SCN}^{-}$. Em altos valores de potencial de polarização, os ânions $\mathrm{SCN}^{-}$desorvem da superfície do $\mathrm{Hg}$, provocando uma diminuição da constante de velocidade da reação.[11]

3. em soluções eletrolíticas com baixa força iônica, quando ânions são reduzidos e cátions oxidados, respectivamente abaixo e acima do potencial de carga zero, um aumento de polarização pode ocasionar repulsão entre o eletrodo e estas espécies eletroativas. Como 
consequência, ocorre uma diminuição da concentração dessas espécies no plano reacional. $[13,15]$

\subsection{Modelo Protótipo Unidimensional: Biestabilidade}

A NDR não é o único fator necessário para a emergência de instabilidades de potencial em sistemas eletroquímicos. Uma compreensão mais detalhada dos pré-requisitos gerais que possibilitam o seu aparecimento também envolve estabelecer o papel desempenhado por parâmetros de controle do sistema, tais como: resistência e potencial para o regime potenciostático, e corrente aplicada para o galvanostático.[1] Com esse objetivo, traça-se a seguir uma análise qualitativa desses pré-requisitos para um sistema operando em modo potenciostático.

Para isso, parte-se do pressuposto de que o sistema eletroquímico em questão possa ser representado pelo circuito equivalente simplificado retratado pela Figura 2, o qual é constituído por dois elementos: um não-linear, destacado por linhas pontilhadas, e outro linear.[14] O primeiro representa uma célula eletrolítica constituída por um eletrodo de trabalho polarizável, cujo potencial $E$ é medido em relação a um eletrodo de referência idealmente não polarizável, disposto paralelamente ao anterior. Note que o eletrodo de referência é omitido da Figura 2, enquanto a interface existente entre o eletrodo de trabalho e a solução é representada por um capacitor de placas paralelas com capacitância $C$, sendo todos os processos faradaicos possíveis de ocorrerem nesta interface expressos por uma impedância faradaica $Z_{F}$. Já o elemento linear é formado por uma resistência $R_{T}$, a qual indica a soma de resistências ôhmicas dispostas em série com o eletrodo de trabalho: resistência do eletrodo de trabalho, de cabos, conexões, do eletrólito, bem como de qualquer resistência que possa ser intencionalmente inserida, externamente, entre o eletrodo de trabalho e o potenciostato.[1, 14] 
Figura 2 - Circuito equivalente simplificado representando uma célula eletrolítica conectada à um potenciostato, em que, C: capacitância; $\mathrm{Z}_{\mathrm{F}}$ : impedância faradaica; $\mathrm{R}_{\mathrm{T}}$ : resistência ôhmica total; I: corrente total; $\mathrm{I}_{\mathrm{F}}$ : corrente faradaica; $\mathrm{I}_{\mathrm{C}}$ : corrente capacitiva; U: potencial aplicado; E: potencial do eletrodo de trabalho $v s$. eletrodo de referência (omitido na figura).

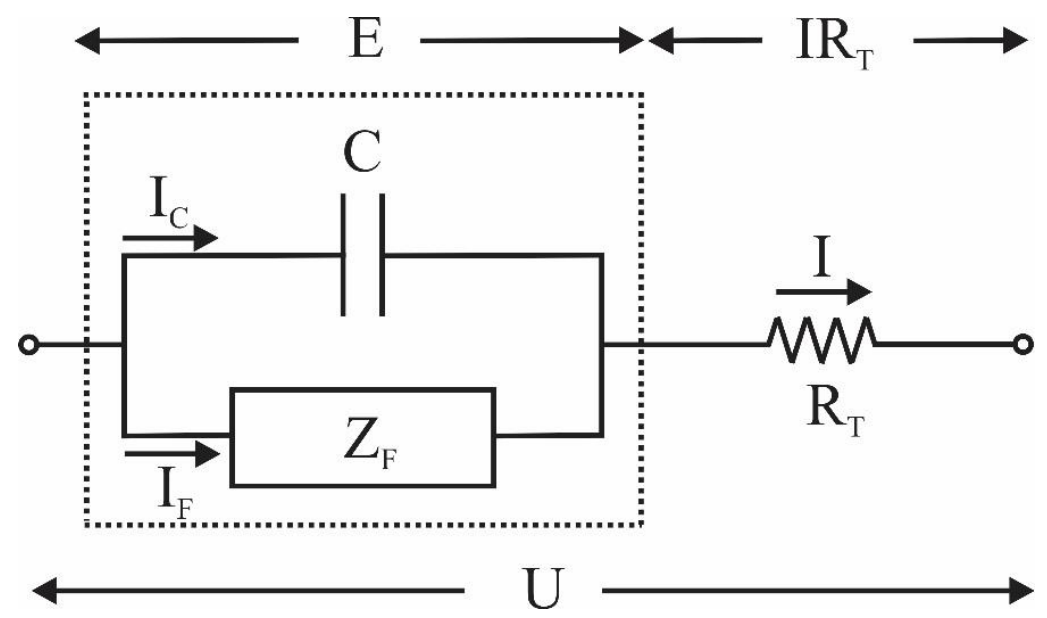

Supondo-se que um potencial $U$, constante, seja aplicado de modo que corrente flua por esse circuito em decorrência, por exemplo, da oxidação de certa espécie eletroativa. Os dois elementos retratados na Figura 2 podem ser relacionados de acordo com a equação: $I=I_{F}+I_{C}$ ou $I_{C}=I-I_{F}$, em que $I, I_{F}$ e $I_{C}$ são as correntes total, faradaica e capacitiva, respectivamente. Aplicando-se as Leis de Ôhm e Kirchhoff ao circuito, encontra-se uma segunda relação entre os elementos, mas agora, em termos de potencial: $U=E+I R_{T}$. Note que o potencial do eletrodo $E$ difere do potencial aplicado $U$ devido à queda ôhmica. Rearranjando-se essa última equação, $I=(U-E) / R_{T}$, e sabendo-se que $I_{C}=C A(d E / d t)$, obtém-se a expressão de conservação de carga do circuito para o regime potenciostático $(U=$ constante $)[1,15]$ :

$$
I_{C}=I-I_{F}=C A \frac{d E}{d t}=\frac{U-E}{R_{T}}-I_{F}
$$

Deve-se destacar que, de acordo com a equação (4), $I_{F}$ é dependente da concentração, bem como uma função não-linear do potencial do eletrodo de trabalho $E$, implicitamente representada pela constante de velocidade de transferência de carga $k(E)$.[15] Assume-se que a concentração da espécie eletroativa e $k(E)$ ajustam-se instantaneamente ao seus valores estacionários a cada valor assumido pelo potencial $E$, ou seja, seus valores são independentes do tempo, não afetando, 
portanto, a dinâmica de $E$ a ser analisada adiante.[1, 14, 16] Consequentemente, a expressão da corrente faradaica pode ser representada simplesmente como uma função de $E, I_{F}(E)$. Visando-se maior simplicidade matemática, também se considera que a capacitância $C$ é constante.[14]

Segundo essas considerações, e fazendo-se com que $E$ não dependa explicitamente do tempo, todas as variáveis dinâmicas possíveis para a equação (6) são reduzidas unicamente a $E$, equação (7). O potencial aplicado $U$ e a resistência total $R_{T}$ são constantes e, portanto, podem ser tratadas como parâmetros de controle.[17] Como $E$ é a única variável dependente do tempo, esse modelo protótipo definido pela equação (7), a ser analisado, será denominada aqui como sistema dinâmico não-linear de primeira ordem[16] ou, simplesmente, modelo unidimensional.[14]

$$
f(E)=\frac{d E}{d t}=\frac{U-E}{A C R_{T}}-\frac{I_{F}(E)}{A C}
$$

Informações sobre soluções dessa equação para uma dada condição inicial podem ser obtidas analiticamente, de forma qualitativa, avaliando-se por meio de um método gráfico a estabilidade de seus estados estacionários perante pequenas perturbações. Evidentemente, soluções estacionárias do potencial do eletrodo $E_{s s}$, ou seja, as soluções dessa equação para $d E / d t=f\left(E_{S S}\right)=0$ ocorrem quando a corrente faradaica $I_{F}\left(E_{\mathrm{ss}}\right)$ é igual à corrente total $I\left(E_{s s}\right)=\left(U-E_{s s}\right) / R_{T}$ ou, equivalentemente, quando essas duas funções interceptam-se no plano cartesiano.[1, 14, 16] Observe que esta última equação mostra que $I(E)$ é dada por uma equação linear com coeficiente angular $-1 / R_{T}$ e linear $U / R_{T}$, já $I_{F}(E)$ é dada por um $k(E)$ condizente com um processo faradaico que resulta em uma NDR: assumindo-se uma reação de oxidação, o processo de transferência de carga deve ter $d k(E) / d E<0$ em certo intervalo de $E$.[14] Assim, nesse intervalo, a velocidade reacional, ou seja, $I_{F}(E)$ deve diminuir com o aumento de $E$.

A Figura 3 apresenta os gráficos de $I_{F}(E)$ e $I(E)$ em um mesmo plano cartesiano. A reta $I(E)$ é dada para diferentes valores de potencial aplicado $U$ e dois valores diferentes de resistência total $R_{T}$, um pequeno e outro suficientemente grande, simbolizados por $R \quad$ e $10 \quad R$, respectivamente.[1, 14, 16] O retrato de fase para cada caso é apresentado esquematicamente na parte inferior de cada plano, paralelamente ao eixo $E$ : a equação (7) é um sistema de primeira ordem, logo, seu campo vetorial é unidimensional.[16] 
Figura 3 - Gráficos das funções $I(E)$ e $I_{F}(E)$ em um mesmo plano cartesiano. Retas $I(E)$ obtidas pela equação $I(E)=(U-E) / R_{T}$, para diferentes valores dos parâmetros de controle $U$ e $R_{T}$ : (a) $\mathrm{U}_{1} \mathrm{e}$ $\mathrm{R}$; (b) $\mathrm{U}_{1}$ e $10 \mathrm{R}$; (c) $\mathrm{U}_{2}$ e $10 \mathrm{R}$; (d) $\mathrm{U}_{3}$ e $10 \mathrm{R}$. Retratos de fase para cada uma dessas condições estão esquematizados paralelamente ao eixo $E$, na parte inferior de cada figura. Ver texto para mais detalhes.[1, 14, 16]

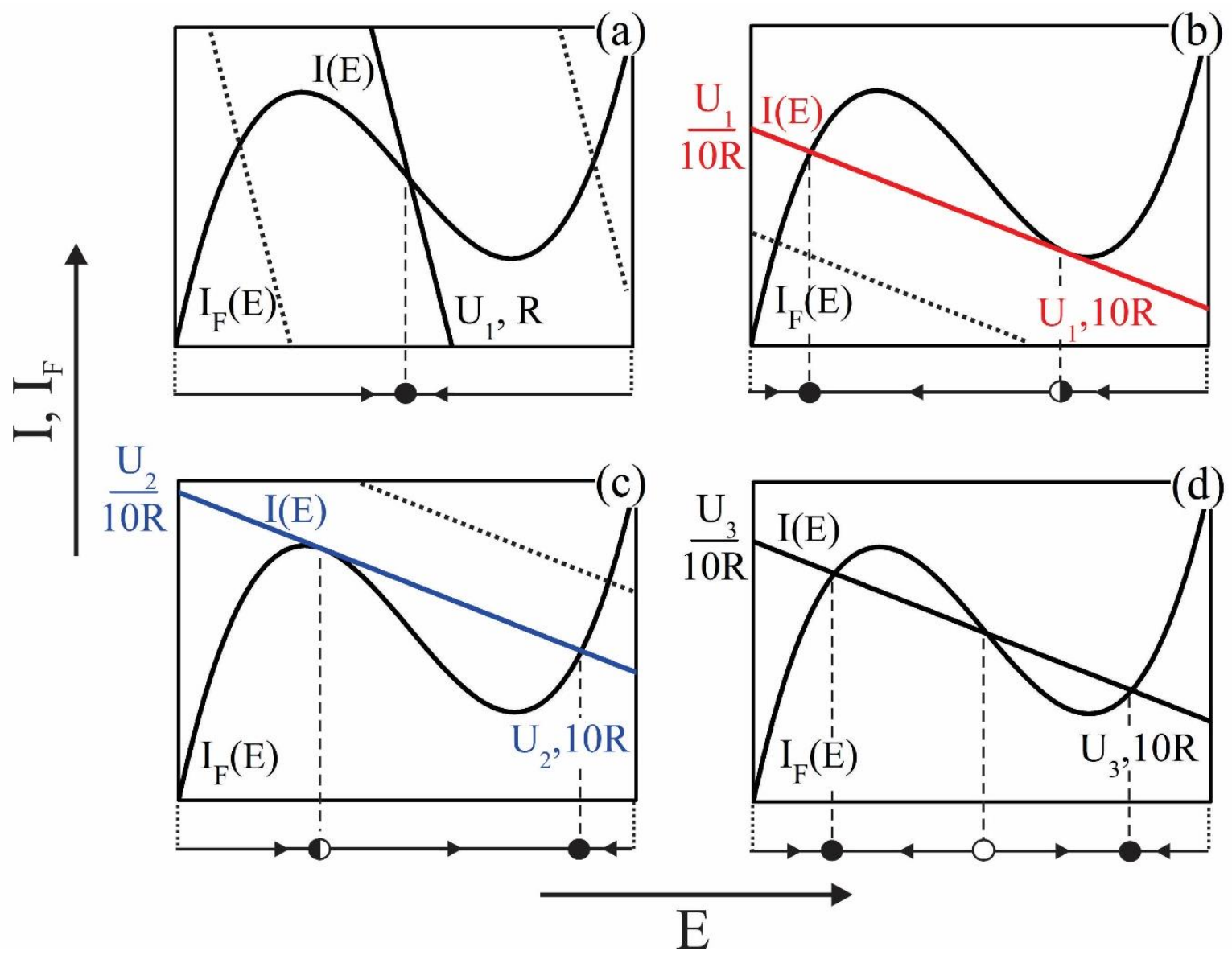

A Figura 3 (a) mostra os gráficos para um par de valores $\left(U_{1}, R\right)$. Quando a resistência total é pequena, a inclinação da reta dada por $-1 / R$ é tal que apenas uma intersecção entre $I(E)$ e $I_{F}(E)$ torna-se possível, resultando em uma única solução estacionária $E_{s s}$ para a equação (7). $\mathrm{O}$ correspondente retrato de fase é esquematizado de acordo com a seguinte abordagem. Sempre que a reta $I(E)$ estiver sobre a curva $I_{F}(E)$, isto é, sempre que $I(E)>I_{F}(E)$, pela equação (7) tem-se que $\mathrm{d} E / d t>0$, consequentemente, o sentido do vetor indicando a trajetória das soluções possíveis em torno de $E_{s s}$ é para a direita. Caso contrário, ou seja, se a reta $I(E)$ estiver sob a curva $I_{F}(E)$, tem-se que $\mathrm{d} E / d t<0$, então, o sentido do vetor é para a esquerda.[16] O retrato de fase obtido é mostrado na Figura 3 (a) e indica que, para o par de parâmetros $\left(\mathrm{U}_{1}, \mathrm{R}\right)$, todas as trajetórias possíveis são no 
sentido da solução estacionária $E_{s s}$, implicando que, para qualquer condição inicial $E_{o}$ ao redor de $E_{s s}$, as soluções da equação (7) sempre tenderão assintoticamente para $E_{s s}[16,18]$ Em termos de estabilidade, o retrato de fase demonstra que qualquer perturbação pequena em $E_{s s}$, seja ela positiva ou negativa, será amortecida no transcorrer do tempo. Quando isso acontece, a solução estacionária $E_{s s}$ é denominada ponto fixo estável e sua representação geométrica no retrato de fase é dada por um círculo preenchido em preto. Para o par de parâmetros de controle $\left(\mathrm{U}_{1}, \mathrm{R}\right)$, o sistema é denominado monoestável.[16]

Deve-se enfatizar que, para diferentes valores de $U$, a reta $I(E)$ na Figura 3 (a), com inclinação constante $-1 / R$, apenas desloca-se horizontalmente em relação ao eixo $E$ seguindo a variação de seu coeficiente linear $U / R$, resultando sempre em uma única interceptação entre as funções $I(E)$ e $I_{F}(E)$. Essa constatação é ilustrada pelas retas pontilhadas na Figura 3 (a), para dois valores quaisquer de $U$. Portanto, para cada valor de $U$, apenas uma certa solução estacionária $E_{s s}$ é possível e os retratos de fase, em cada caso, sempre serão constituídos por um único ponto fixo estável. Em outras palavras, quando a resistência total é pequena, todas as soluções estacionárias $E_{s s}$ da equação (7) são assintoticamente estáveis, independentemente do valor adquirido por $U$.

Fisicamente, isso significa que uma curva de polarização estacionária para esse sistema pode ser obtida medindo-se a corrente total estacionária $I\left(E_{s s}\right)$, ponto por ponto, para cada valor de potencial aplicado $U$.[14] A Figura 4 (a) mostra uma curva de polarização estacionária obtida por resolução numérica da equação (7), para um valor pequeno de resistência total igual a $R$. 
Figura 4 - Curvas de polarização estacionárias obtidas pela resolução numérica da equação (7), para um valor de resistência total $R_{T}$ igual a: (a) R; (b) $10 \mathrm{R}$.

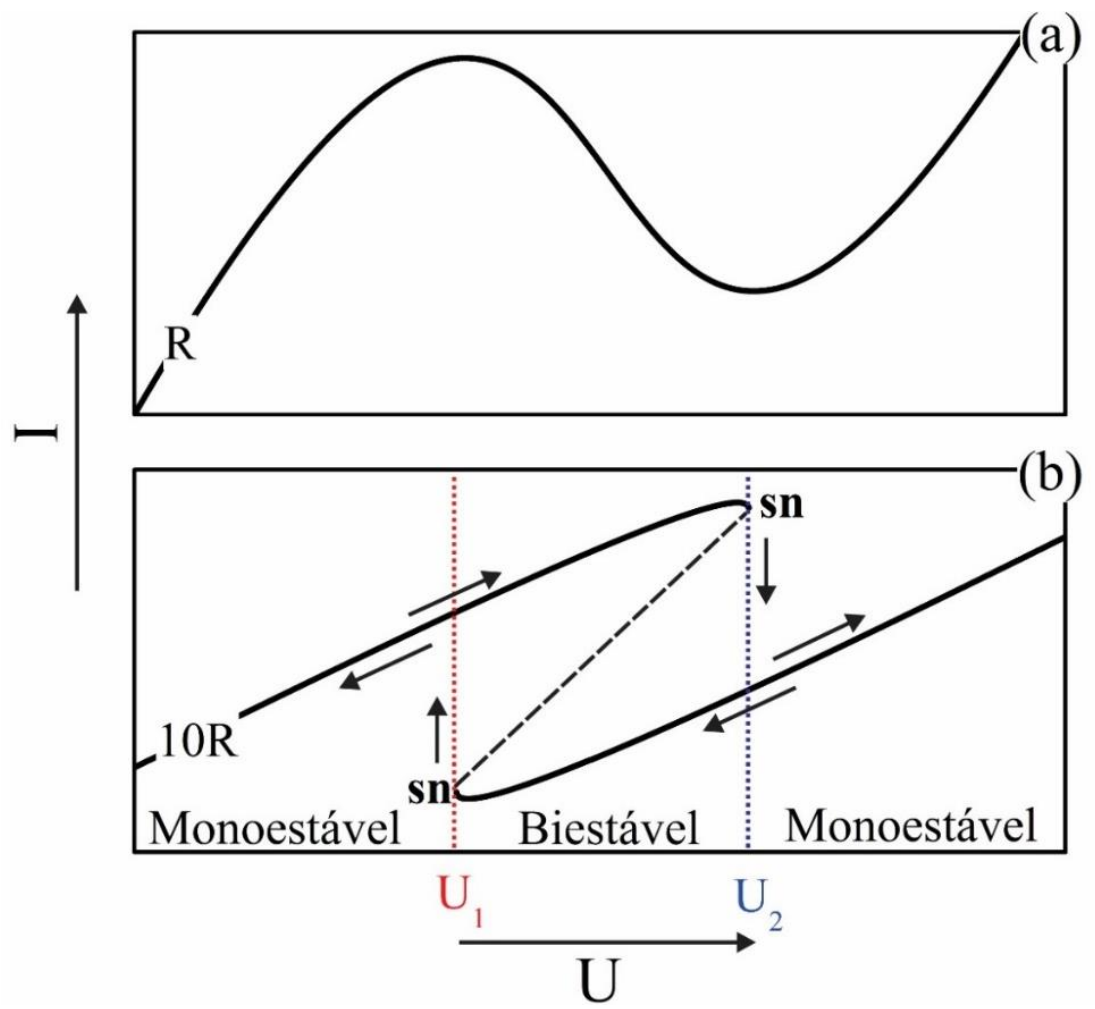

Agora, admite-se que a resistência total $R_{T}$ aumente de $\mathrm{R}$ para $10 \mathrm{R}$, por exemplo, pela inserção de uma resistência externa em série com o eletrodo de trabalho. Para valores de resistência suficientemente grandes, a inclinação da reta $I(E)$ é tal que pode permitir mais de uma intersecção com a curva $I_{F}(E)$ à medida que o valor do potencial aplicado $U$ é variado. Consequentemente, possibilita a existência de mais de uma solução estacionária $E_{s s}$, como demostrado pelas Figuras 3 (b), (c) e (d). Devido a essa maior diversidade, a análise da estabilidade dos estados estacionários do sistema dinâmico determinado pela equação (7) é apresentada a seguir, passo a passo, de acordo com o valor assumido pelo potencial aplicado $U$.

As condições $U=U_{1}$ e $U=U_{2}$ são demonstradas pelas retas coloridas $I(E)$ nas Figuras 3 (b) e (c), respectivamente. Para ambos os casos, duas intersecções entre $I(E)$ e $I_{F}(E)$ são possíveis, logo, dois pontos fixos estão presentes nos retratos de fase de cada figura: um estável, já abordado previamente, e outro meio-estável, sendo este representado geometricamente nos retratos de fase por um círculo branco e preto. Esses pontos fixos meio-estáveis podem ser estáveis ou instáveis, dependendo do sinal da perturbação. Por exemplo, para o ponto fixo meio-estável da Figura 3 (b), 
perturbações positivas são amortecidas, mas negativas são amplificadas, ou seja, basta uma perturbação negativa para que o potencial do eletrodo perca a sua estabilidade e tenda, assintoticamente, para o valor do ponto fixo estável localizado a esquerda.[16] Do ponto de vista prático, esse ponto (ou qualquer ponto fixo meio estável) é efetivamente instável, já que é fisicamente improvável que somente perturbações positivas aconteçam com o passar do tempo.[14] Aplicando-se a mesma análise ao retrato de fase mostrado na Figura 3 (c), conclui-se que, neste caso, o potencial do eletrodo sempre tenderá ao valor do ponto fixo estável localizado a sua direita. Portanto, como existe uma única solução estacionária $E_{s s}$ estável específica para cada uma das condições $\mathrm{U}=\mathrm{U}_{1}$ e $\mathrm{U}=\mathrm{U}_{2}$, em ambas as situações o sistema é classificado como monoestável.

Pontos fixos meio-estáveis são extremamente "delicados": observe que eles estão associados à um ponto de tangência da reta $I(E)$ com a curva $I_{F}(E)$. $[14,16]$ Tão logo o potencial aplicado $U$ seja menor do que $U_{1}$, a reta $I(E)$ na Figura 3 (b) desloca-se verticalmente para baixo em relação ao eixo E, conforme a variação de seu coeficiente linear U/10R. Esse deslocamento é ilustrado nessa figura pela reta pontilhada. No caso da reta $I(E)$ da Figura 3 (c), ocorre um deslocamento para cima assim que $U$ assuma valores maiores do que $U_{2}$, como também é demonstrado por uma reta pontilhada nesta mesma figura. Para esse intervalo: $U_{2}<U<U_{1}$, as soluções estacionárias possíveis são ilustradas pelas intersecções dessas retas pontilhadas com a curva $I_{F}(E)$. Uma única intersecção é possível para ambos os casos e, pela disposição dessas retas em torno de cada intersecção, conclui-se que os retratos de fase são equivalentes aos da Figura 3 (a), sendo, por isso, omitidos. Note que os pontos fixos meio estáveis desaparecem nesse intervalo de potenciais. O sistema é monoestável e a região de monoestabilidade do sistema agora pode ser estendida a $\mathrm{U}_{2} \leq \mathrm{U} \leq \mathrm{U}_{1}$.

Por fim, quando o valor do potencial aplicado $U$ adquire valores entre $\mathrm{U}_{1}$ e $\mathrm{U}_{2}$, ambas as retas $I(E)$ tangenciando a curva $I_{F}(E)$ nas Figuras 3 (b) e (c) passam a interceptar a curva na região da NDR, como ilustrado pela Figura 3 (d). Observe no retrato de fase dessa figura a existência de um ponto fixo instável, geometricamente simbolizado por um círculo vazio. Perturbações positivas na solução estacionária $E_{s s}$ associada a esse ponto fixo serão amplificadas, e o valor do potencial do eletrodo de trabalho $E$ tenderá assintoticamente para o ponto fixo estável à direita. Para perturbações negativas, o valor de $E$ tenderá para o ponto fixo estável à esquerda. Assim, duas soluções estacionária $E_{s s}$ estáveis são possíveis para o par de parâmetros $\left(\mathrm{U}_{3}, 10 \mathrm{R}\right)$ e o sistema é dito biestável.[14, 16] 
Conceitualmente, quando acontece essa transição, diz-se que o sistema dinâmico determinado pela equação (7) sofre bifurcação à medida que $U$ é variado, já que os retratos de fase das Figura 3 (b) e (c) diferem qualitativamente do retrato de fase da Figura 3 (d): os dois primeiros remetem a monoestabilidade, enquanto este último, a biestabilidade. Note que este último retrato de fase surge quando pontos fixos meio estáveis dividem-se em dois: um estável e outro instável. Bifurcação que se dá pela criação de novos pontos fixos é denominada bifurcação sela nó, e os dois pontos fixos meio-estáveis da Figura 3 (b) e (c), de onde teoricamente emerge a bifurcação, são chamados de pontos fixos sela nó. Mais precisamente, como dois pontos fixos meio estáveis são possíveis, a bifurcação é designada bifurcação sela nó caso degenerado.[16]

Implicações experimentais importantes provenientes dessa classificação estabelecida para os estados estacionários do sistema, quando a resistência total $R_{T}$ é suficientemente grande, podem ser visualizadas pela Figura 4 (b), a qual mostra uma curva de polarização estacionária simulada para o valor de resistência total $R_{T}=10 \mathrm{R}$. No intervalo de potenciais aplicados $U$ em que o sistema é monoestável, cada valor da corrente total tende para um certo valor estacionário $I\left(E_{s s}\right)$, pois o potencial do eletrodo $E_{s s}$ é assintoticamente estável. Por outro lado, no intervalo biestável, bifurcação resulta em biestabilidade. Nesse intervalo, para cada valor de potencial aplicado $U$, dois estados estacionários assintoticamente estáveis $E_{s s}$ são possíveis e, consequentemente, $I\left(E_{s s}\right)$ pode tender para dois valores estacionários: de alto ou baixo valor. Além disso, os estados estacionários do potencial do eletrodo $E_{s s}$ associados à região em que $d I\left(E_{s s}\right) / d E<0$ são instáveis, não podendo, portanto, serem medidos experimentalmente, como é evidenciado pela descontinuidade presente nessa curva de polarização.[14]

A existência de dois estados distintos para o sistema: um monoestável e outro biestável, também possibilita a manifestação experimental de histerese, ou seja, da falta de reversibilidade à medida que o potencial aplicado $U$ é variado. Essa característica também pode ser deduzida da Figura 4 (b) supondo-se, neste caso, que o sistema esteja sujeito a uma varredura de potencial. Como indicado pelas setas na parte interna dessa figura, ao se variar $U$ no sentido positivo, o sistema avança pelo ramo estável superior da curva até que em $\mathrm{U}_{2}$, devido à perda de estabilidade associada ao ponto sela-nó (sn), salta para o ramo estável inferior. No sentido negativo, o sistema segue pelo ramo estável inferior e perde sua estabilidade em $\mathrm{U}_{1}$, saltando para o outro ramo da curva.[1, 14, 17] A origem desses saltos pode ser teoricamente compreendida, de forma mais 
detalhada, visualizando-se de forma dinâmica o retrato de fase da Figura 3 (d), como demostrado a seguir.

A medida que $U$ aumenta, a reta $\mathrm{I}(\mathrm{E})$ mostrada na Figura 3 (d) desloca-se para cima conforme a variação sofrida pelo seu coeficiente linear U/10R. O ponto fixo instável e o estável a sua esquerda, movem-se um contra o outro no retrato de fase até colidirem em $\mathrm{U}_{2}$, dando origem ao ponto de bifurcação sela nó (meio estável) mostrado na Figura 3 (c). Como mencionado anteriormente, qualquer perturbação positiva neste ponto será amplificada, e o potencial do eletrodo $E$ tenderá para o ponto fixo estável a direita deste retrato de fase. Essa perda de estabilidade apresentada por pontos fixos sela nó manifesta-se experimentalmente por meio de saltos, de uma região biestável para outra monoestável, como ilustrado pela Figura 4 (b). No sentido negativo, a mesma explicação pode ser aplicada levando-se em conta que uma diminuição de $U$ culminará com a criação do ponto fixo sela nó mostrado na Figura 3 (b).[16]

Como demostrado, os parâmetros de controle $U$ e $R_{T}$ determinam a dinâmica do sistema descrito pela equação (7). Uma síntese das principais ideias apresentadas é dada a seguir fazendo-se referência aos diagramas de estabilidade e de bifurcação mostrados na Figura 5 (a) e (b), respectivamente. Em ambas as figuras, pontos fixos sela-nó delimitam a região biestável. Em (b), as setas ilustram a existência de histerese e saltos, em termos do potencial do eletrodo $E$. 
Figura 5 - Gráficos mostrando uma síntese da dinâmica do modelo unidimensional determinado pela equação (7): (a) diagrama de estabilidade.[19] (b) diagrama de bifurcação.[14, 17] A sigla sn em (a) e (b) marca a posição dos pontos fixos sela-nó, os quais delimitam a região de biestabilidade.

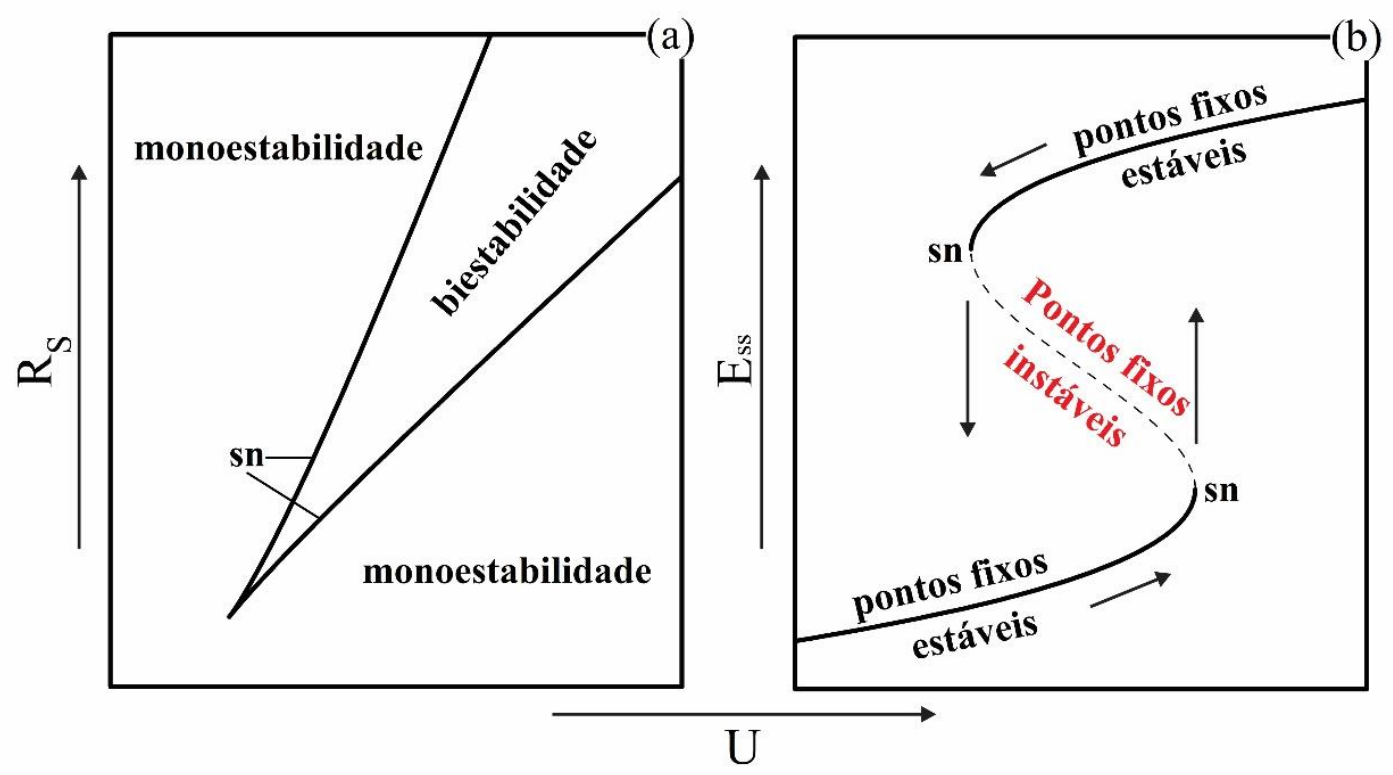

Para pequenos valores de resistência $R_{T}$, como pode ser observado pela Figura 5 (a), o sistema dinâmico determinado pela equação (7) é sempre monoestável, independentemente do valor assumido por $U$. Por outro lado, para valores de resistência suficientemente grandes, bifurcação manifesta-se por meio da biestabilidade: nesta região dos parâmetros, duas soluções estacionárias $E_{s s}$ assintoticamente estáveis podem ser acessadas para cada valor do potencial aplicado $U$. Esse comportamento não-linear pode ser visualizado pelo diagrama de bifurcação para um valor de $R_{T}$ igual a 10R, Figura 5 (b): qualquer perturbação em um ponto fixo do ramo instável será amplificada e o valor de $E$ tenderá para um valor correspondente do ramo estável superior ou inferior, dependendo do sinal da perturbação. A ocorrência de histerese e saltos do potencial do eletrodo durante uma varredura do parâmetro de controle $U$ provém da existência da região de biestabilidade e, em última análise, são manifestações experimentais do fenômeno denominado bifurcação. 


\subsection{Estabilidade Linear para o Sistema Unidimensional}

Como demonstrado qualitativamente, estados estacionários instáveis sempre aparecem associados à região de NDR, quando o valor da resistência total $R_{T}$ é suficientemente grande. Agora, realizando-se uma linearização em torno de uma solução estacionária da equação (7) e avaliando-se a sua estabilidade perante pequenas perturbações, pretende-se estabelecer, de forma mais quantitativa, como essa dependência com o valor de $R_{T}$ está diretamente relacionada com o valor da impedância faradaica $Z_{F \cdot[13]}$

Seguindo os mesmos princípios discutidos anteriormente, soluções estacionárias $E_{s s}$ da equação (7), ou seja, soluções que satisfazem a condição $f\left(E_{s s}\right)=d E_{s s} / d t=0$ são determinadas pela equação (8).

$$
I_{F}\left(E_{S S}\right)=\frac{I-E_{s S}}{R_{T}}
$$

Definindo-se uma pequena perturbação como $\delta(t)=E(t)-E_{s s}$, a estabilidade de soluções estacionárias $E_{s s}$ pode ser determinada avaliando-se o que acontece com essa perturbação ao longo do tempo: se é amplificada ou amortecida. Para isso, derivando-se essa equação em relação ao tempo tem-se que: $d \delta / d t=d\left(E-E_{s s}\right) / d t$, a qual pode ser reescrita levando-se em conta que $E_{s s}$ é um ponto fixo e, portanto, constante: $d \delta / d t=d(E) / d t=f\left(E_{s s}+\delta\right)$. Expandindo-se essa expressão em uma série de Taylor[16] obtém-se:

$$
\frac{d \delta}{d t}=f\left(E_{S S}\right)+\delta f^{\prime}\left(E_{S S}\right)+O\left(\delta^{2}\right) .
$$

Assumindo-se $f^{\prime}\left(E_{s s}\right) \neq 0$, os termos quadráticos em $\delta$ representados por $O\left(\delta^{2}\right)$ podem ser desprezados. Como a condição estacionária é tal que $f\left(E_{s s}\right)=0$, a dinâmica da perturbação pode ser aproximadamente descrita pela relação linear dada pela equação (10), desde que essa perturbação seja pequena o suficiente para não invalidar essa linearização em torno de $E_{s s .}$.[16]

$$
\frac{d \delta}{d t}=\delta \frac{d f\left(E_{S S}\right)}{d E}
$$


Portanto, a linearização em torno de uma solução estacionária da equação (7) é obtida simplesmente derivando-se esta equação em relação ao potencial do eletrodo $E$ :

$$
\frac{d \delta}{d t}=-\frac{1}{C}\left[\frac{1}{R_{T}}+\frac{d I_{F}\left(E_{S S}\right)}{d E}\right] \delta .
$$

Pela definição de impedância faradaica: $Z_{F}^{-1}=d I_{F}(E) / d E$, obtém-se

$$
\frac{d \delta}{d t}=-C^{-1}\left[\frac{1}{R_{T}}+\frac{1}{Z_{F}}\right] \delta .
$$

A partir da equação (12) fica claro que qualquer perturbação, positiva ou negativa, é amortecida no transcorrer do tempo desde que $\left(R_{T}^{-1}+Z_{F}^{-1}\right)>0$ e, tendo-se em conta que os únicos valores de resistência total $R_{T}$ possíveis são nulo e positivo, conclui-se que os estados estacionários da equação (7) são estáveis para a condição

$$
Z_{F}>0
$$

Por outro lado, quando $\left(R_{T}^{-1}+Z_{F}^{-1}\right)<0$, perturbações são amplificadas, logo, os estados estacionários são instáveis quando[1, 12]:

$$
\left|Z_{F}\right|<R_{T}, \quad Z_{F}<0 .
$$

Essa condição de instabilidade mostra que, para ser classificado como instável, não basta que estado estacionário $E_{s s}$ esteja sobre o ramo da curva de polarização caracterizado por apresentar uma impedância faradaica $Z_{F}$ negativa. Tal constatação foi ilustrada qualitativamente para os parâmetros $\left(\mathrm{U}_{1}, \mathrm{R}\right)$, na Figura 3 (a). Para que instabilidades se manifestem, também é imprescindível que o valor da resistência total $R_{T}$ seja maior do que o valor da impedância faradaica $Z_{F}$, como demonstrado para a condição $\left(\mathrm{U}_{1}, 10 \mathrm{R}\right)$ na Figura $3(\mathrm{~d})$.

Como estabelecido anteriormente, perturbações em uma solução estacionária $E_{s s}$ instável são sempre amplificadas. Por isso, é comum dizer que existe um ciclo de retroalimentação positivo no potencial do eletrodo $E$ ou que esta variável é autoativadora. [14]Isso é estritamente válido para processos faradáicos que resultam em uma região de NDR associada a uma curva de polarização 
em formato de "N".[1, 14] É importante evidenciar que esse ciclo de retroalimentação positivo prevê o comportamento não-linear de $E$ e a consequente manifestação da biestabilidade, mas é insuficiente para se explicar a evolução de padrões temporais auto-organizados, tão comuns em sistemas eletroquímicos. Em outras palavras, sistemas contendo uma única variável dinâmica, como o definido pela equação (7), normalmente não exibem soluções periódicas: o retrato de fase apresentado na Figura 3 (d) mostra que as trajetórias das soluções possíveis em torno de um estado estacionário instável não podem ser periódicas, pois estão confinadas em uma linha.[16] Para se descrever o surgimento de oscilações em sistemas eletroquímicos, em adição ao potencial, necessariamente deve-se introduzir um segundo grau de liberdade, conferido por outra variável dependente do tempo.

\subsection{Sistema Bidimensional N-NDR: Oscilações Periódicas Simples}

O primeiro modelo protótipo a explicar razoavelmente em termos físicos e matemáticos a ocorrência de oscilações durante processos faradaicos que resultam em uma curva de polarização em formato de "N", sistemas N-NDR, foi proposto por Koper e Sluyters.[11, 12] Nesse protótipo, além do potencial do eletrodo, os autores consideram a dependência da concentração de uma espécie eletroativa com o tempo, a qual é conjecturada como resultado de um desequilíbrio entre as velocidades de consumo e de reposição por difusão desta espécie no plano reacional. Migração é desprezada nesse modelo.

A formulação matemática adimensional desse protótipo é dada pelas equações diferenciais ordinárias acopladas (15) e (16).[13]

$$
\begin{aligned}
& \frac{1}{\varepsilon} f(e, c)=\frac{d e}{d \tau}=\frac{1}{\varepsilon}\left(\frac{u-e}{\rho}-k(e) c\right) \\
& g(e, c)=\frac{d c}{d \tau}=-k(e) c+1-c
\end{aligned}
$$

Pressupondo-se uma reação de oxidação ocorrendo irreversivelmente, a primeira equação anterior é obtida pela substituição da equação (4) em (7) e descreve a evolução do potencial do eletrodo por meio da conservação de carga do circuito eletroquímico, como anteriormente, mas 
agora, levando-se em consideração a dinâmica da concentração da espécie eletroativa. A segunda descreve essa dinâmica por meio da aproximação linear da camada de difusão: assume-se que a espessura da camada de difusão é constante e que o perfil de concentração através da mesma sempre relaxe instantaneamente para um perfil linear.

As variáveis e, c e $\tau$ são definidas, nesta ordem, como: potencial do eletrodo, concentração e tempo adimensionais. Assume-se que a constante de velocidade adimensional, $k(e)$, compatível com processos faradaicos que resultam em uma NDR, é independente do tempo. Os parâmetros de controle adimensionais que determinam a dinâmica do sistema são $u, \rho$ e $\varepsilon$. O primeiro, $u$, representa o potencial aplicado. O segundo, $\rho$, é diretamente proporcional à resistência total, podendo ser compreendido como a resistência total adimensional do sistema. E o parâmetro de controle adimensional $\varepsilon$ é inversamente proporcional a camada de difusão e expressa a diferença na escala de tempo entre o potencial do eletrodo e a concentração da espécie eletroativa na camada de difusão. O modelo protótipo original[11], bem como as dimensões de parâmetros e variáveis[19] podem ser visualizados nas referências 11 e 19, respectivamente.

De modo análogo ao caso unidimensional apresentado anteriormente, uma análise de estabilidade linear para o modelo determinado pelas equações (15) e (16) mostraria que estados estacionários instáveis sempre aparecem associados à NDR, para valores de resistência acima de um valor crítico.[14] Como foi demonstrado por meio da Figura 5 (b) para o caso unidimensional, trajetórias de soluções ao redor do ramo instável da NDR sempre tendem para um estado estacionário $E_{S S}$ estável, de alto ou baixo valor. Já para o caso bidimensional, além do comportamento biestável, soluções também podem evoluir para um estado oscilatório ao redor desse ramo.[13]

A existência de soluções periódicas autossustentadas para o sistema dinâmico determinado pelas equações (15) e (16) pode ser compreendida com certo detalhe definindo-se as isóclinas[16, 20] de $e$ e $c$, ou seja, fazendo-se $\mathrm{de} / \mathrm{d} \tau=0$ e $\mathrm{dc} / \mathrm{d} \tau=0$, e resolvendo para $c$ de modo a se obter as equações (17) e (18),[13] respectivamente. A Figura 6 (a) mostra o gráfico dessas isóclinas, sendo a intersecção entre elas uma solução estacionária do sistema, já que as condições de/d $\tau=0$ e $\mathrm{dc} / \mathrm{d} \tau=0$ são satisfeitas simultaneamente. Os valores dos parâmetros $u$ e $\rho$ foram fixados de forma que essa intersecção ocorresse no ramo instável da NDR.[13, 14, 19] Em torno desta solução estacionária instável também são mostradas algumas trajetórias de soluções obtidas pela resolução numérica do sistema determinado pelas equações (15) e (16), para diferentes condições iniciais. 


$$
\begin{array}{ll}
\text { isóclina }-e & c=\frac{u-e}{\rho k(e)} \\
\text { isóclina }-c & c=\frac{1}{1+k(e)}
\end{array}
$$

No espaço de fase mostrado pela Figura 6 (a), a existência de um estado oscilatório é evidenciada pela presença de um ciclo limite estável, ou seja, uma trajetória de soluções isolada e fechada que atrai as demais trajetórias em seu entorno.[16, 18, 20] Isolada no sentido de que as trajetórias desenvolvem uma espiral em sua direção, ou seja, são atraídas pelo ciclo limite estável sem se interceptarem.[16] As Figuras 6 (b) e (c) ilustram, respectivamente, soluções periódicas de potencial e concentração ao longo do tempo. Evidentemente, o sistema também exibe oscilações de corrente sob controle potenciostático, as quais não são mostradas na Figura 6. Note que em estado oscilatório, esse modo de controle não pode ser entendido como uma condição verdadeiramente potenciostática,[14] pois o potencial do eletrodo varia continuamente com o tempo.[15] 
Figura 6 - Ilustração da existência de soluções periódicas obtidas pela resolução numérica das equações (15) e (16): (a) linhas finas azul e preta são as isóclinas de $e$ e de $c$, respectivamente. Intersecção entre essas isóclinas determinam um ponto fixo instável do sistema. Linhas grossas em preto e vermelho são soluções obtidas por integração numérica das equações acopladas (15) e (16). (b) soluções periódicas para $e$ em função do tempo. (c) soluções periódicas para $c$ em função do tempo.[16, 18, 20]
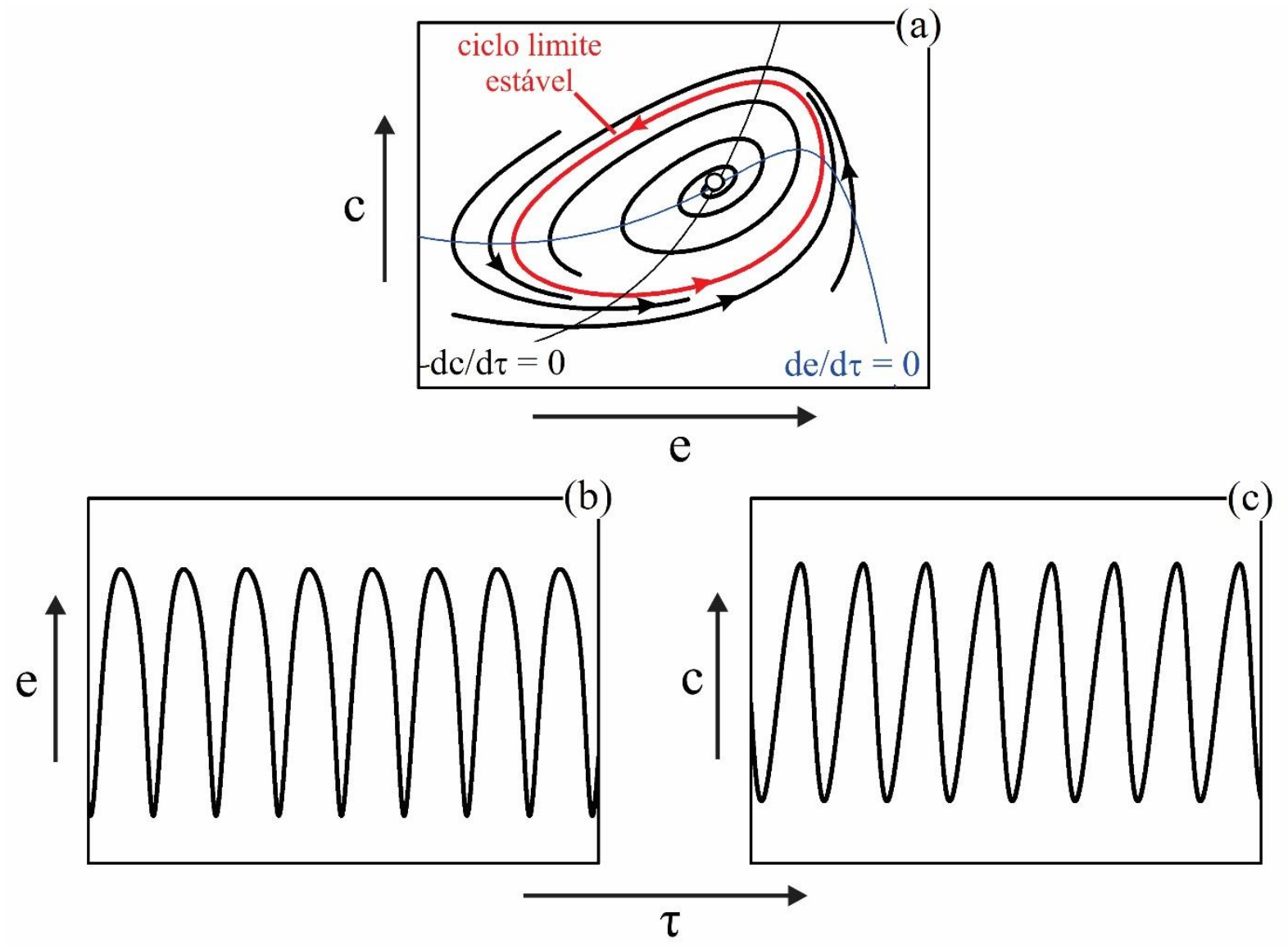

O comportamento matemático das variáveis $e$ e $c$ nas vizinhanças da solução estacionária instável pode ser determinado com o auxílio da Figura 7, a qual mostra os sinais das derivadas das trajetórias de soluções em torno do ponto fixo instável.[14, 16] Esses sinais podem ser facilmente obtidos das trajetórias mostradas na Figura 6 (a), tendo-se em mente que o vetor que indica a direção e o sentido das soluções no plano de fase $c$ vs. $e$ apresenta duas componentes. 
Figura 7 - Análise do comportamento matemático das variáveis $e$ e $c$ : linhas azul e preta são as isóclinas de $e$ e de $c$, respectivamente. Intersecção entre essas isóclinas determinam um ponto fixo instável do sistema. Os sentidos das trajetórias das soluções nas vizinhanças desse ponto são indicados pelos sinais das derivadas.[13, 14, 19]

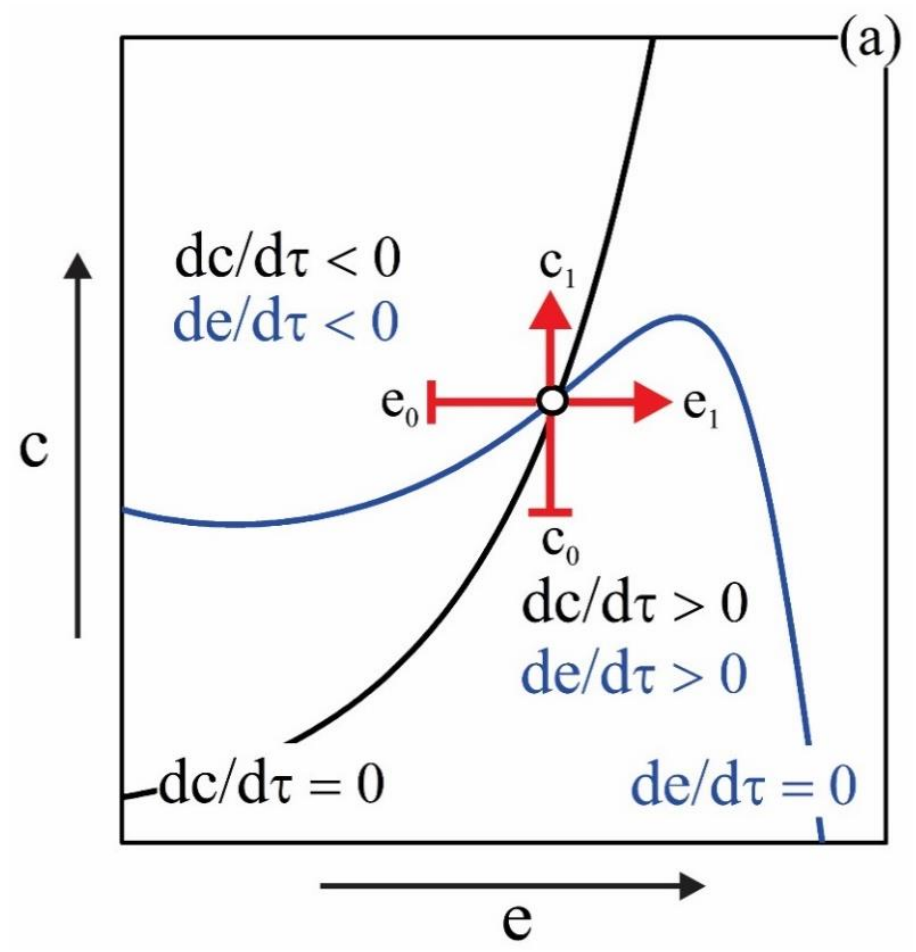

Matematicamente, o potencial do eletrodo $e$ comporta-se como uma variável autoativadora em torno do ramo instável da NDR, como mencionado previamente. Por exemplo, supondo-se que, para uma dada concentração, o potencial sofra uma variação infinitesimal de $e_{0}$ para $e_{1}$, como ilustrado pela seta horizontal na Figura 7. Esse aumento na variável $e$ desencadeia sucessivos aumentos nela mesma, pois o sinal de de/d $\tau$ no espaço de fase $c$ vs. $e$ muda de negativo para positivo: $[(\partial \mathrm{e} / \partial \tau) / \partial \mathrm{e}]>0$. A mesma conclusão é válida para uma variação de $e$ no sentido negativo, mas neste caso, esta variável sofrerá sucessivos decréscimos. Portanto, existe um ciclo de retroalimentação positivo em $e$. Por outro lado, a concentração atua como uma variável autoinibidora em torno da NDR. De acordo com a ilustração dada pela seta vertical na Figura 7, um aumento de $c$ sempre é amortecido, pois o sinal de $\mathrm{dc} / \mathrm{d} \tau$ muda de positivo para negativo: $[(\partial \mathrm{c} / \partial \tau) / \partial \mathrm{c}]<0$. Essa constatação também é válida para uma diminuição da concentração. Como variações são sempre amortecidas, diz-se que existe um ciclo de retroalimentação negativo em $c .[10,14]$ 
Em adição, o potencial do eletrodo $e$ é uma variável ativadora: um aumento ou diminuição de $e$ ativa uma mudança de mesmo sentido na variável $c$. De forma contrária, a concentração $c$ é inibidora: a sua variação provoca uma mudança em sentido oposto na variável $e$. Tais comportamentos também podem ser evidenciados fazendo-se referência à Figura 7, em termos de um aumento de $e$ e de $c$. Perceba que de $\mathrm{e}_{0}$ para $\mathrm{e}_{1}$, o sinal de $\mathrm{dc} / \mathrm{d} \tau$ altera-se de negativo para positivo: $[(\partial \mathrm{c} / \partial \tau) / \partial \mathrm{e}]>0$. Mas um aumente em $c$, de $\mathrm{c}_{0}$ para $\mathrm{c}_{1}$ por exemplo, o sinal de de/d $\tau$ muda de forma contrária, ou seja, de positivo para negativo, logo, $[(\partial \mathrm{e} / \partial \tau) / \partial \mathrm{c}]<0$.[14]

Modelos cujas variáveis dinâmicas apresentam esses comportamentos são denominados ativador-inibidor[14] e são bastante comuns em diversas áreas do conhecimento, como já mencionado.[9, 10] Modelos desse tipo podem exibir soluções periódicas caso as suas variáveis tenham escalas de tempo distintas.[10, 14] Para o sistema definido pelas equações (15) e (16), a razão entre as escalas de tempo é dada pelo parâmetro $\varepsilon:[14]$

$$
\frac{d c}{d e}=\varepsilon \frac{g(e, c)}{f(e, c)}
$$

Determinado o comportamento das variáveis, o mecanismo pelo qual se dá a dinâmica temporal dessas soluções periódicas autossustentadas pode, agora, ser visualizado com base na Figura 8 (a), a qual mostra as isóclinas de $e$ e de $c$, bem como um ciclo limite estável. Para enfatizar diferenças nas escalas de tempo das variáveis $e$ e $c$, fixou-se $\varepsilon$ em um valor extremamente pequeno.[16]

Como estabelecido anteriormente, o potencial do eletrodo $e$ varia de forma "autocatalítica" ao mesmo tempo que atua como ativante nas vizinhanças do estado estacionário instável, induzindo uma mudança de mesmo sentido em $c$. Mas como $c$ é autoinibidora, para baixos valores de $\varepsilon$, essa mudança é muito mais lenta do que a de $e$. De fato, a equação (19) mostra que, para $\varepsilon \ll<1$, a velocidade com que $c$ varia em relação a $e$ tenderá a zero. Essa constatação é válida para qualquer condição inicial entre $\mathrm{AD}$ e $\mathrm{BC}$, exceto sobre o ponto fixo. Note que nesses intervalos as trajetórias são praticamente horizontais, evidenciando que $c$ praticamente não se altera. Mudanças dessa variável só acontecem de forma significativa nas regiões $\mathrm{AB}$ e $\mathrm{CD}$ e, portanto, com um certo atraso. Quando a trajetória atravessa a isóclina de $e$ em A e C, as variações "autocatalíticas"[10] de $e$ passam a ser suprimidas por $c$, pois esta variável também é inibidora. Portanto, nos intervalos $\mathrm{AB}$ e CD, e passa a mudar lentamente, assim como $c$, mas em um sentido contrário.[14, 16] Observe 
que essas duas escalas de tempo distintas inerentes ao ciclo limite também são evidentes nas oscilações de potencial mostradas na Figura 8 (b).[16]

Figura 8 - Análise da dinâmica de e e de c durante um ciclo oscilatório: (a) linhas azul e preta são as isóclinas de e e de c, respectivamente. Intersecção entre essas isóclinas determinam um ponto fixo instável do sistema, em torno do qual é mostrado um ciclo limite estável, em vermelho.[13, 14] (b) oscilações de potencial em função do tempo.[16]
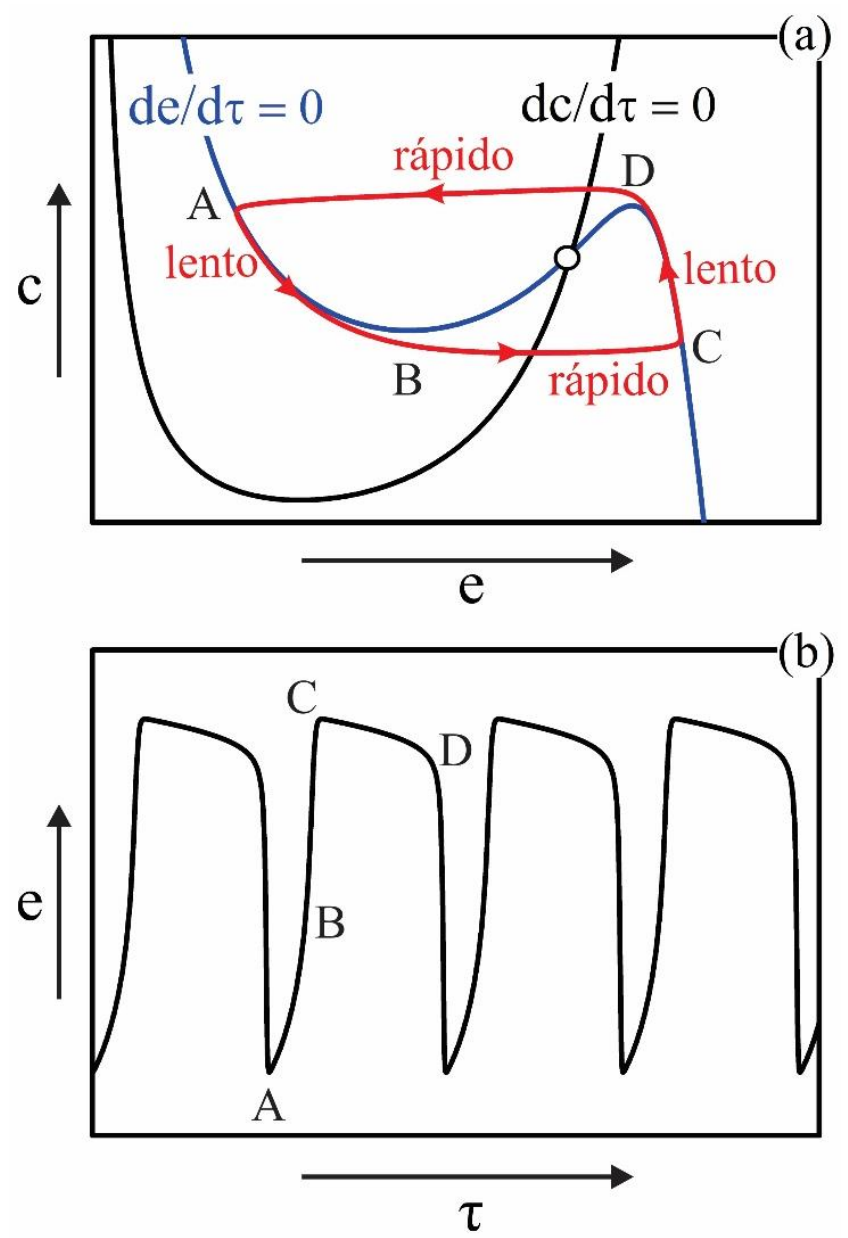

O mecanismo anterior pode ser dado em termos físicos, considerando um sistema eletroquímico limitado por transporte de massa: como $\varepsilon$ é inversamente proporcional à camada de difusão, baixíssimos valores deste parâmetro podem ser alcançados, por exemplo, para um eletrodo rotatório submetido a baixas velocidades de rotação.[19] Partindo-se da região AB, um aumento infinitesimal de sempre é acompanhado por uma diminuição di, já que ao redor da NDR as velocidades dos processos diminuem com o aumento do potencial do eletrodo, pois como definido 
previamente, $\mathrm{dk}(\mathrm{e}) / \mathrm{de}<0$ para uma reação de oxidação. Consequentemente, sob restrição potenciostática, a queda ôhmica também sofre uma diminuição $\rho \mathrm{d} i$, levando a um aumento adicional com este mesmo valor em $e$, pois o potencial aplicado $u$ é constante $(u=e+\rho i)$. Por sua vez, esse aumento adicional provoca uma nova diminuição de $i$ e de $\rho i$, desencadeando-se, assim, sucessivos aumentos de $e$ e diminuições de $i$. Perceba que as variações de $e$ são continuamente amplificadas por um fator dado pelo valor de $\rho i$, até acontecer um abrupto aumento em BC. No intervalo $\mathrm{CD}$, como resultado da menor velocidade de transferência de carga em altos potenciais, a reposição da espécie eletroativa a partir da solução torna-se mais eficiente, resultando em um contínuo aumento de concentração na camada de difusão. Portanto, $i$ e $\rho$ d $i$ também aumentam continuamente, enquanto $e$ vai diminuindo pelo fator $\rho i$ até sofrer uma brusca diminuição em AD. Devido a maior velocidade de transferência de carga em baixos potenciais, $c$ e $i$ voltam a diminuir, o aumento de $e$ é reestabelecido e o ciclo se repete novamente por si só.[1, 10, 14, 19]

Por fim, o modelo bidimensional definido pelas equações (15) e (16) reproduz duas características fundamentais de sistemas eletroquímicos classificados como sendo do tipo N-NDR, as quais podem ser visualizadas por meio do diagrama mostrado na Figura 9.[10] Nessa figura, a região de biestabilidade é similar à do caso unidimensional, ou seja, tem um formato de "V", não apresentando, portanto, um limite superior de valores de $\rho$ para os quais o sistema exibe a biestabilidade.[19] Por outro lado, existe um limite superior de $\rho$ para o qual as oscilações acontecem, implicando que sistemas eletroquímicos N-NDR só exibem oscilações a potencial constante ou sob uma varredura de potencial. Sob o modo de controle galvanostático, um sistema N-NDR apresenta somente a biestabilidade devido ao alto valor de resistência inerente a este regime.[14] Portanto, somente a biestabilidade é possível sob a restrição galvanostática. 
Figura 9 - Diagrama mostrando a região dos parâmetros $\rho$ e u onde o sistema bidimensional N-NDR exibe oscilações e biestabilidade.[10] Figura modificada a partir da referência 10.

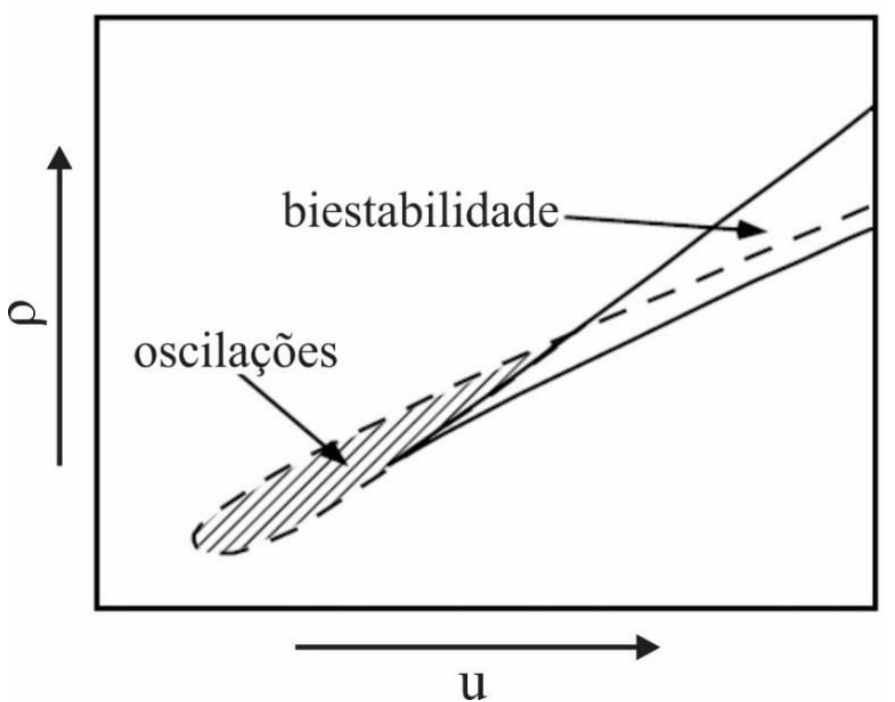

Em síntese, o modo de operação potenciostático, combinado com uma reação que resulta em uma NDR, confere um ciclo de retroalimentação positivo em $e$, desde que o valor da resistência total $\rho$ esteja acima de um valor crítico e abaixo de um limite superior. Para baixos valores do parâmetro $\varepsilon$, um ciclo de retroalimentação negativo em $c$ pode acoplar-se ao positivo, e a dependência mútua[10] dessas variáveis possibilita a ocorrência de oscilações. À medida em que $\varepsilon$ aumenta, as escalas de tempo de $e$ e $c$ vão tornando-se parecidas. Para um aumento extremo, o modelo dado pelas equações (15) e (16) reduz-se a um sistema unidimensional, passando a exibir somente a biestabilidade em um certo intervalo dos parâmetros.[14]

\subsection{Sistema Bidimensional HN-NDR: Oscilações Periódicas Simples}

Uma outra classe de sistemas eletroquímicos que exibem oscilações autossustentadas é denominada, em inglês, Hidden N-Shaped Negative Differential Resistence, HN-NDR.[21] Como sugerida pelo nome, a principal característica desses sistemas é apresentar uma curva de polarização estacionária corrente $v s$. potencial cuja região com $d I / d E<0$ está parcialmente escondida por causa da supressão da corrente total. Um exemplo é o processo de envenenamento causado por cátions e ânions.[14] O bloqueio de sítios ativos da superfície do catalisador devido a adsorção de cátions e ânions inibe a adsorção da espécie eletroativa e, consequentemente, diminui 
a velocidade da reação. Diferentemente do caso N-NDR, esses sistemas também exibem oscilações em regime galvanostático.

A derivação de um modelo protótipo HN-NDR genérico requer, necessariamente, que dois processos com as seguintes características sejam considerados:[19]

1. a velocidade da reação global tem que diminuir com o aumento do potencial do eletrodo, mais precisamente, assumindo-se uma reação de oxidação, esta deve possuir $d k(e) / d e<0$ em um certo intervalo de potenciais, assim como para o caso N-NDR. A Figura 10 (a) ilustra a dependência de uma constante de velocidade com o potencial do eletrodo que permite a existência de uma NDR na curva de polarização corrente $v s$. potencial;

2. ao menos um processo de adsorção deve interpor-se ao processo descrito em (1) de modo a esconder, parcialmente, a inclinação negativa da curva de polarização com seu formato característico de "N". E ainda, o recobrimento da espécie adsorvida tem que diminuir com o aumento do sobrepotencial para a reação global dentro da região da NDR. Uma isoterma de adsorção compatível com essas características é mostrada na Figura 10 (b).

Deve-se destacar que a comparação dessas características, com aquelas discutidas inicialmente sobre o mecanismo reacional de moléculas orgânicas pequenas, configuram a eletro-oxidação destas moléculas como sendo sistemas do tipo HN-NDR. Portanto, uma leitura comparativa entre os aspectos que são apresentados a seguir, com aqueles iniciais, pode ajudar a estabelecer uma compreensão um pouco mais rigorosa sobre a dinâmica da oxidação oscilatória dessas moléculas.

O modelo genérico adimensional mais simples capaz de formular os processos (1) e (2) em termos matemáticos foi proposto por Krischer[19], o qual é dado pelas equações diferenciais ordinárias acopladas (20) e (21). O grau de recobrimento da espécie relacionada ao processo descrito no item 2 é simbolizado por $\theta$ e a sua isoterma de adsorção por $\theta_{0}(e)$. As variáveis $e$ e $\tau$, assim como os parâmetros de controle $u$ e $\rho$, têm o mesmo significado já atribuído anteriormente para o caso do modelo N-NDR. A razão entre as escalas de tempo de $e$ e $\theta$ é dada pelo parâmetro $\varepsilon$, o qual é proporcional à constante de velocidade de relaxação de $\theta$ ao equilíbrio.

A equação (20), de forma similar à (15), descreve as variações de $e$ no transcorrer do tempo. Mas a corrente faradaica adimensional no modelo HN-NDR é proporcional ao número de sítios livres (1- $\theta$ ). A evolução temporal de $\theta$ é expressada pela equação (21), a qual é dada em termos do desvio do valor de $\theta$ num dado instante em relação ao seu valor de equilíbrio $\theta(e)$. Note pela 
equação (21) que, no modelo em questão, o processo de adsorção, dependente do potencial do eletrodo, não constitui uma reação faradaica.

$$
\begin{gathered}
\frac{1}{\varepsilon} f(e, \theta)=\frac{d e}{d \tau}=\frac{1}{\varepsilon}\left[\frac{u-e}{\rho}-k(e)(1-\theta)\right] \\
g(e, \theta)=\frac{d \theta}{d \tau}=\theta_{0}(e)-\theta
\end{gathered}
$$

A Figura 9 (c)[19] apresenta, em preto, uma curva de polarização estacionária corrente vs. potencial obtida pela resolução das equações (20) e (21). Sobreposta a essa curva também é mostrada oscilações de potencial, portanto, obtidas sob restrição galvanostática. Tendo-se em mente que essa curva de polarização resulta da interação entre os processos ilustrados pelas curvas em (a) e (b), observe que o aumento da corrente total ocorre justamente quando o valor de equilíbrio $\theta_{0}(e)$ começa a diminuir. Mas como isso acontece na região da $\operatorname{NDR}(d k(e) / d e<0$ para uma reação de oxidação), a corrente total rapidamente passa a diminuir dando origem a um pico. Sob controle galvanostático, oscilações de potencial surgem na região destacada em vermelho. Perceba que, diferentemente dos sistemas eletroquímicos do tipo N-NDR, as oscilações acontecem nas vizinhanças da curva de polarização com inclinação positiva, pois a NDR está parcialmente escondida devido a interposição de um processo de adsorção que inibe a velocidade da reação global. Nesse modo de controle, apenas a linha contínua da curva de polarização pode ser acessada experimentalmente, ou seja, esta linha indica estados estacionários $\left(\mathrm{e}_{\mathrm{ss}}, \theta_{\mathrm{ss}}\right)$ estáveis, enquanto a tracejada, estados instáveis. Tendo-se em mente que diferenças nas escalas de tempo de $e$ e $\theta$ são dadas pelo parâmetro $\varepsilon$, o qual é proporcional a constante que determina a velocidade com que $\theta$ relaxa ao seu valor de equilíbrio, \{Orlik, $2012 \# 1\}$ as oscilações em sistemas eletroquímicos HNNDR podem ser fisicamente compreendidas como se segue. 
Figura 10 - Gráficos ilustrando algumas propriedades do modelo HN-NDR: (a) constante de velocidade em função do potencial do eletrodo. b) isoterma de adsorção de uma espécie inibidora. (c) Curva de polarização estacionária corrente vs. potencial em preto e oscilações em regime galvanostático em vermelho.[19]
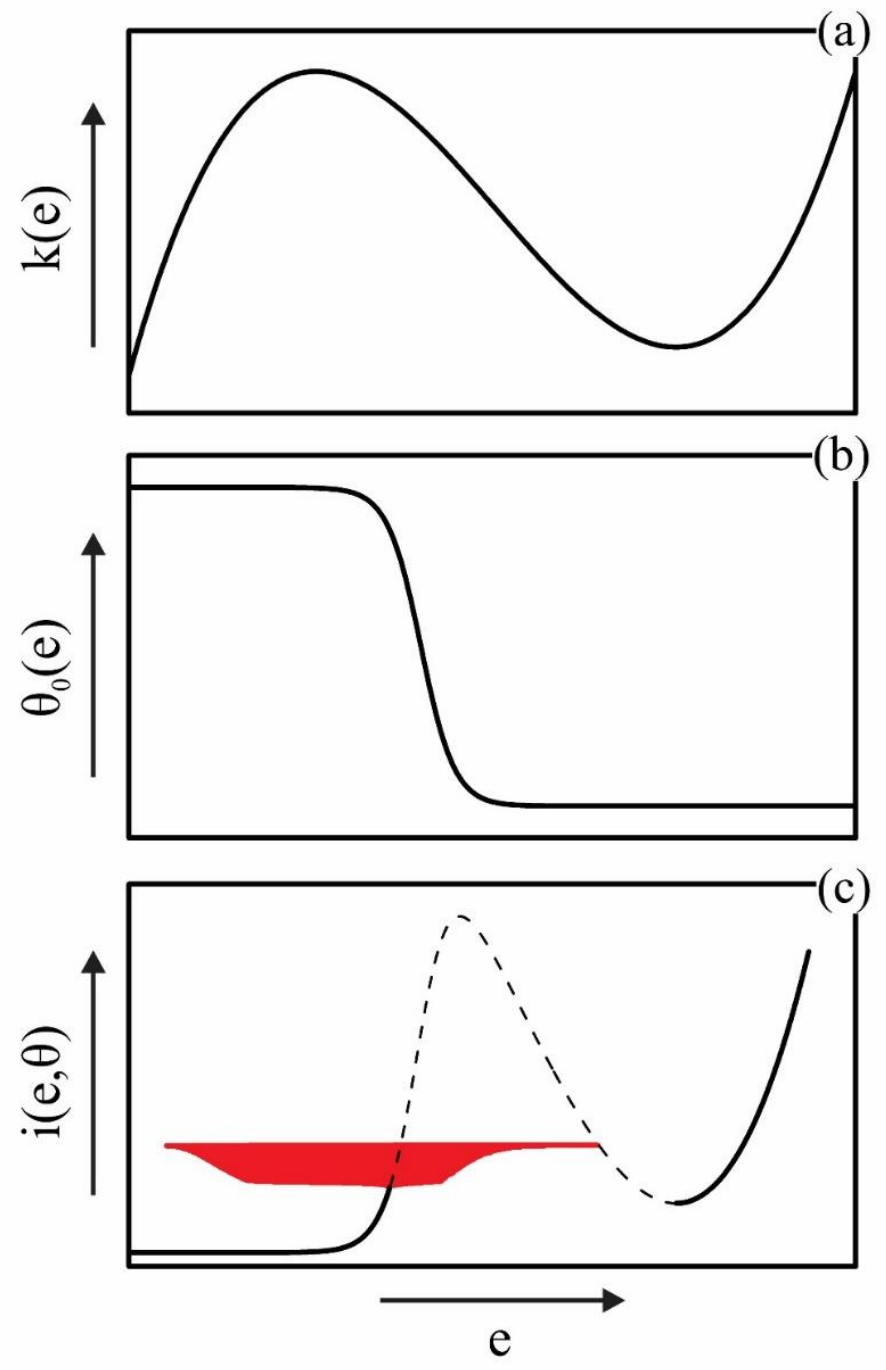

Sob restrição potenciostática e assumindo-se que a resistência total adimensional $\rho$ esteja acima de um valor crítico, uma perturbação em um estado estacionário $e_{s s}$ situado no ramo central da NDR será amplificada por um fator $\rho i$, movendo o potencial do eletrodo $e$ para altos valores.[14] Inicialmente, essas variações amplificadas de $e$ praticamente não são afetadas pelo grau de recobrimento $\theta$, desde que depois da perturbação o seu estado estacionário $\theta_{s s}$, entre 0 e 1 , relaxe lentamente ao seu menor valor de equilíbrio em altos potenciais. Portanto, somente com um certo atraso, ocorre a diminuição de $\theta$, induzida pelo aumento da variável $e$, ao redor da região da NDR. 
Quando isso acontece, o aumento de sítios livres (diminuição de $\theta$ ) provoca um aumento de $i$, suprimindo o abrupto aumento de $e$ em um primeiro momento e, posteriormente, levando a um decréscimo de $e$, que amplificado pela queda ôhmica, culmina com uma abrupta diminuição.

De acordo com a discussão apresentada, o mecanismo pelo qual se dá as oscilações é matematicamente similar ao do caso N-NDR. A equação (20) introduz um ciclo de retroalimentação positivo em $e$ devido à interação entre a NDR e a queda ôhmica do sistema que, sob restrição potenciostática, desestabiliza o potencial do eletrodo. Essa desestabilização somente acontece quando a NDR se manifesta devido ao decréscimo de $\theta_{0}(e)$. Já a equação (21) confere um ciclo de retroalimentação negativo em $\theta$, para baixos valores de $\varepsilon$. Todavia, de acordo com a explicação exposta no parágrafo imediatamente anterior, variações em $e$ induzem mudanças contrárias em $\theta$. Por sua vez, variações em $\theta$ provocam mudanças de mesmo sentido em $e$. Por isso, o modelo HN-NDR determinado pelas equações (20) e (21) é classificado como ativador-inibidor cruzado.[14] Para fins de comparação, a Figura 11[10, 14] apresenta uma representação esquemática do comportamento matemático das variáveis dos modelos N-NDR e HN-NDR. Na parte superior e inferior dessa figura estão representados os ciclos de retroalimentação positivo e negativo, respectivamente. E, nas partes laterais, o caráter inibidor ou ativador dessas variáveis. Diferentemente do modelo N-NDR, a variável $e$ do sistema dinâmico HN-NDR é inibidora e $\theta$, ativadora.

Figura 11 - Ciclos de retroalimentação positivo e negativo dos modelos N-NDR e HN-NDR. Nesses mecanismos matemáticos, o sinal positivo indica ativação e o negativo, inibição.[10, 14]
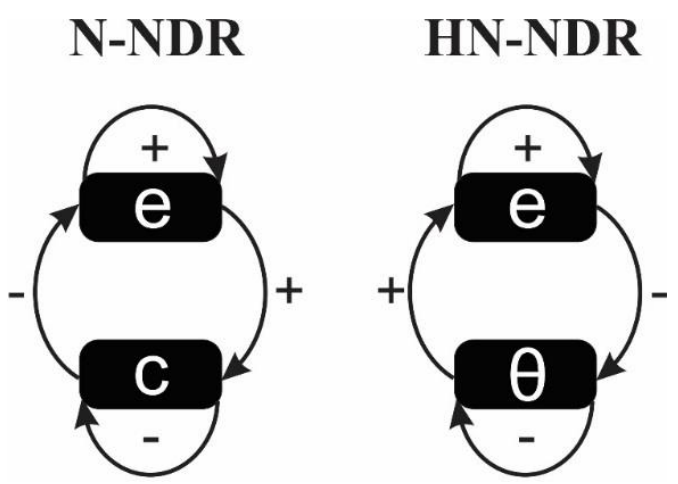

O diagrama apresentado na Figura 12[10] demonstra as regiões dos parâmetros $\rho$ e $u$ em que o modelo HN-NDR exibe oscilações e biestabilidade. A ausência de um limite superior de $\rho$ 
para a região de oscilações indica que elas são possíveis tanto em regime potenciostático, quanto em galvanostático.

Figura 12 - Diagrama mostrando as regiões dos parâmetros $\rho$ e u onde o sistema bidimensional HN-NDR exibe oscilações e biestabilidade.[10] Figura modificada a partir da referência 10.

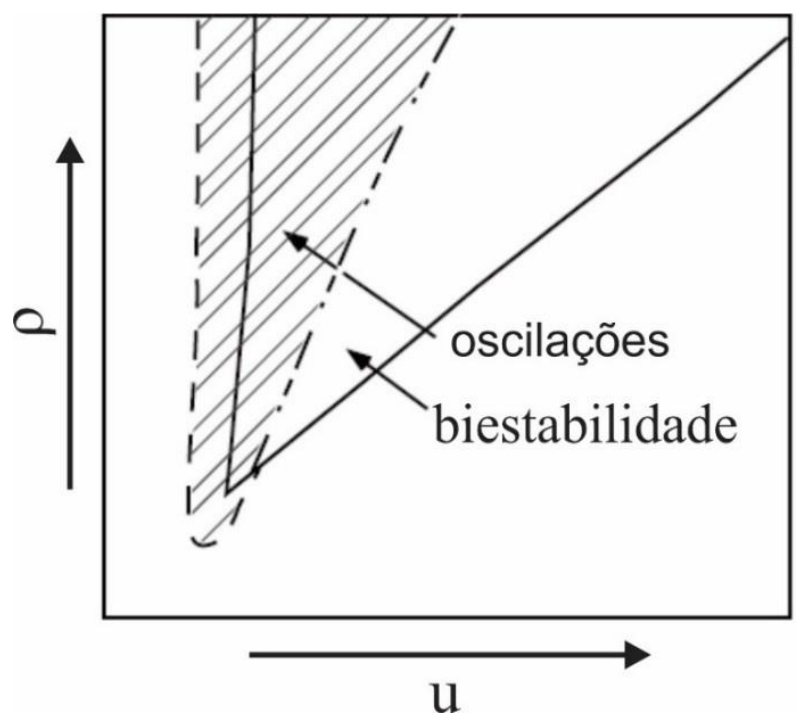

\subsection{Considerações}

A principal propriedade a ser destacada a seguir refere-se à morfologia das oscilações do potencial do eletrodo, a qual está intrinsicamente relacionada à origem das diferentes escalas de tempo, expressadas pelo parâmetro $\varepsilon$. Desde que neste trabalho estuda-se somente oscilações periódicas simples obtidas durante a eletro-oxidação de algumas moléculas orgânicas, o modelo HN-NDR é suficiente para orientar a discussão nesse sentido.

Para o modelo NDR, $\varepsilon$ é inversamente proporcional à espessura da camada de difusão, portanto, a morfologia das oscilações está relacionada com o transporte de massa por difusão da espécie eletroativa. A Figura 6 (b) e a Figura 8 (b), apresentadas anteriormente, ilustram diferenças na morfologia das oscilações para diferentes valores de $\varepsilon$, mantendo-se constante os demais parâmetros.

Já para o modelo HN-NDR, $\varepsilon$ é proporcional à constante cinética de adsorção de uma espécie adsorvida em baixos potenciais, sendo a morfologia dos ciclos oscilatórios originada, portanto, pela cinética de adsorção desta espécie. Sob a perspectiva do mecanismo reacional de 
moléculas orgânicas pequenas catalisadas por platina, em termos gerais, esta espécie é o monóxido de carbono $\mathrm{CO}_{\mathrm{ad}}$, como já exemplificado inicialmente. Desse modo, diferenças na morfologia das oscilações de potencial envolvendo a oxidação dessas moléculas expressam especificidades cinéticas inerentes às etapas de desidrogenação ou desidratação de cada mecanismo reacional, que levam à formação de $\mathrm{CO}_{\mathrm{ad}}$.

Como estabelecido anteriormente, outra característica fundamental do mecanismo reacional da oxidação eletroquímica dessas moléculas sobre platina, que tornam as suas reações de oxidação susceptíveis a exibirem instabilidades, provém da inibição do processo de adsorção dessas moléculas provocado pela formação de espécies oxigenadas. No protótipo HN-NDR, essa característica não foi representada por uma isoterma de adsorção, já que o mesmo é um modelo genérico simples. Mas, evidentemente, a cinética de formação de espécies oxigenadas, bem como a cinética de sua reação com $\mathrm{CO}_{\mathrm{ad}}$ também contribuem para a morfologia de um ciclo oscilatório. Quando o potencial aumenta abruptamente durante um ciclo, induz a formação de espécies oxigenadas de forma "autocatalítica". Oscilações são possíveis somente se os graus de recobrimento de $\mathrm{CO}_{a d}$ e de espécies oxigenadas apresentarem escalas de tempo distintas, ou seja, a formação de espécies oxigenadas deve ser muito mais rápida do que a reação envolvendo ambas as espécies via uma etapa de Langmuir-Hinshelwood.

Assim, para uma releitura dos ciclos de retroalimentação positivo e negativo do modelo HN-NDR já apresentado na Figura 11, do ponto de vista do mecanismo reacional da eletro-oxidação de moléculas orgânicas pequenas, $\mathrm{CO}_{\mathrm{ad}}$ e espécies oxigenadas devem ser considerados. O grau de recobrimento de $\mathrm{CO}_{a d}$ é a variável lenta, já o grau de recobrimento de espécies oxigenadas é a variável rápida. Ambas as variáveis estão acopladas por meio do potencial do eletrodo e evoluem de acordo com o mecanismo do ciclo de retroalimentação discutido, determinando, assim, a morfologia de um ciclo oscilatório de acordo com as características particulares do mecanismo reacional de cada molécula.

Agora, levando-se em consideração o mecanismo reacional complexo de eletro-oxidação dessas moléculas, a desestabilização do potencial do eletrodo induz um comportamento não-linear em todas as constantes cinéticas e a velocidade de todas as etapas reacionais oscilam. Em outras palavras, os graus de recobrimento de todos os intermediários também podem influenciar o ciclo de retroalimentação fundamental, esboçado anteriormente, imprimindo informações mecanísticas importantes em um perfil oscilatório. 


\section{OBJETIVOS}

O estudo da eletro-oxidação de algumas moléculas orgânicas pequenas, catalisada por platina em meio ácido, foi realizado com os seguintes objetivos:

1. desenvolver uma metodologia, sustentada por um modelo de regressão linear multivariada, que seja aplicável na análise de resultados espectrométricos on line obtidos durante a eletro-oxidação oscilatória de moléculas orgânicas. E, inferir sobre a contribuição faradaica de vias que não resultam em produtos detectáveis.

2. partindo-se de resultados obtidos sob condições experimentais equivalentes, investigar a eletro-oxidação oscilatória de moléculas orgânicas pequenas enfatizando a eficiência eletrocatalítica em termos do sobrepotencial inerente a cada um dos sistemas. 


\section{EXPERIMENTAL}

\subsection{Sistema Eletroquímico Convencional}

Utilizou-se como eletrodo de trabalho placas de platina e, como eletrodo auxiliar, placas de platina de altas áreas superficiais. Mediu-se o potencial do eletrodo de trabalho em função de um eletrodo de referência de hidrogênio (ERH), preparado com o eletrólito de suporte. A célula de vidro foi de-aerada borbulhando-se argônio na solução eletrolítica e, depois, um fluxo incessante de argônio mantido sobre a superfície da solução. A temperatura da célula, igual a 25,0 $\pm 0,1{ }^{\circ} \mathrm{C}$, foi controlada por meio de um banho termostático. Para todos os experimentos, o eletrodo de trabalho foi aquecido até chegar ao rubro por meio de uma chama gerada pela combustão do gás butano. Em seguida, o eletrodo foi imediatamente transferido para o interior da célula eletroquímica aonde resfriou-se, acima do eletrólito de suporte e sob fluxo de argônio. Então, realizou-se diversas ciclagens entre $0,05 \mathrm{~V}$ e $1,5 \mathrm{~V}$ até se obter uma curva voltamétrica estável. Antes de cada experimento galvanostático, todos os sistemas contendo a molécula orgânica apropriada foram novamente submetidos a dez ciclagens voltamétricas a $0,1 \mathrm{~V} \mathrm{~s}^{-1}$, no mesmo intervalo de potencial mencionado anteriormente. Depois disso, um certo valor de corrente foi imediatamente aplicado. Determinou-se a área superficial ativa do eletrodo de trabalho por meio da carga envolvida na região de adsorção/desorção de hidrogênio, encontrando-se os seguintes valores para os eletrodos empregados nos experimentos com formaldeído, ácido fórmico e metanol: $0,38 \mathrm{~cm}^{2}, 0,26 \mathrm{~cm}^{2}$ e $0,26 \mathrm{~cm}^{2}$, respectivamente.

\subsection{Célula Eletroquímica Acoplada à um Espectrômetro de Massas: Detecção de Produtos Gasosos}

O aparato instrumental da técnica Diferential Electrochemical Mass Spectrometry on line (DEMS)[22] é formado basicamente por dois compartimentos denominados pré-câmara e câmara principal. Ambas são evacuadas por duas bombas moleculares do tipo turbo-drag $(60000 \mathrm{rpm}$, Pfeiffer) e interconectadas por um orifício de $3 \mathrm{~mm}$, de forma a gerar uma diferença de pressão da ordem de $10^{2}$ entre elas (aproximadamente $10^{-5}$ mbar na pré-câmara e $10^{-7}$ mbar na principal). A célula eletroquímica de vidro foi acoplada à pré-câmara seguindo princípios já publicados.[23] Em 
síntese, a única separação entre a solução eletrolítica e os compartimentos consiste de uma membrana de politetrafluoretileno, a qual também atua como um suporte para a deposição do catalisador poroso, como é explicado logo adiante. Desta forma, produtos gasosos gerados sobre a membrana podem rapidamente atravessá-la e adentrar, primeiramente, na pré-câmara e, então, na principal, onde se encontra o quadrupolo (QMA 200 Pfeiffer) do espectrômetro.

As medidas eletroquímicas foram realizadas concomitantemente às medidas de intensidades de corrente iônica para certos fragmentos de razão massa/carga (m/z) previamente selecionados. A resolução temporal das medidas de correntes iônicas, isto é, o atraso entre as medidas eletroquímicas e as registradas pelo DEMS on line foi menor do que $0,1 \mathrm{~s}$, valor determinado de acordo com um procedimento sugerido por Wolter and Heitbaum.[3, 23]

A corrente iônica para o fragmento de razão massa/carga, $m / z=44$, atribuída à produção de $\mathrm{CO}_{2}$, foi monitorada durante a eletro-oxidação do ácido fórmico com uma frequência de aquisição de $4 \mathrm{~Hz}$. Para experimentos envolvendo metanol, as correntes m/z $=44$ e 60 devido ao $\mathrm{CO}_{2}$ e ao metilformiato, respectivamente, foram simultaneamente registradas a $5,7 \mathrm{~Hz}$. Enquanto que para o etanol, três correntes iônicas foram medidas concomitantemente a $1 \mathrm{~Hz}$ : a corrente $\mathrm{m} / \mathrm{z}$ $=44$, a qual apresenta contribuições de fragmentos provenientes do $\mathrm{CO}_{2}$ e do acetaldeído, e as correntes $m / z=15$ e 29 , referentes ao acetaldeído. Essa baixa frequência de aquisição de $1 \mathrm{~Hz}$ foi utilizada para se minimizar o impacto do ruído nos parâmetros estatísticos. Deve-se evidenciar que, para os experimentos galvanostáticos envolvendo o etanol, não há contribuição de fragmentos provenientes do metano no sinal $\mathrm{m} / \mathrm{z}=15$, já que as oscilações de potencial ocorrem acima de $0,4 \mathrm{~V} \cdot[24,25]$

Mediu-se o potencial do eletrodo de trabalho em função de um eletrodo de referência de hidrogênio (ERH), o qual foi preparado utilizando-se a solução do eletrólito de suporte. Um eletrodo de platina com grande área superficial serviu como contra eletrodo. Para a eletro-oxidação de ácido fórmico e metanol, empregou-se como eletrodo de trabalho uma membrana de politetrafluoretileno (Gore-Tex PTFE - espessura de $50 \mu \mathrm{m}$ e tamanho de poro de 0,02 $\mu \mathrm{m}$ ) recoberta com platina (espessura de aproximadamente $50 \mathrm{~nm}$ ). Enquanto que para etanol, visandose garantir uma boa relação sinal/ruído, o eletrodo foi preparado com uma suspensão aquosa contendo 4,3 g de $\mathrm{H}_{2} \mathrm{O}, 0,0128 \mathrm{~g}$ de nanopartículas de platina (platina black) e $65 \mu \mathrm{L}$ de Nafion $6 \%(\mathrm{~m} / \mathrm{m})$. Depois de homogeneizada utilizando-se um ultrassom, $60 \mu \mathrm{L}$ dessa suspensão foi pipetado no centro de uma membrana de politetrafluoretileno recoberta por ouro e com as mesmas 
dimensões anteriormente citadas para os eletrodos de platina. O eletrodo foi mantido em um forno a $60{ }^{\circ} \mathrm{C}$ por cerca de $10 \mathrm{~min}$, para que a água residual fosse evaporada. Todos os eletrodos foram avaliados por meio de stripping de $\mathrm{CO}$, sendo as seguintes áreas superficiais ativas determinadas: $4,3 \pm 0,3 \mathrm{~cm}^{2}, 3,5 \pm 0,3 \mathrm{~cm}^{2}$ e $15,5 \pm 0,7 \mathrm{~cm}^{2}$, para os eletrodos usados na eletro-oxidação do ácido fórmico, metanol e etanol, respectivamente.

A célula de vidro foi de-aerada borbulhando-se argônio na solução eletrolítica e, posteriormente, um fluxo de argônio mantido sobre a superfície da solução durante os experimentos. A temperatura da célula, de $20,0 \pm 0,1^{\circ} \mathrm{C}$, foi controlada por meio de um banho termostático (Cole-Parmer Polystat). Até se obter um perfil voltamétrico estável, um número suficiente de ciclos foi realizado antes de se iniciar os experimentos com ácido fórmico, metanol e etanol, em um intervalo de potencial de 0,15 a 1,3 V, 0,05 a 1,5 V e 0,15 a 1,2 V, respectivamente. Antes de cada experimento galvanostático, todos os sistemas foram novamente submetidos a dez ciclagens voltamétricas a $0,1 \mathrm{~V} \mathrm{~s}^{-1}$, nos mesmos intervalos de potencial mencionados. Depois disso, um certo valor de corrente foi imediatamente aplicado. No início e no final de cada medida, o sistema eletroquímico foi mantido em potencial de circuito aberto por tempo suficiente para se garantir uma linha de base bem definida, como critério de demarcação do zero de corrente iônica registrada pelo DEMS on line, a qual foi utilizada posteriormente em uma operação de subtração de linha de base no tratamento de todas as medidas espectrométricas.

\subsection{Procedimento de Limpeza}

As células eletroquímicas, seus componentes e demais vidrarias foram deixados submersos em um béquer contendo uma solução de permanganato de potássio levemente básica por, pelo menos, doze horas. No dia a serem realizados os experimentos, retirou-se o excesso de permanganato de potássio com água, sendo o ânion permanganato remanescente eliminado pela adição de uma solução aquosa de peróxido de hidrogênio acidificada com ácido sulfúrico. Em seguida, o béquer contendo os utensílios foi completado com água ao menos três vezes, fervendo-se a água antes de cada troca. 


\subsection{Reagentes}

As dispersões e soluções foram preparadas com água de alta pureza (Milli-Q, 18,2 M $\Omega \mathrm{cm}$ ), $\mathrm{H}_{2} \mathrm{SO}_{4}$ (Merck, 98\%), $\mathrm{HCOOH}$ (Sigma-Aldrich, $\geq 98 \%$ ), $\mathrm{H}_{3} \mathrm{COH}$ (J.T. Baker, 99,9\%), $\mathrm{CH}_{3} \mathrm{CH}_{2} \mathrm{OH}$ (Merck, 99,8\%). $\mathrm{H}_{3} \mathrm{COH}$ (J.T. Baker, 99.97\%). Antes de cada experimento, o formaldeído HCHO (Mallinckrodt Baker) foi aquecido até $60^{\circ} \mathrm{C}$ durante $30 \mathrm{~min}$ com o intuito de se remover traços de metanol. Todos os outros reagentes foram utilizados sem tratamento prévio. 


\section{MODELAGEM E MÉTODOS}

\subsection{Descrição Algébrica do Modelo de Regressão Linear Multivariada}

A partir do balanço de carga de um circuito eletroquímico, pode-se deduzir a equação:

$$
j_{T}=C_{d} \frac{d \varphi}{d t}+j_{F}
$$

na qual a densidade de corrente total que flui através do circuito, $j_{T}$, constitui-se da soma de um termo não faradaico e outro faradaico. O primeiro é dado pelo produto das variáveis $C_{d}$ e $d \varphi / d t$, denominadas capacitância da dupla camada elétrica e derivada primeira do potencial do eletrodo, respectivamente, enquanto que o segundo é representado pela densidade de corrente faradaica, $j_{F}$. Sob controle galvanostático, o potencial do eletrodo de trabalho, U, é medido em função de um eletrodo de referência, logo, a variável d $\varphi / d t$ pode ser estimada derivando-se $\mathrm{U}$ em relação ao tempo, de modo que:

$$
\frac{d U}{d t}=\frac{1}{C_{d}} j_{T}-\frac{1}{C_{d}} j_{F}
$$

Em um experimento galvanostático, a corrente aplicada, $j$, é mantida constante. Assumindo-se que a capacitância da dupla camada elétrica também permanece constante, o termo $d U / d t$ pode ser descrito simplesmente como proporcional a $-j_{F}$. Tal aproximação implica em considerar que qualquer mudança em uma dessas variáveis é acompanhada por uma mudança em sentido contrário na outra, como evidencia o sinal negativo na equação (23). Em reações complexas, tais como a eletro-oxidação de moléculas orgânicas pequenas, a corrente faradaica total pode ser interpretada como sendo a soma das correntes parciais provenientes de cada etapa reacional.

A técnica DEMS on line, por meio das correntes iônicas medidas, $j_{i}$, permite monitorar espécies voláteis resultantes de certas etapas reacionais, nesse sentido, cada $j_{i}$ expressa a corrente faradaica parcial proveniente de uma dada etapa. Diante disso, as correntes iônicas podem ser 
usadas para se inferir sobre a contribuição da produção dessas espécies para a corrente faradaica total. A derivada primeira do potencial, agora representada como $d U_{p} / d t$, pode de ser estimada em função das correntes iônicas de acordo com a seguinte equação:

$$
\frac{d U_{p}}{d t}=\alpha_{1}+\beta_{1} j_{1}+\alpha_{2}+\beta_{2} j_{2}+\cdots+\alpha_{n}+\beta_{n} j_{n}
$$

sendo $\alpha$ e $\beta$ os parâmetros de ajuste associados com cada corrente iônica. Reescrevendo essa equação de maneira mais compacta, tem-se que:

$$
\frac{d U_{p}}{d t}=A+\sum_{i=1}^{n} \beta_{i} j_{i}
$$

em que o termo A incorpora a soma de todos os parâmetros $\alpha$ e o outro, a soma de cada contribuição $i$.

Regressão linear multivariada (RLM)[26, 27] é uma metodologia estatística para se prever valores de uma ou mais variáveis dependentes (respostas) a partir de um conjunto de variáveis independentes, Z. Para uma resposta simples $\mathrm{Y}$, a sua relação matemática com a variável Z pode ser descrita como: $\mathrm{Y}=\mathrm{A}+\mathrm{BZ}+\varepsilon$, em que A e B são os parâmetros de ajuste ou de regressão, e $\varepsilon$, o erro. Com o intuito de se igualar $\mathrm{dU}_{\mathrm{p}} / \mathrm{dt}$ com o valor obtido experimentalmente, $d U / d t$, empregou-se a RLM, ajustando-se os parâmetros de regressão pelo método dos mínimos quadrados. Comparando-se as equações (23) e (24), fica claro que $\beta_{i}$ deve ser negativo quando associado com uma oxidação e positivo no caso de uma corrente de redução. Como somente reações de oxidação serão abordadas neste tratamento matemático, teve-se que, implicitamente, incorporar a restrição $\beta_{i}<0$ para se estimar $d U_{p} / d t$. Assim, esse termo resulta da melhor combinação das correntes iônicas. Em outras palavras, as análises de RLM computam a máxima contribuição possível proveniente da produção de espécies voláteis para a corrente faradaica total. No transcorrer deste texto ficará mais claro que o principal objetivo é comparar o termo predito, $d U_{p} / d t$, com a corrente faradaica total experimental, aproximada como sendo igual a $d U / d t$.

O erro, $\varepsilon$, foi definido em cada instante de acordo com a equação: 


$$
\varepsilon=\frac{d U}{d t}-\frac{d U_{p}}{d t}
$$

Como a equação (26) sugere, o erro deve ter as mesmas características da derivada primeira do potencial do eletrodo e consiste de valores positivos e negativos distribuídos em torno de zero. Em antecipação às próximas seções, o erro inclui informações sobre espécies que não estão sendo detectadas utilizando-se o DEMS on line, como espécies parcialmente oxidadas de baixa volatilidade e reações de dissociação ocorrendo na superfície do eletrodo. Para uma análise quantitativa comparativa do resíduo, antes de se realizar a RLM, $U, d U / d t$ e $j$ foram normalizados para se estenderem de zero até um.

\subsection{Breves Descrições Algébrica e Matricial do Método dos Mínimos Quadrados}

O ajuste dos parâmetros da regressão $\alpha$ e $\beta$ foi realizado empregando-se o método dos mínimos quadrados,[27] o qual consiste em ajustá-los de modo que o somatório dos quadrados do erro, $\sum_{l}^{n} \varepsilon_{i}{ }^{2}$, resulte no menor valor global possível. Para isso, parte-se do princípio de que as derivadas de $\sum_{l}^{n} \varepsilon_{i}^{2}$ em relação ao somatório $\sum_{l}^{n} \alpha_{i}$, e em relação aos parâmetros $\beta_{i}$ devem ser zero, equações (27) e (28), respectivamente.

$$
\begin{aligned}
& \frac{\partial\left(\sum_{1}^{n} \varepsilon_{i}^{2}\right)}{\partial\left(\sum_{1}^{n} \alpha_{i}\right)}=0 \\
& \frac{\partial\left(\sum_{1}^{n} \varepsilon_{i}^{2}\right)}{\partial \beta_{i}}=0
\end{aligned}
$$

De maneira mais simples, pode-se calcular o valor dos parâmetros de ajuste resolvendo somente a seguinte equação matricial:

$$
b=\left(Z^{t} Z\right)^{-1} Z^{t} Y
$$


em que a matriz $b$ incorpora todos os parâmetros de regressão a serem calculados, $\alpha \mathrm{e} \beta$. As matrizes $Y$ e $Z$ são formadas pelos valores obtidos experimentalmente de $d U / d t$ e $j_{i}$, respectivamente. $Z^{t}$ e $\left(Z^{t} Z\right)^{-1}$ são, nesta ordem, a matriz transposta de $Z$ e a matriz inversa do produto matricial $Z^{t} Z$.

\subsection{Covariâncias Populacional e Amostral}

Visando-se ampliar a análise do erro da RLM, calculou-se as covariâncias populacional e amostral, as quais indicam a tendência de um par de variáveis se desviarem de forma parecida em relação às suas respectivas médias. Isso permite avaliar as tendências previstas pelas equações (25) e (26), como será discutido na próxima seção. As correspondentes covariâncias populacionais de $d U / d t$ e $j_{i}$ em relação ao resíduo, $\varepsilon$, foram calculadas pelas equações (30) e (31), respectivamente:

$$
\begin{gathered}
\operatorname{Cov}\left(\varepsilon, \frac{d U}{d t}\right)=\left(\varepsilon_{i}-\bar{\varepsilon}\right)\left(\frac{d U_{i}}{d t}-\frac{\overline{d U}}{d t}\right) \\
\operatorname{Cov}\left(\varepsilon, j_{i}\right)=\left(\varepsilon_{i}-\bar{\varepsilon}\right)\left(j_{i}-\bar{\jmath}\right)
\end{gathered}
$$

em que $\varepsilon_{i}, d U_{i} / d t$ e $j_{i}$ são os valores das observações individuais para cada elemento i, enquanto que $\bar{\varepsilon}, \overline{d U} / d t$ e $\bar{\jmath}$ são as médias amostrais de cada variável em questão. Afim de se obter a tendência geral, obteve-se a covariância amostral dividindo-se o termo a direita das equações (30) e (31) por $\mathrm{N}-1$, sendo $\mathrm{N}$ o número de elementos em cada amostra de variáveis.

\subsection{Resíduo por Ciclo Oscilatório: $\varepsilon_{c}$}

Com o intuito de representar numericamente a corrente faradaica complementar não capturada pelas correntes iônicas detectadas pelo DEMS on line, definiu-se o resíduo por ciclo oscilatório, $\varepsilon_{c}$, como sendo:

$$
\varepsilon_{c}=\frac{p}{t} \int_{0}^{t}|\varepsilon(t)| d t=\frac{p}{t} \int_{0}^{t}\left|\left(\frac{d U}{d t}-\frac{d U_{p}}{d t}\right)\right| d t
$$


em que $p$ e $t$ são o período da oscilação e a duração do intervalo da série temporal estudado, respectivamente. $\mathrm{O}$ módulo em $\varepsilon(t)$ indica o cálculo de uma integral absoluta, resultando na área da curva definida por valores positivos e negativos. Utilizou-se cerca de quatro ciclos para se estimar $\varepsilon_{c}$, portanto, $p / t \sim 4$.

Deve-se destacar que a implementação desse modelo, utilizando-se o software MATLAB ${ }^{\circledR}$, foi realizada por Melke Augusto do Nascimento, ex-aluno do Prof. Hamilton Varela. 


\section{RESULTADOS E DISCUSSÃO}

\subsection{Produção de Espécies Voláteis Fundamentada por um Modelo de Regressão Linear Multivariada}

\subsubsection{Voltametrias Cíclicas}

A Figura 13 apresenta as curvas resultantes de uma voltametria cíclica obtida durante a eletro-oxidação de uma solução $0,5 \mathrm{~mol} \mathrm{~L}^{-1} \mathrm{em} \mathrm{H}_{2} \mathrm{SO}_{4}$ contendo $1,0 \mathrm{~mol} \mathrm{~L}^{-1}$ de ácido fórmico. Os resultados mostrados incluem: (a) o voltamograma cíclico (VC) e (b) o correspondente voltamograma cíclico de espectrometria de massas (VCEM) para a corrente iônica $\mathrm{m} / \mathrm{z}=44$, atribuída a produção de $\mathrm{CO}_{2}$. 
Figura 13 - Medidas simultâneas de (a) VC e (b) VCEM para a corrente iônica $\mathrm{m} / \mathrm{z}=44$, durante a eletro-oxidação de ácido fórmico sobre um eletrodo de platina. $[\mathrm{HCOOH}]=1,0 \mathrm{~mol} \mathrm{~L}^{-1}$, $\left[\mathrm{H}_{2} \mathrm{SO}_{4}\right]=0,5 \mathrm{~mol} \mathrm{~L}^{-1}$ e $\mathrm{T}=20^{\circ} \mathrm{C}$. Velocidade de varredura $=0,01 \mathrm{~V} \mathrm{~s}^{-1}$. Setas indicam o sentido da varredura de potencial.
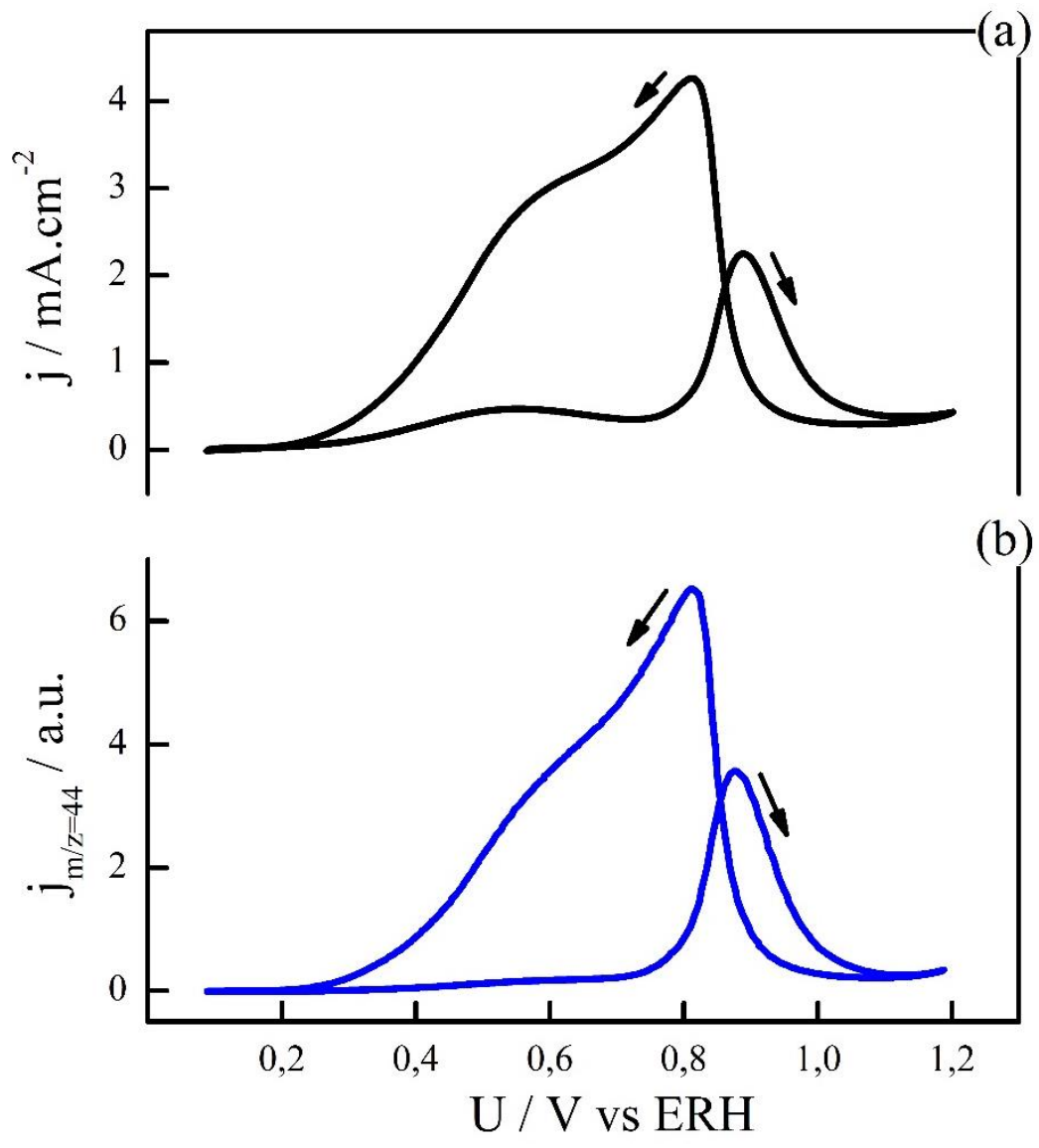
Os perfis voltamétricos obtidos durante uma varredura de potencial de uma solução de 0,5 mol L-1 em $\mathrm{H}_{2} \mathrm{SO}_{4}$ contendo 2,0 $\mathrm{mol} \mathrm{L}^{-1}$ de metanol sobre um eletrodo de platina são apresentados na Figura 14: (a) VC; VCEM para as correntes iônicas $m / z=$ (b) 44 e (c) 60, atribuídas ao $\mathrm{CO}_{2}$ e ao metilformiato, respectivamente.

Figura 14 - Medidas simultâneas de: (a) VC; VCEM para as correntes iônicas (b) $\mathrm{m} / \mathrm{z}=44$, (c) $\mathrm{m} / \mathrm{z}=60$, durante a eletro-oxidação de metanol sobre um eletrodo de platina. $\left[\mathrm{CH}_{3} \mathrm{OH}\right]=2,0 \mathrm{~mol} \mathrm{~L}^{-1},\left[\mathrm{HClO}_{4}\right]=0,5 \mathrm{~mol} \mathrm{~L}^{-1}$ e $\mathrm{T}=20{ }^{\circ} \mathrm{C}$. Velocidade de varredura $=0,01 \mathrm{Vs}^{-1}$. Setas indicam o sentido da varredura de potencial. Dados brutos foram publicados nas ref. 3 e 34 .
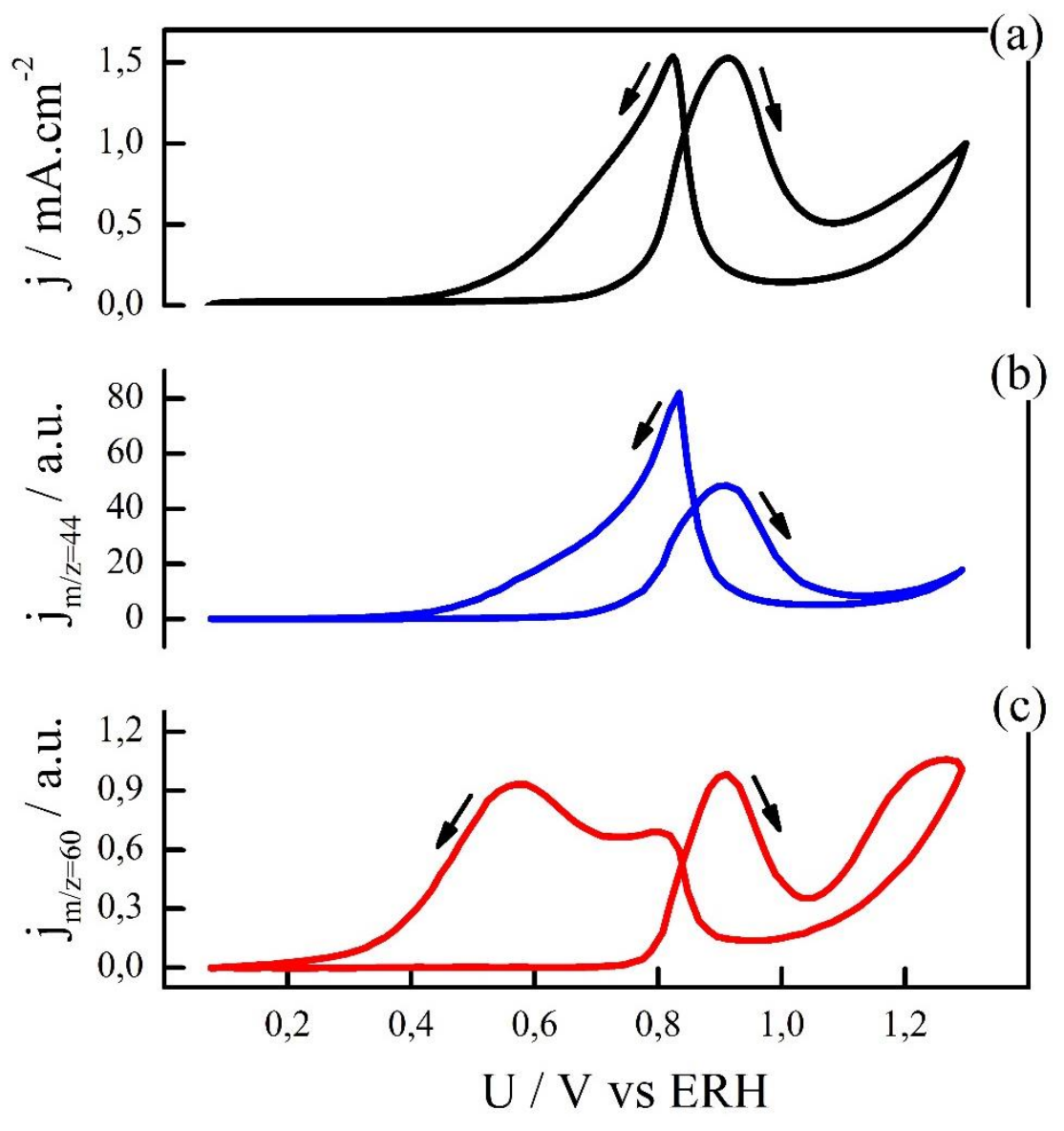
A Figura 15 mostra os resultados provenientes da eletro-oxidação de uma solução $0,5 \mathrm{~mol} \mathrm{~L}^{-1} \mathrm{em} \mathrm{H}_{2} \mathrm{SO}_{4}$ contendo $1 \mathrm{~mol} \mathrm{~L}^{-1}$ de etanol sobre platina black, durante uma varredura de potencial. A figura inclui: (a) VC; VCEM para as correntes iônicas $m / z$ : (b) 44, (c) 15 e (d) 29. A corrente $\mathrm{m} / \mathrm{z}=44$ possui contribuições de fragmentos provenientes do $\mathrm{CO}_{2}$ e do acetaldeído, enquanto a 15 e a 29 são atribuídas ao acetaldeído.

Figura 15 - Medidas simultâneas de (a) VC, VCEM para as correntes iônicas de (b) m/z = 44, (c) $\mathrm{m} / \mathrm{z}=15$ e (d) $\mathrm{m} / \mathrm{z}=29$, durante a eletro-oxidação de etanol sobre nanopartículas de platina (platina black). $\left[\mathrm{CH}_{3} \mathrm{CH}_{2} \mathrm{OH}\right]=1,0 \mathrm{~mol} \mathrm{~L} \mathrm{~L}^{-1},\left[\mathrm{H}_{2} \mathrm{SO}_{4}\right]=0,5 \mathrm{~mol} \mathrm{~L}-1$ e $\mathrm{T}=20{ }^{\circ} \mathrm{C}$. Velocidade de varredura $=0,01 \mathrm{Vs}^{-1}$. Setas indicam o sentido da varredura de potencial.

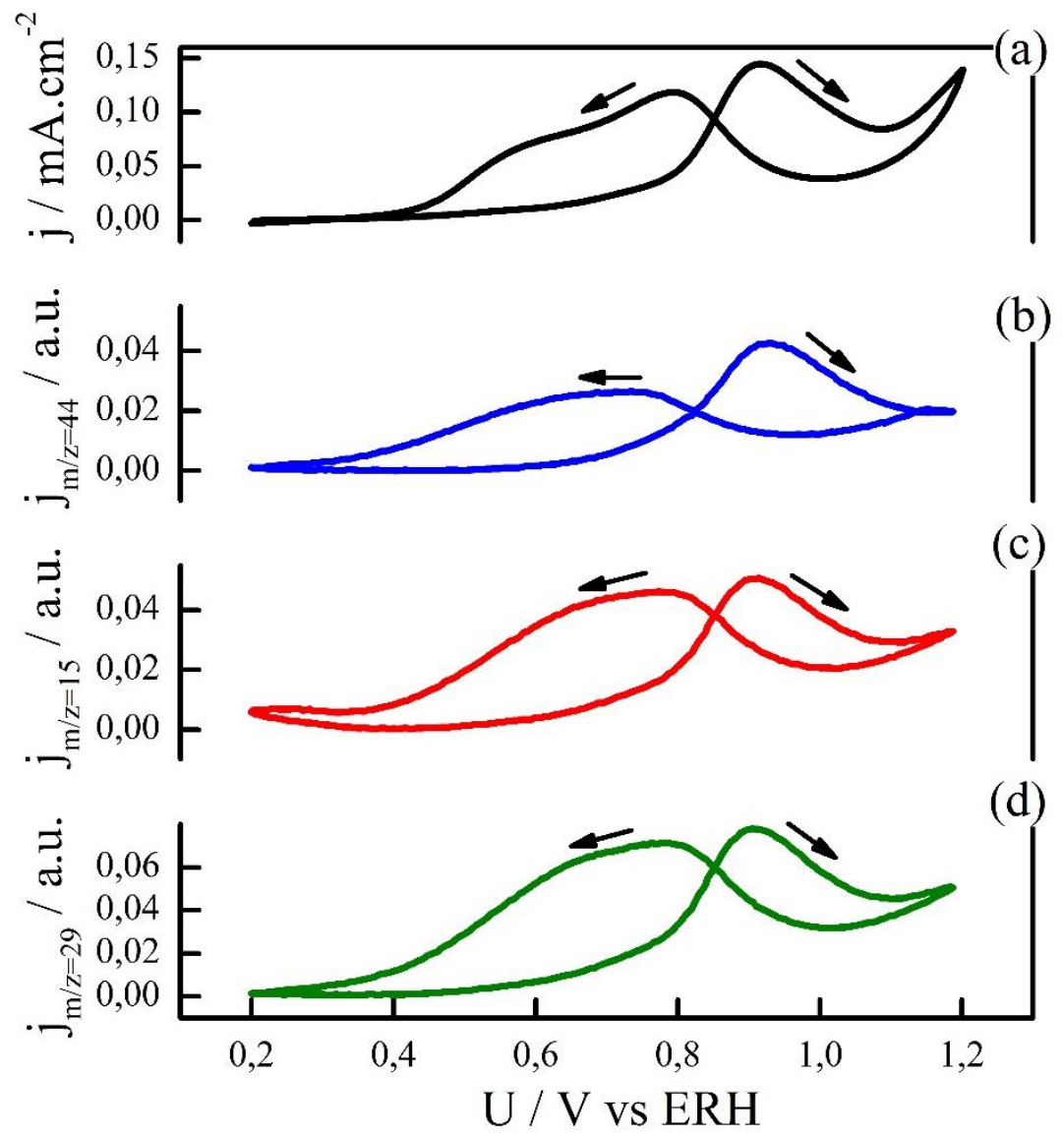




\subsubsection{Regressão Linear Multivariada: Resultados Obtidos para Ácido Fórmico}

Concomitantemente às oscilações espontâneas do potencial do eletrodo durante a eletro-oxidação de ácido fórmico, monitorou-se, usando-se o DEMS online, a corrente iônica para o fragmento de $m / z=44$, atribuído à produção de $\mathrm{CO}_{2}$, o único produto volátil detectável neste sistema. A Figura 16 mostra séries temporais típicas para: (a) o potencial do eletrodo, $U$, e (b) a corrente iônica de $m / z=44, j_{m / z}=44$. As oscilações de potencial são similares às observadas em eletrodos de platina policristalina maciça[28-30] e alguns aspectos do mecanismo reacional têm sido razoavelmente explicados.[30-32] A série temporal para a produção de $\mathrm{CO}_{2}$, Figura 16 (b), mostra um perfil bastante constante em regiões em que o potencial varia mais lentamente, o qual é interrompido por abruptas variações associadas com bruscas mudanças de $U$. Como será discutido nos próximos parágrafos, esse perfil é completamente compatível com a corrente faradaica estimada pela equação (23). 
Figura 16 - Evolução temporal (a) do potencial do eletrodo de trabalho, U e (b) da corrente iônica $\mathrm{m} / \mathrm{z}=44, \mathrm{j}_{\mathrm{m} / \mathrm{z}=44}$, durante a eletro-oxidação oscilatória de ácido fórmico a $\mathrm{j}=0,44 \mathrm{~mA} \mathrm{~cm}^{-2}$. $[\mathrm{HCOOH}]=1,0 \mathrm{~mol} \mathrm{~L}^{-1},\left[\mathrm{H}_{2} \mathrm{SO}_{4}\right]=0,5 \mathrm{~mol} \mathrm{~L}^{-1} \mathrm{e} \mathrm{T}=20^{\circ} \mathrm{C}$. Para informações adicionais, ver seção Experimental.

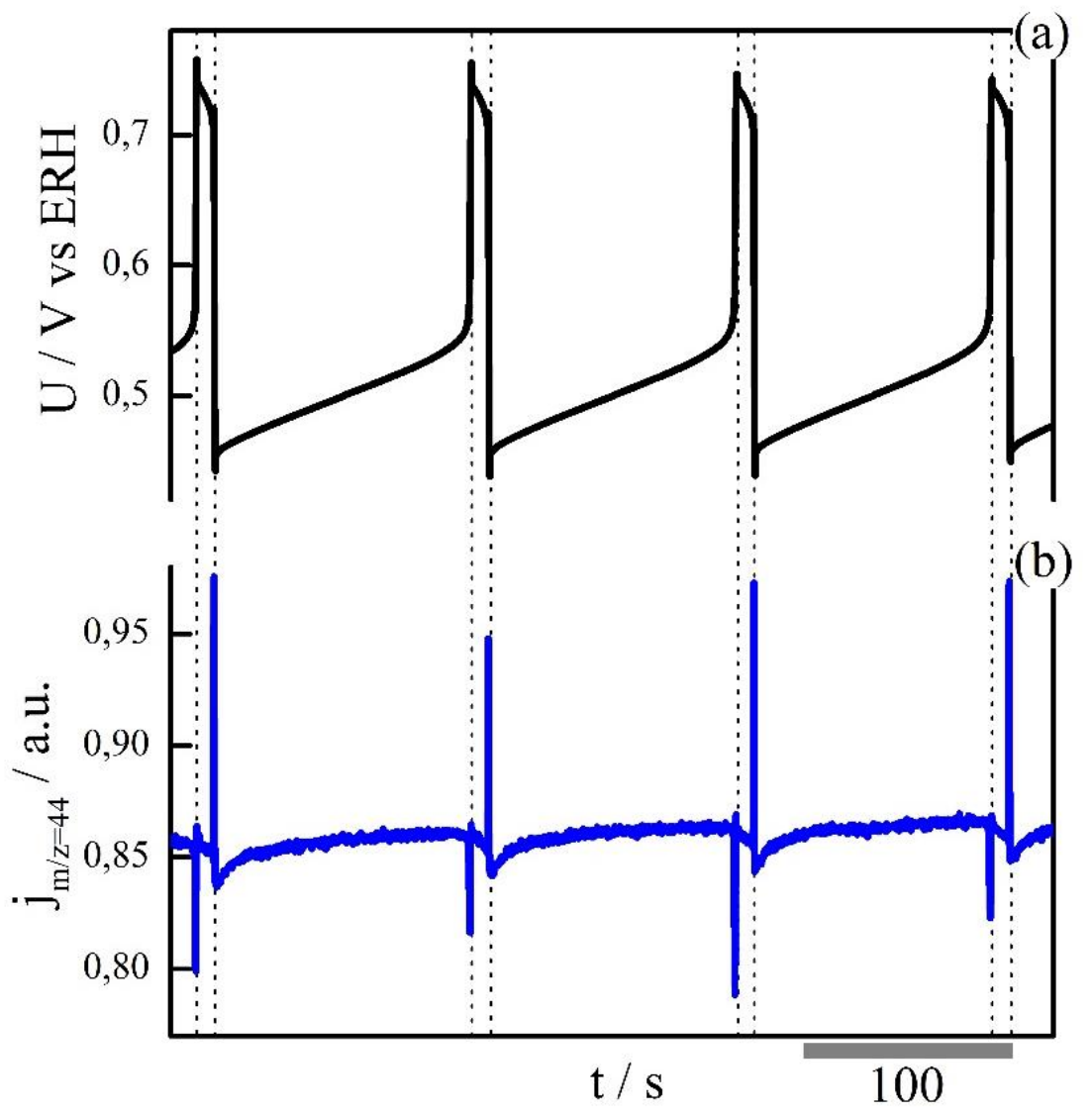

De acordo com o modelo de RLM já apresentado, a derivada primeira do potencial do eletrodo, $d U_{p} / d t$, foi estimada em função da corrente iônica de $m / z=44$, então, reescrevendo-se a equação (25), tem-se:

$$
\frac{d U_{p}}{d t}=A+\beta_{1} j_{m / z=44}
$$

em que os parâmetros de ajuste $A=+0,8292$ e $\beta_{1}=-0,5528$.

A Figura 17 (a) evidencia que as curvas de $d U / d t$ experimental (linha preta) e de $d U_{p} / d t$ predita (linha azul) são muito parecidas. Essa similaridade provém do fato de que todas as etapas reacionais que envolvem transferência de elétrons, para a eletro-oxidação de ácido fórmico, resultam na produção de $\mathrm{CO}_{2}$, o qual é capturado pelo fragmento de $m / z=44$. Isso se tornará mais 
claro adiante, ao se comparar esse resultado com aqueles obtidos para metanol e etanol. Tal fato é corroborado pelo perfil da corrente iônica $j_{m / z}=44$, Figura 16 (b), o qual é espelhado pela curva de $d U / d t$, Figura 17 (a). E também reforçado pela semelhança existe entre os perfis de $d U / d t$ e o erro, $\varepsilon$.

Figura 17 - Séries temporais normalizadas: (a) derivada primeira do potencial do eletrodo experimental a $\mathrm{j}=0,44 \mathrm{~mA} \cdot \mathrm{cm}^{-2}, d U / d t$ (linha preta), acompanhado pela derivada primeira do potencial do eletrodo predita, $d U p / d t$ (linha azul); (b) derivada primeira do potencial residual, o erro $\varepsilon$. $[\mathrm{HCOOH}]=1,0 \mathrm{~mol} \mathrm{~L}^{-1},\left[\mathrm{H}_{2} \mathrm{SO}_{4}\right]=0,5 \mathrm{~mol} \mathrm{~L}^{-1} \mathrm{e} \mathrm{T}=20^{\circ} \mathrm{C}$. Dados mostrados em (a) foram obtidos a partir dos resultados mostrados na Figura 16. Como foi normalizada, a escala no eixo horizontal está ausente: tem a sua origem no zero e termina em 1.

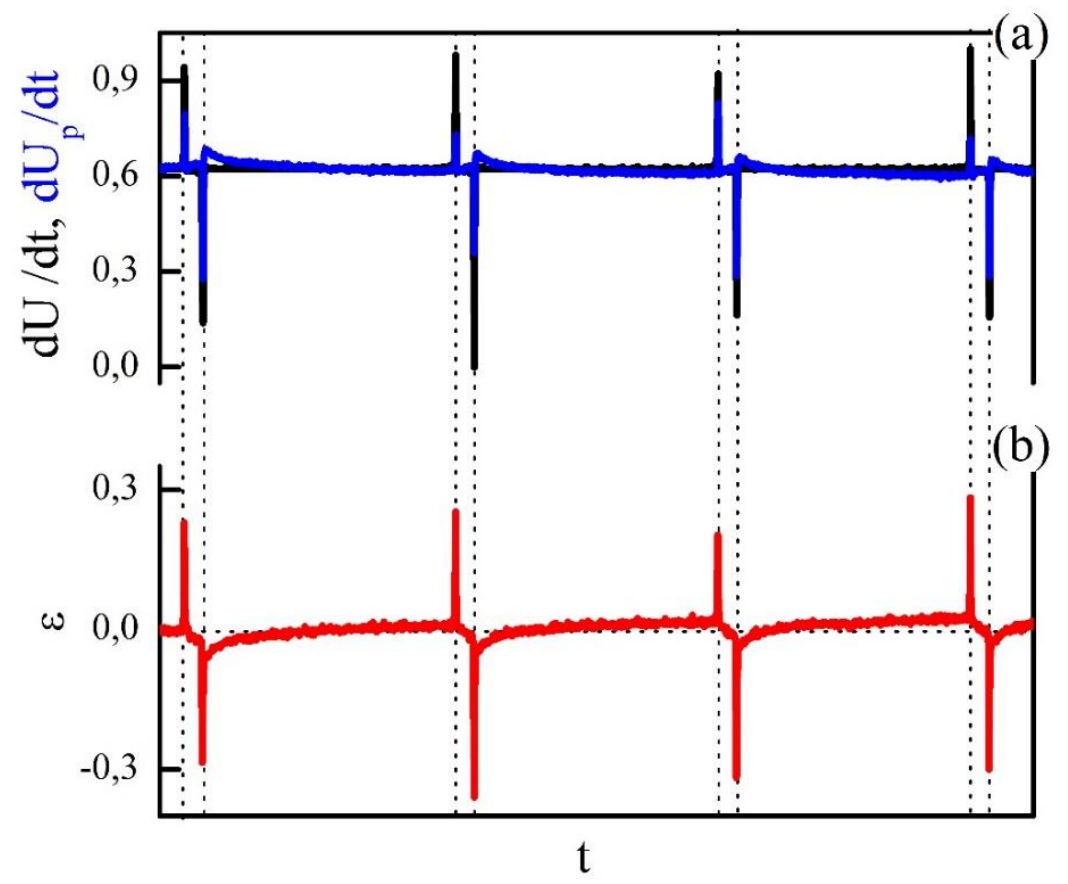

Visando-se aprofundar a comparação entre a corrente faradaica total, aproximada como sendo igual a - $d U / d t$, e aquela estimada em função da produção de espécies voláteis, $d U_{p} / d t$, calculou-se a covariância entre diferentes pares de variáveis. Esse parâmetro estatístico indica como duas variáveis mudam juntas em relação às suas respectivas médias, e o principal aspecto a ser considerado no gráfico a seguir é o sinal da covariância. Uma covariância positiva implica que as variáveis mudam, isto é, aumentam ou diminuem, no mesmo sentido. Quando a covariância é negativa, as variáveis mudam em sentidos opostos. 
A Figura 18 mostra as séries temporais para a derivada primeira do potencial experimental, $d U / d t$, e a corrente iônica de $m / z=44, j_{m / z}=44$, e as suas respectivas covariâncias em relação a $\varepsilon$, $\operatorname{Cov}(\varepsilon, d U / d t)$ e $\operatorname{Cov}\left(\varepsilon, j_{m / z}=44\right)$.

Figura 18 - Análise de covariância para as séries temporais normalizadas resultantes da eletro-oxidação oscilatória de ácido fórmico (a) derirada primeira do potencial do eletrodo experimental, $d U / d t$; (b) covariância populacional entre $\varepsilon$ and $d U / d t, \operatorname{Cov}(\varepsilon, \mathrm{dU} / \mathrm{dt}$ ); (c) corrente iônica $m / z=44, j_{m / z}=44$; (d) covariância populacional entre $\varepsilon$ e $j_{m / z}=44$, $\operatorname{Cov}\left(\varepsilon, \mathrm{j}_{\mathrm{m} / z=44}\right)$. Como foi normalizada, a escala no eixo horizontal está ausente: tem a sua origem no zero e termina em 1.

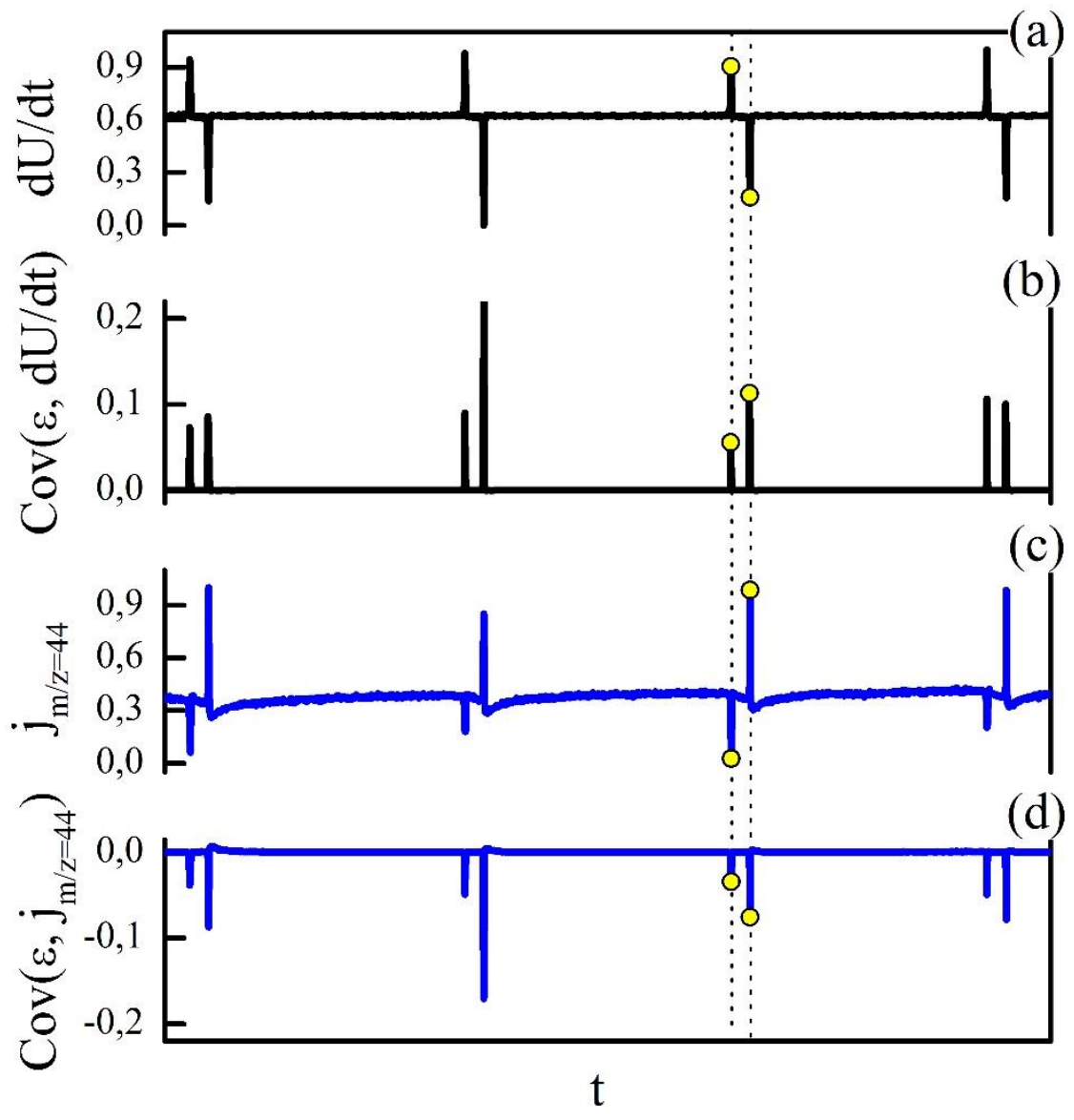

Relembrando a equação (26), $\varepsilon$ deve ter, em princípio, as mesmas características de $d U / d t$, e seus desvios de linearidade em relação a $\varepsilon$ provém da variável $d U_{p} / d t$. Portanto, espera-se que o sinal de $\operatorname{Cov}(\varepsilon, d U / d t)$ seja positivo quando seus valores desviarem-se de zero. Para o caso do ácido fórmico, é previsto que os valores de $\varepsilon$ mudem em sentido oposto aos de $j_{m / z}=44$, como evidencia o sinal negativo implicitamente incorporado pela restrição $\beta_{i}<0$, na equação (25). Se 
mais de uma corrente iônica medida pelo DEMS on line estiver sendo computada na RLM, a situação se torna mais complicada, como será demonstrado para os casos do metanol e etanol. Os resultados apresentados na Figura 18 evidenciam as características atribuídas, por princípio, ao erro $\varepsilon$, pois os sentidos das mudanças previstos pelas equações são corroborados por ambas covariâncias populacionais $\operatorname{Cov}(\varepsilon, d U / d t)$ e $\operatorname{Cov}\left(\varepsilon, j_{m / z}=44\right)$. Com a finalidade de se representar a tendência global apresentada pelos valores de covariância populacional dispostos em função do tempo, calculou-se a covariância amostral. A covariância entre $\varepsilon$ e $d U / d t$ é $+8 \times 10^{-4}$ e entre $\varepsilon$ e $j_{m / z}=44,-1 \times 10^{-4}$. Como já mencionado, os sinais dessas covariâncias amostrais concordam com a relação prevista pela equação (25).

Outro aspecto a ser considerado é a magnitude dos valores absolutos de covariância populacional obtidos de um mesmo conjunto de dados, dimensão possível de ser alcançada pela comparação dos valores entre si. Os valores de covariância populacional expressam a força da relação entre o par de variáveis. Um alto valor indica uma forte relação entre o par e, um baixo valor, significa o contrário. Os maiores valores do resíduo sempre ocorrem associados com os vértices de $d U / d t$, Figura 17 (a) e (b). Percebe-se claramente na Figura 18 (b) e (d), que os maiores valores absolutos de covariância populacional também ocorrem sempre associados com os vértices de $d U / d t$. Ver linhas tracejadas e pontos amarelos como forma de orientação. Portanto, a relação entre os pares de variáveis $\varepsilon$ e $d U / d t$, bem como entre $\varepsilon$ e $j_{m / z}=44$, tende a ser mais forte nesta região. Essa tendência deve-se, provavelmente, às mudanças de capacitânia que acompanham variações abruptas de $U$ e, portanto, inerentes ao termo $d U / d t$. Tais mudanças não são computadas pelo modelo de RLM, o qual considera $d U_{p} / d t$ como sendo diretamente proporcional a $-i_{F}$, ou seja, a capacitância é considerada constante, c.f. equação 23 e 25. Essa questão ainda será abordada mais adiante, perante novos aspectos observados nas análises de RLM envolvendo metanol e etanol.

\subsubsection{Regressão Linear Multivariada: Resultados Obtidos para Metanol}

A investigação da eletro-oxidação oscilatória de metanol empregando-se a técnica DEMS on line foi recentemente realizada pelo nosso grupo, sendo que os dados brutos utilizados nesta seção são os mesmos já publicados nas referências 3 e 34 .

Em adição ao fragmento $m / z=44$, registrado para o caso do ácido fórmico, a corrente iônica $m / z=60$, correspondente à produção de metilformiato, também foi monitorada durante a 
eletro-oxidação de metanol. Essa espécie parcialmente oxidada provavelmente é formada a partir do ataque nucleofílico de uma molécula de metanol a uma espécie intermediária adsorvida, "HCO”.[33]

A Figura 19 mostra as séries temporais para: (a) potencial do eletrodo, (b) corrente iônica de $m / z=44$ e (c) corrente iônica de $m / z=60$. Os picos múltiplos presentes na série temporal do dióxido de carbono foram explicados por Nagao et al.,[3, 34] por meio de experimentos, modelagem e simulações numéricas. Em síntese, os autores atribuíram o pico $i$ à produção de $\mathrm{CO}_{2}$ proveniente da eletro-oxidação do monóxido de carbono adsorvido $\mathrm{CO}_{\mathrm{ad}}$, enquanto que os picos $i i$ e iii, ao $\mathrm{CO}_{2}$ produzido pela via que não envolve $\mathrm{CO}_{\mathrm{ad}}$.

Figura 19 - Evolução temporal (a) do potencial do eletrodo de trabalho, U, e das correntes iônicas de (b) $\mathrm{m} / \mathrm{z}=44, \mathrm{j}_{\mathrm{m} / \mathrm{z}=44} \mathrm{e}$ (c) $\mathrm{m} / \mathrm{z}=60, \mathrm{j}_{\mathrm{m} / \mathrm{z}=60}$, durante a eletro-oxidação oscilatória de metanol a $\mathrm{j}=0,35 \mathrm{~mA} \mathrm{~cm}{ }^{-2}$. $\left[\mathrm{CH}_{3} \mathrm{OH}\right]=1,0 \mathrm{~mol} \mathrm{~L}^{-1},\left[\mathrm{HClO}_{4}\right]=0,5 \mathrm{~mol} \mathrm{~L}^{-1}$ e T $=20{ }^{\circ} \mathrm{C}$. Para informações adicionais, ver Seção Experimental. Dados brutos foram publicados nas ref. 3 e 34.

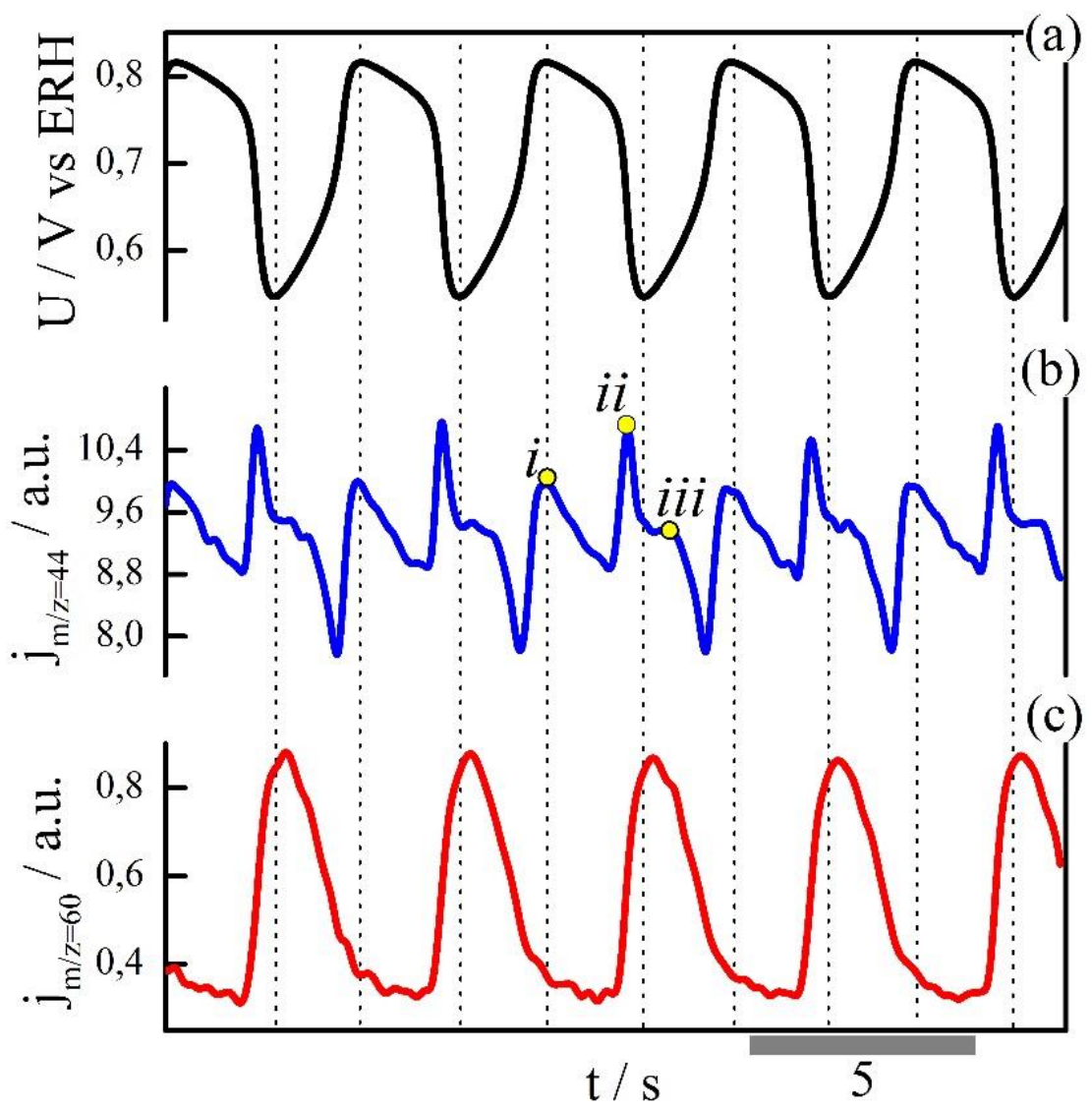


O termo $d U_{p} / d t$ para metanol foi estimado computando-se as correntes iônicas $m / z=44$ e 60, então, escreve-se a equação (25) como:

$$
\frac{d U_{p}}{d t}=A+\beta_{1} j_{m / z=44}+\beta_{2} j_{m / z=60}
$$

Os parâmetros de ajuste calculados foram: $A=+0,9296, \beta_{1}=-0,6939$ e $\beta_{2}=-1 \times 10^{-6}$. O baixíssimo valor de $\beta_{2}$ corresponde à tolerância usada na regressão e comparando-o com o valor de $\beta_{1}$, torna-se evidente que a contribuição da produção de metilformeato para a corrente faradaica total é extremamente baixa, frente à da produção de $\mathrm{CO}_{2}$. $\mathrm{O}$ ajuste dos parâmetros $\beta_{1}$ e $\beta_{2}$ pelo método dos mínimos quadrados garante a melhor combinação das correntes iônicas individuais visando-se igualar o termo predito $d U_{p} / d t$ com a corrente faradaica total experimental, aproximada como sendo proporcional a - $d U / d t$. Consequentemente, as contribuições da produção de $\mathrm{CO}_{2}$ e metilformiato para a corrente faradaica corresponde à máxima contribuição possível. Qualquer mudança na otimização desses parâmetros acarretaria uma pior combinação da contribuição da produção dessas espécies para a corrente faradaica total.

A Figura 20 (a) mostra que os perfis de $d U / d t$ (linha preta) e $d U_{p} / d t$ (linha azul), diferentemente daqueles para o ácido fórmico, não se sobrepõem tão bem. Além disso, o perfil do resíduo na Figura 20 (b) não segue os do $\mathrm{CO}_{2}$ e do metilformiato, Figuras 19 (b) e (c), respectivamente.

Comparando-se as Figuras 17 (b) e 20 (b), torna-se perceptível que o resíduo para o caso do metanol é mais pronunciado do que o do ácido fórmico. Também pode-se distinguir duas contribuições para o resíduo: uma devido a mudanças abruptas de $U$, logo localizadas nesta região, e outra dicernível onde $U$ muda mais lentamente com o tempo. Como já mencionado para os resultados obtidos para o ácido fórmico, a primeira contribuição deve ser inerente às mudanças de capacitância que seguem variações abruptas em $U$ e que, portanto, afeta primariamente a corrente faradaica total experimental, aproximada como sendo equivalente a $d U / d t$, c.f. equação 23. Quando $\varepsilon$ é diferente de zero em regiões em que $U$ varia lentamente com o tempo, espera-se que a falta de ajuste seja inerente ao termo predito, $d U_{p} / d t$, por não representa tão bem $d U / d t$. Nota-se, comparativamente, por meio das Figuras 17 (b) e 20 (b), que os valores do resíduo para o metanol são diferentes de zero quase a todo instante, enquanto que para o ácido fórmico, as discrepâncias 
estão quase que completamente confinadas nas regiões em que $U$ varia abruptamente. Essa comparação reforça não somente a boa concordância entre a corrente faradaica experimental e aquela estimada em função da produção de $\mathrm{CO}_{2}$, para o caso do ácido fórmico, como também evidencia que as correntes faradaicas parciais associadas com a produção de $\mathrm{CO}_{2}$ e metilformiato representam muito mal a corrente faradaica total gerada durante a eletro-oxidação oscilatória de metanol e dessa forma, pode-se inferir que espécieis parcialmente oxidadas que difundem para a solução devem desempenhar um papel significativo. Como a corrente faradaica devido à produção de espécies voláteis detectadas foi estimada de modo a se obter a máxima contribuição possível, a produção de espécies parcialmente oxidadas, não detectadas por meio do DEMS online, é bastante evidente para o metanol. Esse ponto será discutido de forma mais abrangente na próxima seção.

Figura 20 - Séries temporais normalizadas: (a) derivada primeira do potencial do eletrodo experimental a j $=0,35 \mathrm{~mA} \mathrm{~cm}{ }^{-2}, \mathrm{dU} / \mathrm{dt}$ (linha preta), acompanhado pela derivada primeira do potencial do eletrodo predita, $\mathrm{dU}_{\mathrm{p}} / \mathrm{dt}$ (linha azul); (b) derivada primeira do potencial residual, $\mathrm{o}$ erro $\varepsilon$. $\left[\mathrm{CH}_{3} \mathrm{OH}\right]=1,0 \mathrm{~mol} \mathrm{~L}^{-1},\left[\mathrm{HClO}_{4}\right]=0,5 \mathrm{~mol} \mathrm{~L}^{-1} \mathrm{e} \mathrm{T}=20{ }^{\circ} \mathrm{C}$. Dados apresentados em (a) foram obtidos a partir daqueles mostrados na Figura 19. A escala no eixo horizontal é omitida pois foi normalizada

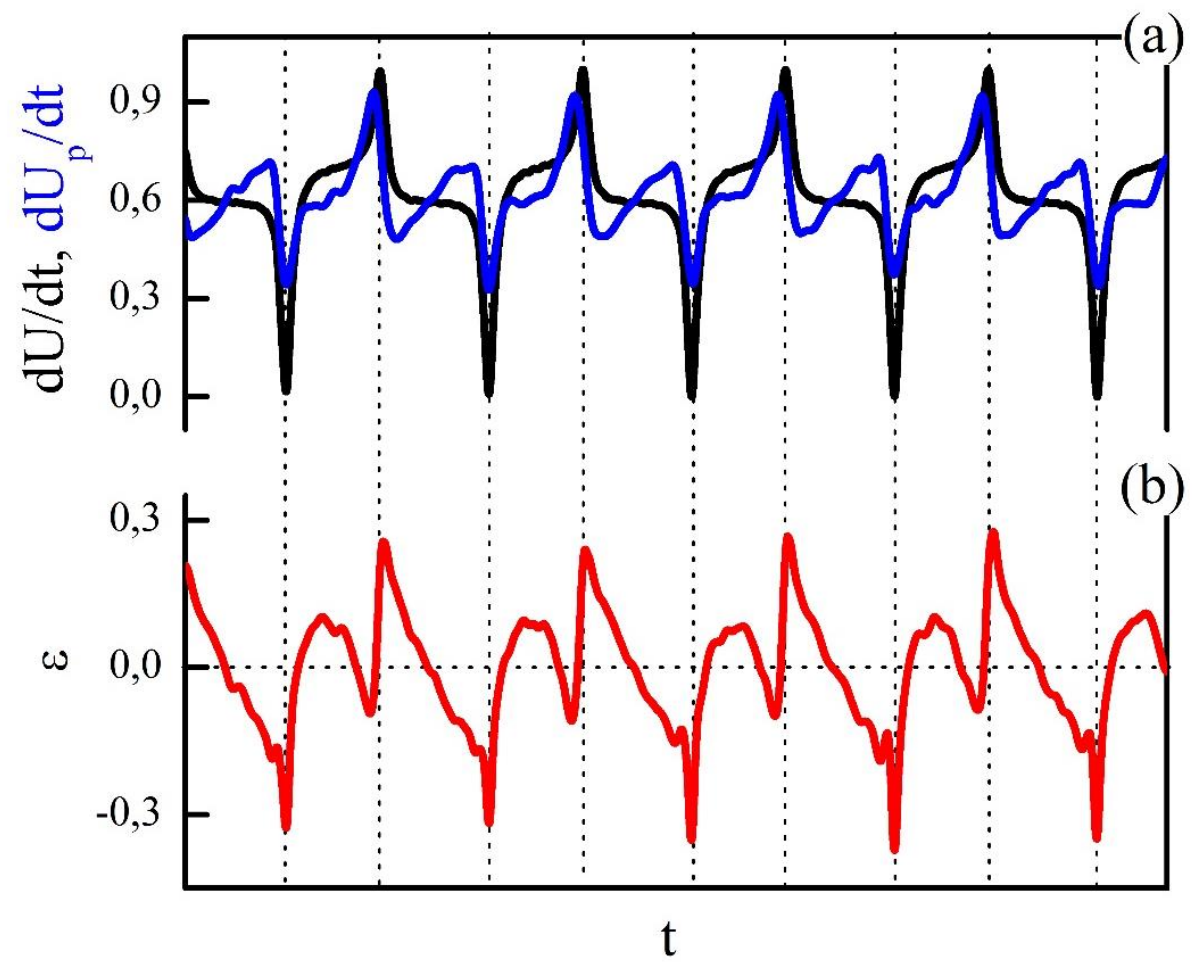


A Figura 21 mostra as séries temporais para a derivada primeira do potencial experimental, $d U / d t$, e as suas respectivas covariâncias em relação a $\varepsilon, \operatorname{Cov}(\varepsilon, d U / d t)$. Na Figura 21 (b), percebe-se um pequeno desvio no sentido negativo (círculo vermelho), evidenciando um pior ajuste se comparado com o obtido para ácido fórmico. A covariância amostral entre $\varepsilon$ e $d U / d t$ é $+0,014$, e o sinal positivo está de acordo com a tendência esperada, como discutido na Figura 18 (b).

Figura 21 - Análise de covariância para as séries temporais normalizadas resultantes da eletrooxidação oscilatória de metanol (a) derirada primeira do potencial do eletrodo experimental, dU/dt; (b) populacional corariência entre $\varepsilon$ e dU/dt, $\operatorname{Cov}(\varepsilon, \mathrm{dU} / \mathrm{dt})$; (c) corrente iônica $\mathrm{m} / \mathrm{z}=44, \mathrm{j}_{\mathrm{m} / \mathrm{z}=44 \text {; }}$; (d) covariância populacional entre $\varepsilon$ e $\mathrm{jm} / \mathrm{z}=44$, $\operatorname{Cov}(\varepsilon, \mathrm{j} \mathrm{m} / \mathrm{z}=44)$; (e) corrente iônica $\mathrm{m} / \mathrm{z}=60$, $\mathrm{j}_{\mathrm{m} / \mathrm{z}=60}$; (f) covariância populacional entre $\varepsilon$ e $\mathrm{j}_{\mathrm{m} / \mathrm{z}=60}$, $\operatorname{Cov}\left(\varepsilon, \mathrm{j}_{\mathrm{m} / \mathrm{z}=60}\right)$. A escala no eixo horizontal está omitida, pois foi normalizada.

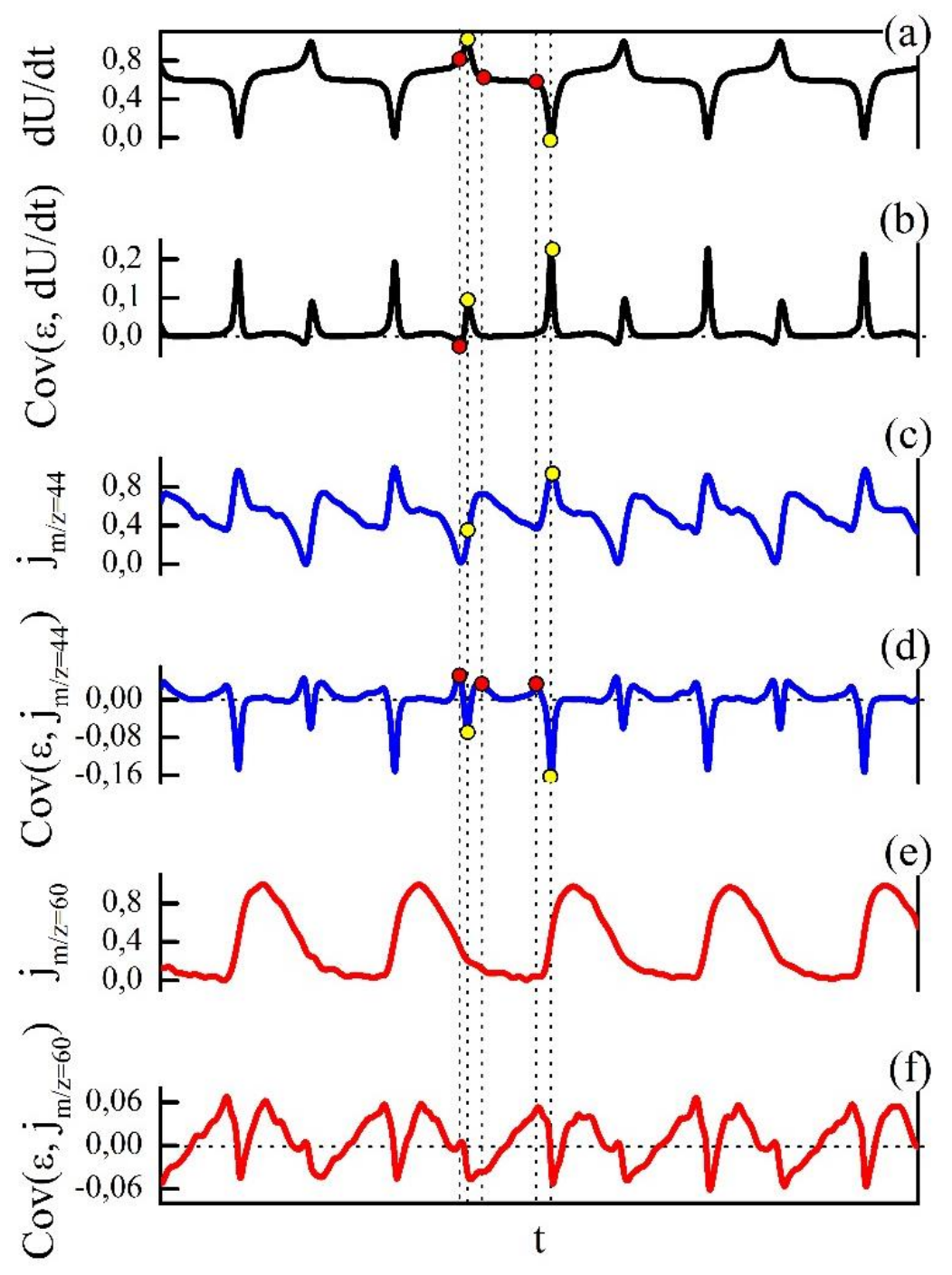


A análise de covariância entre $\varepsilon$ e as correntes iônicas individuais, $j_{i}$, é mais complicada do que para o caso do ácido fórmico, em que apenas a corrente iônica $m / z=44$ foi computada na RLM. Como já discutido, a tendência prevista é que os valores de $\varepsilon$ mudem em sentido oposto aos valores de $j_{i}$, mas isto é estritamente válido se apenas uma corrente iônica for considerada na RLM. Se a análise for realizada com mais de uma corrente iônica, pode ser que um aumento ou uma diminuição na corrente faradaica global seja alcançada por um ajuste inesperado da combinação das correntes iônicas computadas pelo modelo. Em outras palavras, pode ser que uma grande diminuição em uma contribuição faradaica seja compensada por um grande aumento em outra, de modo a se buscar representar o comportamento da corrente faradaica global, cf. equações 25 e 26. Nesse sentido, o método da "máxima contribuição possível" evidentemente pode superestimar ou subestimar uma dada contribuição faradaica buscando-se o melhor ajuste possível entre $d U / d t$ e $d U_{p} / d t$

Diante disso, nota-se na Figura 21 (d) valores de covariância populacional positivos e negativos distribuídos em torno de zero. Os maiores valores absolutos de covariância populacional (círculos amarelos), assim como no caso do ácido fórmico, situam-se nos vértices de $d U / d t$. Como já explicado, isso deve estar associado às mudanças de capacitânia inerentes ao termo $d U / d t$, não computadas pelo modelo de RLM. O sinal negativo dos valores de covariância populacional situados nesta região são concordantes com as equações. Por outro lado, nesta mesma figura é visível valores de covariância positivos (círculos vermelhos) associados com regiões em que $U$ varia lentamente e portanto, tal tendência deve-se, como dito anteriormente, à falta de acurácia de $d U_{p} / d t$ representar $d U / d t$. A tendência geral, ou seja, a covariância amostral entre $\varepsilon$ e $j_{m / z}=44$ resultou em um valor positivo: $+6 \times 10^{-5}$.

Observando-se a Figura 21 (f), torna-se indubitável a maior discrepância para os valores de covariância populacional entre $\varepsilon$ e $j_{m / z}=60$, $\operatorname{Cov}\left(\varepsilon, j_{m / z}=60\right)$, evidenciada pelas amplas regiões constituídas de valores positivos. Isso está em conformidade com a baixa contribuição desta via reacional para a corrente faradaica total, como denota o baixíssimo valor de $\beta_{2}$. $\mathrm{O}$ valor da covariância amostral entre $\varepsilon$ e $j_{m / z}=60$ é $+9 \times 10^{-3}$. Uma outra combinação entre $j_{m / z}=44$ e $j_{m / z}=60$ poderia minimizar essa discrepância, mas isso necessariamente resultaria em uma pior predição do termo $d U_{p} / d t$. Lembrando-se de que os resultados da regressão aqui apresentados são os que podem ser alcançados sem a incorporação de uma restrição adicional, além daquela necessária para se representar uma corrente proveniente de uma reação de oxidação, $\beta_{i}<0$. 


\subsubsection{Regressão Linear Multivariada: Resultados Obtidos para Etanol}

A Figura 22 mostra a evolução temporal para (a) potencial do eletrodo e para as correntes iônicas de $m / z$ : (b) 44, (c) 15 e (d) 29, registradas simultaneamente durante a eletro-oxidação de etanol em regime galvanostático. A derivada primeira do potencial do eletrodo, $d U_{p} / d t$, foi estimada por meio dessas três correntes iônicas,

$$
\frac{d U_{p}}{d t}=A+\beta_{1} j_{m / z=44}+\beta_{2} j_{m / z=15}+\beta_{3} j_{m / z=29}
$$

Os parâmetros de ajuste obtidos são: $A=+0,9799, \beta_{1}=-0,1256, \beta_{2}=-0,0754$, $\beta_{3}=-1 \times 10^{-6}$. Relembrando o que já foi mencionado na seção experimental, para o caso do etanol, o fragmento de $m / z=44$ incorpora contribuições provenientes do $\mathrm{CO}_{2}$ e do acetaldeído, enquanto que os fragmentos de $m / z=15$ e 29 são atribuídos ao acetaldeído.

Existem poucos trabalhos sobre cinética em regime oscilatório envolvendo etanol e nenhuma discussão mecanística em relação às oscilações foi proposta até o momento.[35, 36] Diferentemente das séries temporais obtidas para ácido fórmico e metanol, os perfis das correntes iônicas são, de certo modo, semelhantes ao do potencial do eletrodo. Comparando-se as correntes iônicas, o intenso aumento em $j_{m / z}=44$, depois desta ter alcançado o seu ponto mínimo, pode ser devido à produção de $\mathrm{CO}_{2}$, pois $j_{m / z}=15$ e $j_{m / z}=29$, atribuídas ao acetaldeído, não apresentam esta característica. De fato, a coincidência entre essas séries temporais medidas por meio do DEMS on line e essa pequena característica devido a produção de $\mathrm{CO}_{2}$ presente na corrente iônica $m / z=44$, sugere que a maior parte da corrente faradaica provém da produção de acetaldeído. 
Figura 22 - Evolução temporal (a) do potencial do eletrodo de trabalho, U, e das correntes iônicas de (b) $\mathrm{m} / \mathrm{z}=44, \mathrm{j}_{\mathrm{m} / \mathrm{z}=44}$, (c) $\mathrm{m} / \mathrm{z}=15, \mathrm{j}_{\mathrm{m} / \mathrm{z}=15}$ e (c) $\mathrm{m} / \mathrm{z}=29, \mathrm{j}_{\mathrm{m} / \mathrm{z}=29}$ durante a eletro-oxidação oscilatória de etanol a j $=0,043 \mathrm{~mA} \mathrm{~cm}^{-2}$. $\left[\mathrm{CH}_{3} \mathrm{CH}_{2} \mathrm{OH}\right]=1,0 \mathrm{~mol} \mathrm{~L}^{-1},\left[\mathrm{H}_{2} \mathrm{SO}_{4}\right]=0,5 \mathrm{~mol} \mathrm{~L}^{-1} \mathrm{e}$ $\mathrm{T}=20{ }^{\circ} \mathrm{C}$. Para informações adicionais, ver Seção Experimental.

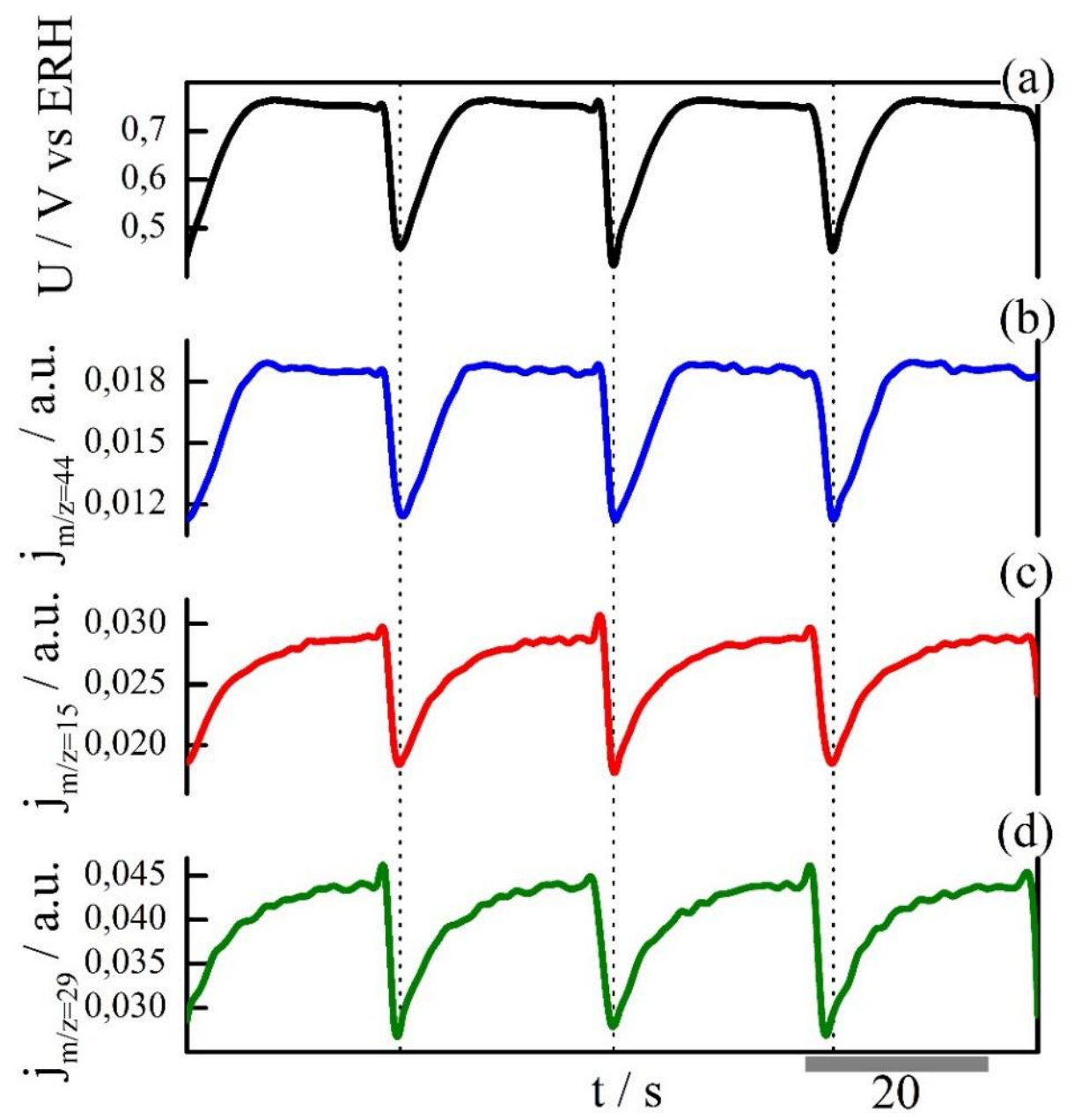

A Figura 23 apresenta: (a) a comparação entre $d U / d t$ e $d U_{p} / d t$, e (b) a série temporal do erro, $\varepsilon$. Como obtido para o ácido fórmico, Figura 17 (b), mas diferentemente do caso do metanol, Figura 20 (b), é claro na Figura 23 (b) que consideráveis desvios do zero estão situados nas regiões em que $U$ varia abruptamente. Como já discutido, esse fato indica uma melhor representação da corrente faradaica total em função da produção de espécies voláteis para etanol do que para metanol. 
Figura 23 - Séries temporais normalizadas: (a) derivada primeira do potencial do eletrodo experimental a $\mathrm{j}=0,043 \mathrm{~mA} \mathrm{~cm} \mathrm{c}^{-2}, \mathrm{dU} / \mathrm{dt}$ (linha preta), acompanhado pela derivada primeira predita do potencial do eletrodo, $\mathrm{dU}_{\mathrm{p}} / \mathrm{dt}$ (linha azul); (b) derivada primeira do potencial residual, $\varepsilon$. $\left[\mathrm{CH}_{3} \mathrm{CH}_{2} \mathrm{OH}\right]=1,0 \mathrm{~mol} \mathrm{~L}^{-1},\left[\mathrm{H}_{2} \mathrm{SO}_{4}\right]=0,5 \mathrm{~mol} \mathrm{~L}^{-1}$ e $\mathrm{T}=20{ }^{\circ} \mathrm{C}$. Dados mostrados em (a) foram obtidos a partir daqueles mostrados na Figura 22, ver texto para maiores detalhes. A escala no eixo horizontal está omitida, pois foi normalizada

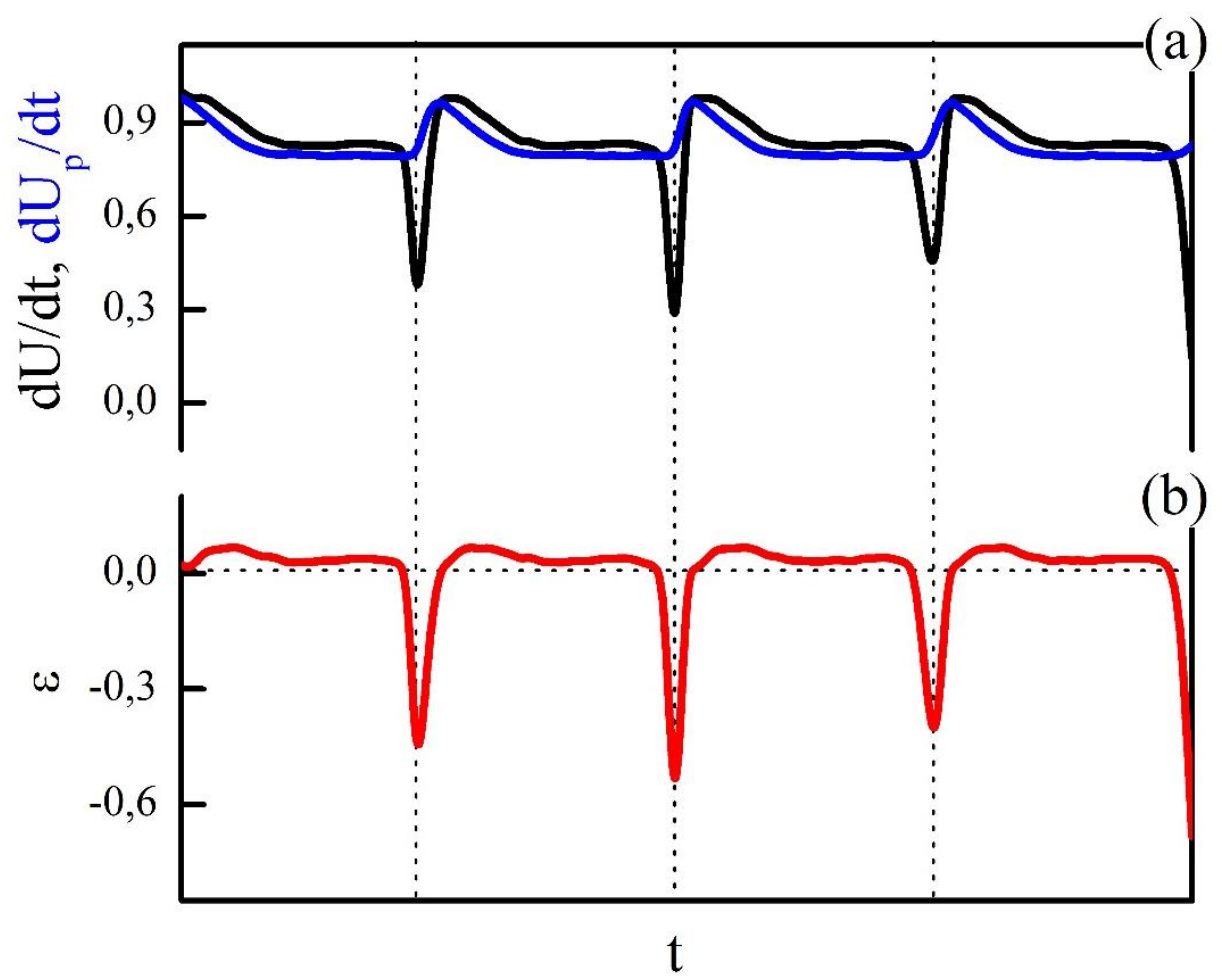

As séries temporais normalizadas para $d U / d t$ e para as correntes iônicas $m / z=44,15$ e 29 , acompanhadas por suas respectivas covariâncias populacionais em relação a $\varepsilon$, são apresentadas na Figura 24. A covariância amostral, obtida para os resultados associados ao etanol, segue a tendência encontrada para o metanol, ou seja, um esperado e positivo valor para a covariância entre $\varepsilon$ e $d U / d t$, $+0,021$; mas positivos valores para os outros pares de variáveis: $\varepsilon$ e $j_{m / z}=44\left(+9 \times 10^{-4}\right), \varepsilon$ e $j_{m / z}=15\left(+4 \times 10^{-4}\right)$, e $\varepsilon$ e $j_{m / z}=29\left(+9 \times 10^{-3}\right)$. 
Figura 24 - Análise de covariância para as séries temporais normalizadas resultantes da eletrooxidação oscilatória de etanol (a) derivada primeira do potencial do eletrodo experimental, dU/dt; (b) populacional covariância entre $\varepsilon$ e dU/dt, $\operatorname{Cov}(\varepsilon, \mathrm{dU} / \mathrm{dt}$ ); (c) corrente iônica $\mathrm{m} / \mathrm{z}=44, \mathrm{j} \mathrm{m} / \mathrm{z}=44$;

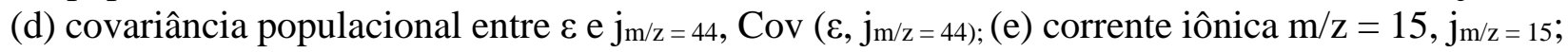
(f) covariância populacional entre $\varepsilon$ e $\mathrm{j}_{\mathrm{m} / \mathrm{z}}=15, \operatorname{Cov}(\varepsilon, \mathrm{j} \mathrm{m} / \mathrm{z}=15)$; (g) corrente iônica $\mathrm{m} / \mathrm{z}=29, \mathrm{j} \mathrm{m} / \mathrm{z}=29$; (h) covariância populacional entre $\varepsilon$ e $\mathrm{j}_{\mathrm{m} / \mathrm{z}=29}, \operatorname{Cov}\left(\varepsilon, \mathrm{j}_{\mathrm{m} / \mathrm{z}}=29\right)$. A escala no eixo horizontal está omitida pois, foi normalizada
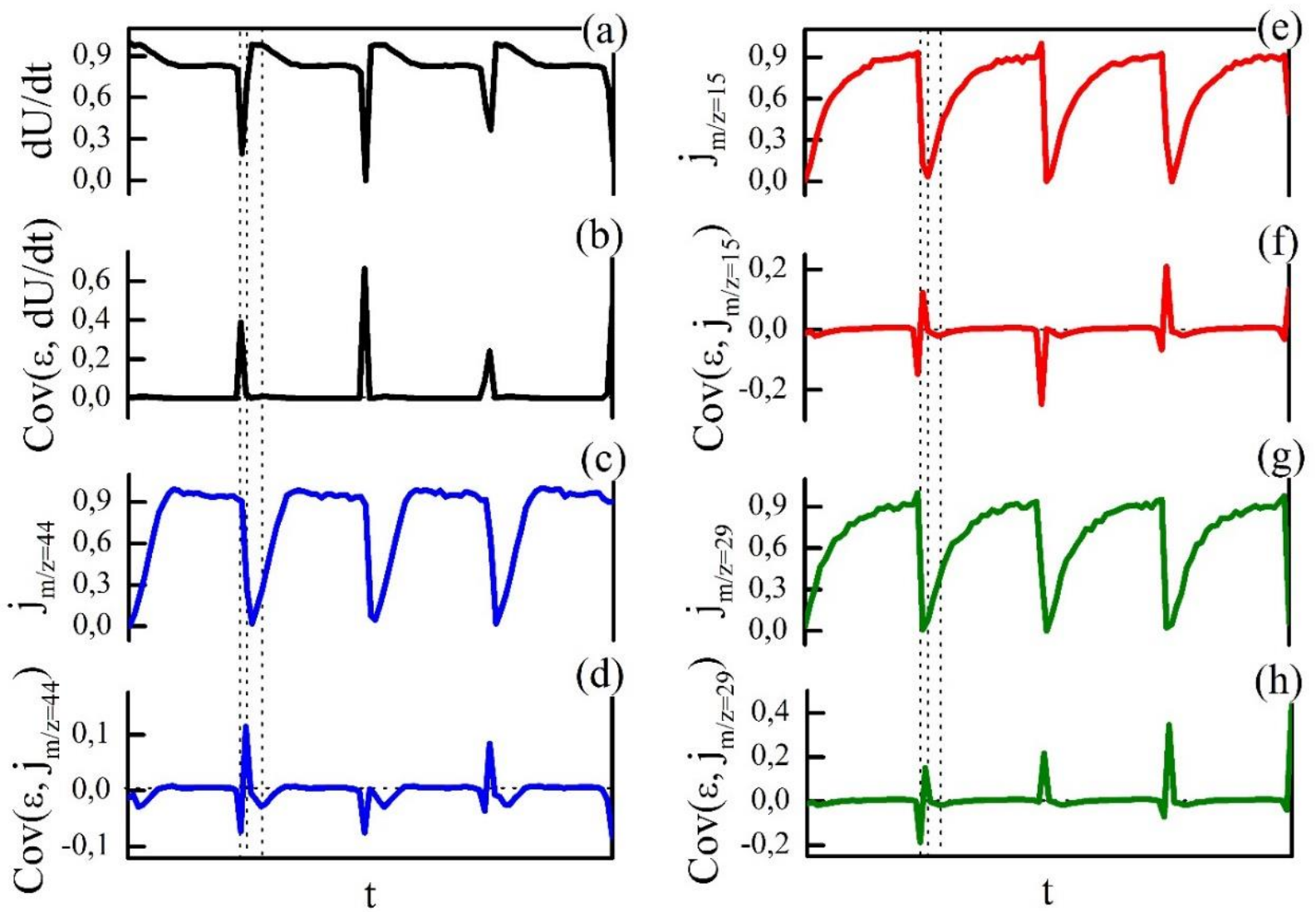

c)

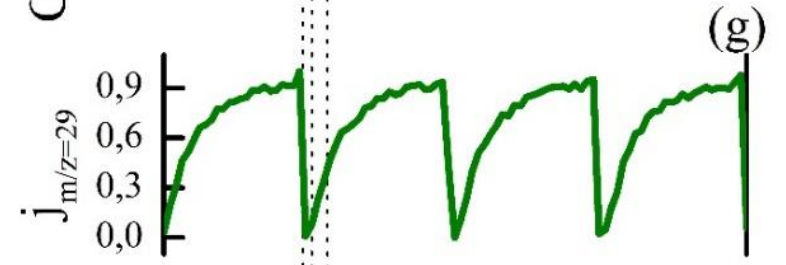

d)

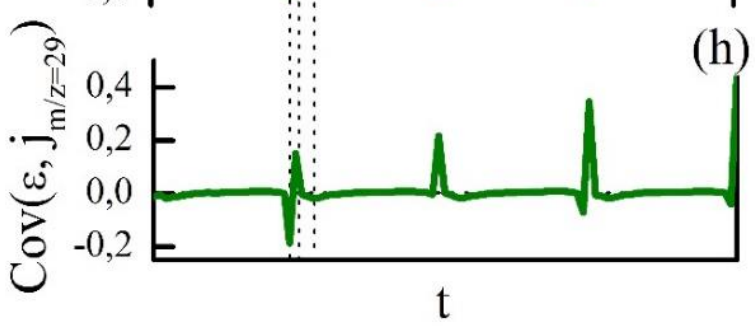

\subsubsection{Aspectos Mecanísticos}

$\mathrm{Na}$ abordagem introduzida neste trabalho, essencialmente se comparou a corrente faradaica total, aproximada como sendo proporcional a - $d U / d t$, c.f. equação (23) e (25), com a corrente associada com a produção de espécies voláteis, o termo predito $d U_{p} / d t$. A corrente reacional global gerada durante a eletro-oxidação de moléculas orgânicas pequenas consiste de contribuições de correntes parciais provenientes de diversas etapas, tais como adsorção dissociativa e formação de subprodutos parcialmente oxidados. Evitar subprodutos e favorecer a completa oxidação a $\mathrm{CO}_{2}$ em 
baixos sobrepotenciais tem sido o principal alvo visando-se aplicações dessas moléculas como combustíveis anódico. Assim, um aspecto importante a ser explorado nessa abordagem é a quantificação da porção da corrente faradaica devido aos produtos voláteis ou, pelo menos, devido aos que podem ser detectados utilizando-se o DEMS on line. Nas discussões sobre o erro disposto em função do tempo ficaram claras as regiões das séries temporais em que a corrente faradaica é bem representada pela produção de espécies voláteis. A seguir, compara-se a produção relativa dessas espécies gasosas para os três sistemas investigados. Para isso, diante do conhecimento prévio do mecanismo reacional da eletro-oxidação de cada molécula estudada, realiza-se inferências sobre etapas que contribuem para a corrente faradaica, mas que não resultam em produtos detectáveis.

Os valores obtidos para o resíduo por ciclo oscilatório, $\varepsilon_{c}$, são: 0,004, 0,020 e 0,016, para ácido fórmico, metanol e etanol, respectivamente. Se por um lado os valores individuais de $\varepsilon_{c}$ não apresentam significado físico, a comparação entre eles pode ser abordada segundo alguns aspectos mecanísticos gerais. Como já comentado, o menor valor encontrado para ácido fórmico não é uma surpresa, já que todas as etapas que envolvem transferência de elétrons resultam, no final, na produção de $\mathrm{CO}_{2}$, espécie detectada pelo DEMS on line. Considerando o resultado obtido para o ácido fórmico a referência, comparativamente, o resíduo por ciclo oscilatório para metanol e etanol foram cinco e quatro vezes maior, respectivamente.

Um descritor adicional para se quantificar a máxima corrente faradaica atribuída à produção de espécies voláteis pode ser alcançado dividindo-se a área absoluta de $\varepsilon(t)$ versus o tempo pela área da curva de $d U / d t$ normalizado. O valor resultante indica a porcentagem de $d U / d t$ que não está sendo capturada pela RLM. Os valores obtidos são: 2,3\%, 15\% e 7,8\%, para ácido fórmico, metanol e etanol, nesta ordem.

Esses resultados podem ser discutidos apoiando-se na Figura 25, a qual demonstra um esquema simplificado para a eletro-oxidação de (a) ácido fórmico, (b) metanol e (c) etanol. São enfatizados o número de elétrons transferidos em cada etapa reacional, as espécies voláteis detectadas pelo DEMS on line (em azul) e as espécies solúveis parcialmente oxidadas que não foram detectadas (em vermelho). Note que as setas não visam indicar etapas elementares e que espécies tais como prótons, moléculas de água e sítios livres são omitidas para assegurar a compreensão. Além disso, a estequiometria também é desprezada. 
Figura 25 - Esquema simplificado do mecanismo de eletro-oxidação de (a) ácido fórmico, (b) metanol e (c) etanol sobre platina. Espécies em azul são as detectadas pelo DEMS on line e em vermelho, espécies solúveis parcialmente oxidadas que não são detectáveis.

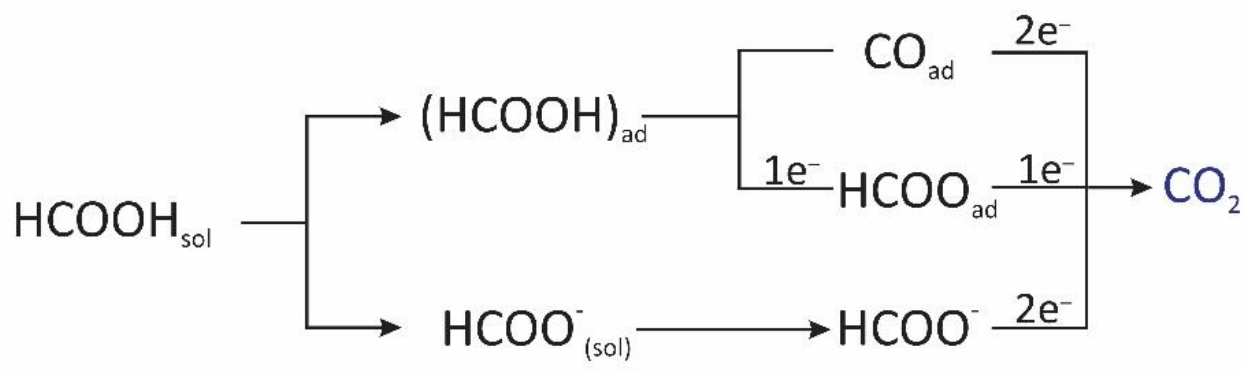

(b)

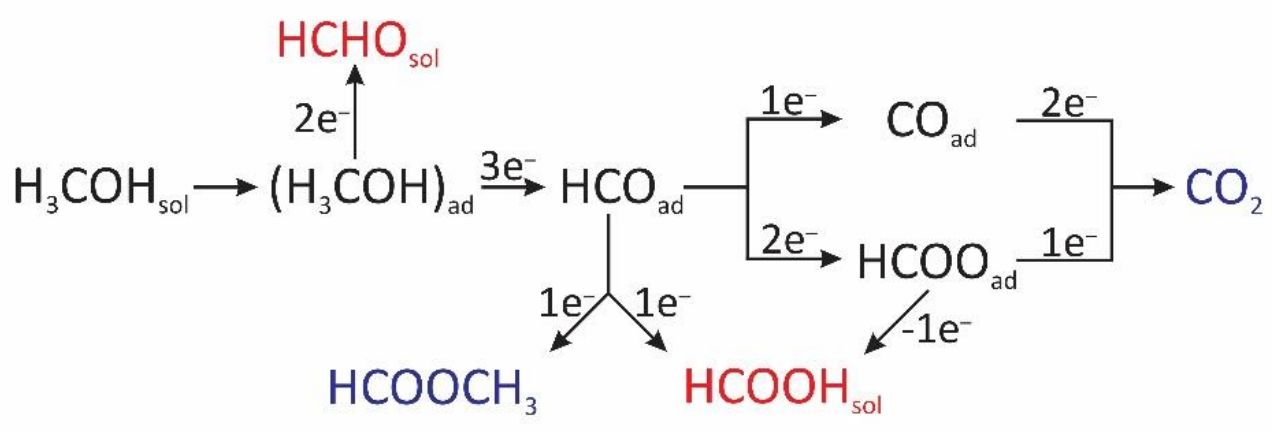

(c)

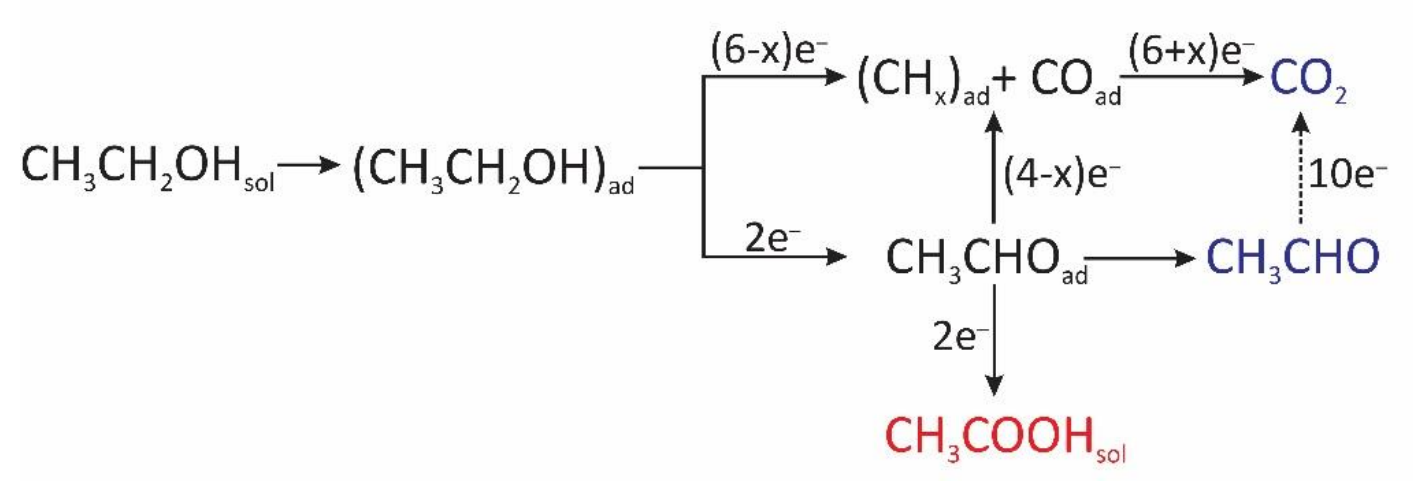

De acordo com o esquema da Figura 25 (a), a eletro-oxidação de ácido fórmico ocorre através de três vias paralelas,[30, 37-39] gerando 2 elétrons e culminando na formação de $\mathrm{CO}_{2}$, o qual foi detectado pelo DEMS on line. Dada a boa concordância entre a corrente faradaica experimental e a predita por meio da produção de $\mathrm{CO}_{2}$, esse esquema reacional simplificado parece ser representativo da situação observada durante as oscilações, o que corrobora a consideração de 
se utilizar, dentre os três sistemas aqui estudados, os resultados obtidos para o ácido fórmico como referência de uma análise comparativa.

Apesar da aparente similaridade entre os mecanismos de reacionais de ácido fórmico e metanol, durante a eletro-oxidação deste último existem provas experimentais da produção de três subprodutos ou espécies parcialmente oxidadas: formaldeído, metilformiato e ácido fórmico. A Figura 25 (b) apresenta um esquema do mecanismo reacional para o caso do metanol. Tal esquema é corroborado por diversas evidências experimentais presentes na literatura[33, 40-47] e inclui a produção de espécies gasosas que são detectáveis via DEMS on line, $\mathrm{CO}_{2}$ e $\mathrm{HCOOCH}_{3}$, bem como espécies de baixa volatilidade, $\mathrm{HCHO}$ e $\mathrm{HCOOH}$, que difundem para a solução. Re-adsorção e posterior oxidação dessas duas últimas espécies são possíveis, mas não foram consideradas neste esquema simplificado. Além disso, em competição com a formação de metilformiato via ataque nucleofílico do intermediário HCO pelo metanol, metilformiato também pode ser formado por uma reação de esterificação entre metanol e o ácido fórmico produzido.

A partir do número de elétrons envolvidos em cada etapa, Figura 25 (b), pode-se definir um segundo descritor, teórico, para ilustrar a contribuição faradaica relativa proveniente da produção do $\mathrm{CO}_{2}$ e metilformiato. A completa eletro-oxidação de metanol produzindo dióxido de carbono envolve a transferência de 6 elétrons, enquanto a rota que leva à formação de metilformiato procede com a transferência de 4 elétrons. A produção de formaldeído e ácido fórmico seguem vias reacionais de 2 e 4 elétrons, respectivamente. Supondo que a eletro-oxidação de 4 mol de metanol resulte na formação de $1 \mathrm{~mol}$ de $\mathrm{CO}_{2}$ e $1 \mathrm{~mol}$ de cada sub-produto: $\mathrm{HCHO}, \mathrm{HCOOH}$ e $\mathrm{HCOOCH}_{3}$, seriam transferidos $16 \mathrm{~mol}$ de elétrons num dado intervalo de tempo. Neste caso, a corrente faradaica parcial proveniente da produção de $\mathrm{CO}_{2}$ e $\mathrm{HCOOCH}_{3}$, espécies detectadas pelo DEMS on line e incorporadas no modelo multivariado, corresponderia a 8/5 da corrente faradaica total. $\mathrm{O}$ considerável peso de espécies parcialmente oxidadas não detectadas sugerido pelo valor desse último descritor está de acordo com o valor obtido para $\varepsilon_{c}$ (cinco vezes maior do que o do ácido fórmico) e também com experimentos independentes disponíveis na literatura.[33, 40, 42, 43, 48, 49] Desde de que as correntes iônicas foram normalizadas para se estenderem de zero até 1 e que o modelo de RLM baseia-se no cálculo da máxima contribuição das correntes provenientes da produção de espécies voláteis, a real proporção da corrente faradaica total decorrente de cada etapa reacional não afeta o ajuste dos parâmetros de regressão. Isso corresponderia a uma resposta estacionária, em que o peso de cada etapa é determinado por características puramente superficiais. 
No entanto, sob regime oscilatório, a produção relativa de diferentes espécies varia continuamente ao longo do tempo em consequência do potencial do eletrodo deslocar-se autônoma e visitar diferentes regiões de valores. Séries temporais em regime oscilatório refletem uma evolução temporal auto-organizada do grau de recobrimento de diferentes adsorbatos e, portanto, como alterações do potencial do eletrodo induz adsorção, desorção, oxidação, etc., produção de espécies parcialmente oxidadas. Isso é mais transparente para metanol, mas também o é para etanol, c.f. Figura 23. Essas observações atentam sobre a grande complexidade desses dois sistemas, mas também demonstram a perspectiva de se obter informações sobre a contribuição de grupos de etapas reacionais para a corrente faradaica total, como prova essa abordagem aqui introduzida.

O mecanismo da eletro-oxidação de etanol é esquematicamente representado na Figura 25 (c), em que a sua oxidação incompleta leva aos subprodutos acetaldeído e ácido acético, enquanto a completa segue uma via de 12 elétrons gerando $\mathrm{CO}_{2}$.[50-56] O termo $\mathrm{x}(=1,2$ ou 3) simboliza o número de átomos de hidrogênio constituindo o intermediário adsorvido $\left(\mathrm{CH}_{\mathrm{x}}\right)_{\mathrm{ad}} \mathrm{e}$ a linha tracejada indica a possibilidade do acetaldeído ser posteriormente oxidado a $\mathrm{CO}_{2}$. Como descrito na sessão experimental, o fragmento $\mathrm{m} / \mathrm{z}=44$ incorpora contribuições provenientes do $\mathrm{CO}_{2}$ e do acetaldeído, enquanto os $m / z=15$ e 19 provém desta última espécie. Como todas as séries temporais foram normalizadas e o ajuste dos parâmetros baseia-se na máxima contribuição possível das correntes iônicas, não há a necessidade de se distinguir cada contribuição presente na corrente iônica $\mathrm{m} / \mathrm{z}=$ 44. Essa observação pode ser extrapolada para qualquer corrente iônica constituída por diferentes contribuições.

Seguindo o mesmo raciocínio usado para a comparação dos pesos de diferentes etapas reacionais para a eletro-oxidação de metanol, o consumo de 3 mol de etanol e a formação de 1 mol de $\mathrm{CO}_{2}$ e 1 mol de cada subproduto: $\mathrm{CH}_{3} \mathrm{CHO}$ e $\mathrm{CH}_{3} \mathrm{COOH}$, resultaria na transferência de 18 mol de elétrons. A contribuição faradaica das etapas reacionais que culminam em $\mathrm{CO}_{2}$ e $\mathrm{CH}_{3} \mathrm{CHO}$, espécies cuja produção foi medida pelo DEMS online e incorporada no modelo de RLM, corresponderia a 7/9 da corrente faradaica total. De fato, diferentemente do que é constatado para metanol, sob altas concentrações de etanol, tem sido demonstrado que a produção de $\mathrm{CO}_{2}$ durante a eletro-oxidação deste último é muito pequena, sendo quase toda a corrente faradaica proveniente da oxidação de etanol para acetaldeído.[50, 51, 57] A aparente discordância observada na série temporal do resíduo, c.f. Figura 23 (b), pode indicar o papel da produção de ácido acético, espécie 
de baixa volatilidade. Investigações experimentais neste sentido vem sendo desenvolvida pelo Grupo de Eletroquímica do IQSC-USP.

Comparando-se a porção da corrente faradaica total que não é capturada pela melhor combinação possível das correntes iônicas dos produtos voláteis detectados em cada caso, os valores teóricos obtidos são 3/8 e 2/9, para metanol e etanol, respectivamente. Como já mencionado, apesar dessa proporção ser afetada pela quantidade de cada espécie produzida em condição não estacionária, ela ilustra claramente a boa concordância entre os valores obtidos para o resíduo em cada caso, $\varepsilon_{c}$, e independentes resultados experimentais disponíveis na literatura.

Existem relatos de sofisticados procedimentos para se quantificar a produção de diferentes espécies empregando-se DEMS on line.[51, 57, 58] Aqui, determinou-se a máxima contribuição possível de produtos voláteis detectáveis por meio da melhor combinação de suas correntes iônicas. Tal abordagem não requer qualquer tipo de constante de calibração e/ou considerações mecanísticas. O método foi testado na investigação de três sistemas em regime oscilatório, possibilitando o ordenamento da contribuição faradaica proveniente da formação de produtos voláteis para a corrente total na seguinte sequência: ácido fórmico > etanol > metanol. Finalmente, é notável o fato de não se ter nenhuma conclusão óbvia ao se comparar as séries temporais das correntes iônicas dos três sistemas estudados. Essa foi a principal motivação da análise que resultou na abordagem aqui apresentada.

\subsection{Desempenho Eletrocatalítica durante a Oxidação de Moléculas Orgânicas Pequenas em Regime Oscilatório}

Nas seções seguintes são apresentados os resultados e as discussões referentes ao segundo objetivo desta tese. A eletro-oxidação de formaldeído, ácido fórmico e metanol foi realizada em regimes convencional e oscilatório a fim de se comparar a eficiência de potencial destes sistemas. $\mathrm{Na}$ parte final é apresentada uma discussão sobre os mecanismos reacionais de eletro-oxidação dessas moléculas. 


\subsubsection{Eficiência em Termos de Sobrepotencial}

A Figura 26 apresenta curvas voltamétricas (linhas pretas) obtidas durante uma varredura de potencial no sentido positivo, bem como oscilações de potencial (linhas vermelhas) típicas para a eletro-oxidação de (a) formaldeído, (b) ácido fórmico e (c) metanol. As varreduras foram realizadas a $0.002 \mathrm{~V} \mathrm{~s}^{-1}$ e representam respostas quase-estacionárias. A atividade, inferida pela corrente de pico, diminui na seguinte sequência: formaldeído $\approx$ ácido fórmico > metanol. Os perfis dessas curvas são relativamente similares, mas, para formaldeído e metanol, um pequeno ombro é observado no ramo de inclinação positiva. De forma contrastante com os potenciais padrão indicados na Tabela I, na parte inicial desta tese, velocidades reacionais detectáveis sob controle potenciostático são discerníveis apenas em altos potenciais e um sobrepotencial de pelo menos 500 $\mathrm{mV}$ pode ser associado com a eletro-oxidação dessas moléculas sobre platina. Esse alto sobrepotencial é devido à formação de intermediários adsorvidos em baixos potenciais, que somente são oxidados em potenciais mais elevados, como mencionado previamente. Deve-se ainda destacar que não é possível estimar, por meio desses gráficos, a quantidade de $\mathrm{CO}_{2}$ proveniente da oxidação do formaldeído e do metanol, pois a ocorrência de caminhos paralelos que levam à formação de espécies solúveis parcialmente oxidadas também contribuem para a corrente reacional global.[40, 59] Técnicas in situ e on line são obrigatórias para investigações mecanísticas nesse sentido, como já apresentado na seção anterior. 
Figura 26 - Curvas potenciodinâmicas (linhas pretas) obtidas durante uma varredura lenta $\left(\mathrm{dU} / \mathrm{dt}=0.002 \mathrm{~V} \mathrm{~s}^{-1}\right)$ do potencial de eletrodos de platina imersos em $0,5 \mathrm{~mol} \mathrm{~L}^{-1}$ de (a) HCHO, (b) $\mathrm{HCOOH}$, (c) $\mathrm{CH}_{3} \mathrm{OH}$, contidos em uma solução aquosa de $\mathrm{H}_{2} \mathrm{SO}_{4} 0,5 \mathrm{~mol} \mathrm{~L}^{-1}$. Da esquerda para a direita, curvas galvanostáticas (linhas vermelhas) obtidas sob as seguintes correntes aplicadas: (a) $2.6 \mathrm{~mA} \mathrm{~cm}^{-2}$, (b) $2.7 \mathrm{~mA} \mathrm{~cm}^{-2}$, (c) $0.77 \mathrm{~mA} \mathrm{~cm}^{-2}$. O potencial médio a cada ciclo é dado pelos pontos em verde. $\mathrm{T}=25^{\circ} \mathrm{C}$.
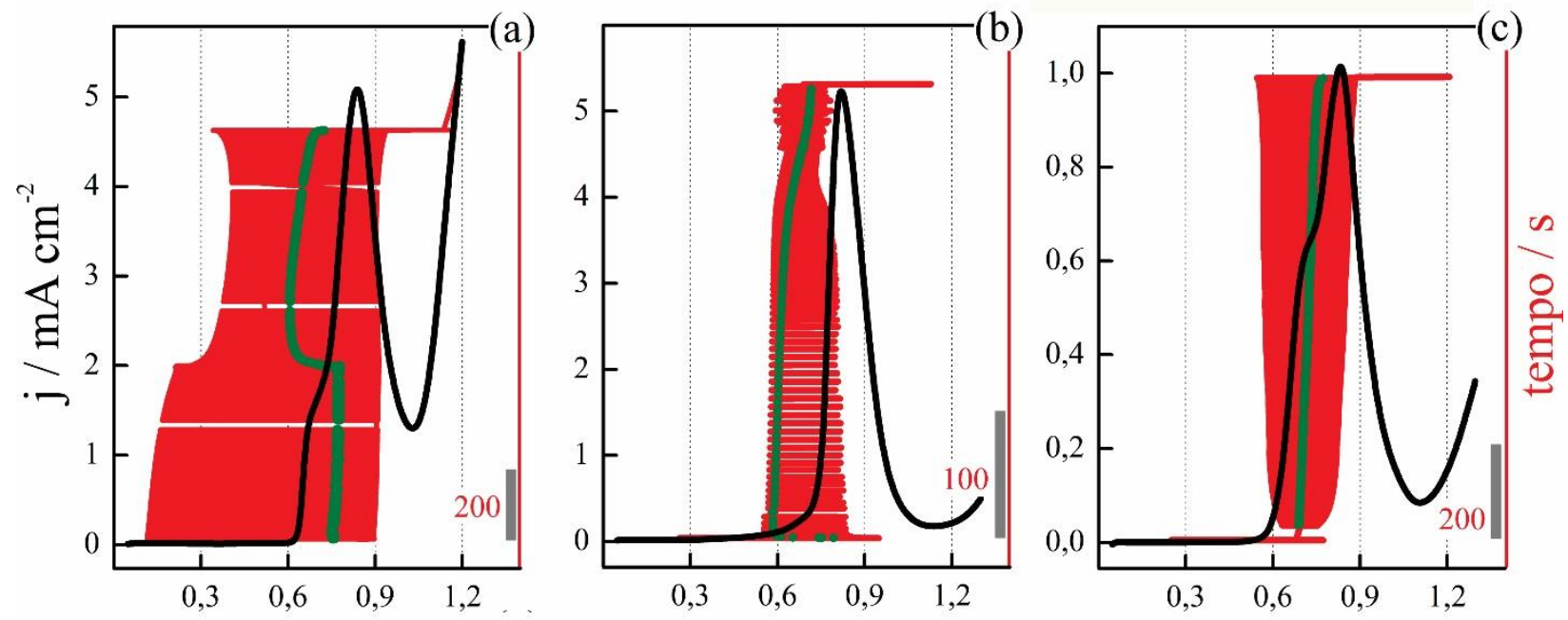

$\mathrm{U} / \mathrm{V} v$ s. ERH

Como extensivamente constatado para osciladores eletroquímicos do tipo HN-NDR, oscilações de potencial espontâneas aparecem para um certo intervalo de corrente aplicada.[10] As curvas em vermelho na Figura 26 representam oscilações observadas em regime galvanostático para valores de corrente selecionados dentro de um intervalo oscilatório e os pontos verdes indicam o potencial médio a cada ciclo, $\mathrm{U}_{\mathrm{m}}$, o qual é definido como:

$$
\frac{1}{t_{2}-t_{1}} \int_{t_{1}}^{t_{2}} U(t) d t
$$

O primeiro aspecto a ser pontuado é o fato de que, apesar dos perfis das curvas voltamétricas serem praticamente indistinguíveis, os perfis das oscilações para cada sistema diferem bastante entre si, c.f. Figura 28. Uma característica particular da dinâmica oscilatória é que ela traz mais informações mecanísticas do que, por exemplo, curvas voltamétricas ou curvas cronoamperométricas convencionais, c.f. Figure 26 e 28. Na verdade, oscilações são mais sensíveis 
às especificidades de cada mecanismo reacional porque o peso relativo das diferentes etapas reacionais de transferência de carga muda conforme o recobrimento superficial de diferentes adsorbatos oscilam. Diferentemente, respostas regulares, não-oscilatórias, estacionárias de corrente e potencial refletem contribuições independentes do tempo de distintas etapas elementares. Esse aspecto é explorado mais adiante.

As escalas de tempo de cada série oscilatória mostrada na Figura 26 são indicadas pelas barras verticais. Embora todos os parâmetros controlados experimentalmente tenham se mantido constantes, o potencial médio aumenta gradativamente no transcorrer do tempo por causa de processos lentos que desativam a superfície do catalisador.[60, 61] E, o tempo de duração da série oscilatória para cada sistema depende, dentre outros fatores, da corrente aplicada. Todavia, a duração total ou a estabilidade de todas as séries mostradas na Figura 26 são comparáveis.

As oscilações, para todos os casos apresentados na Figura 26, desenvolvem-se ao redor do ramo da curva corrente $v s$. potencial quase-estacionária em que $\mathrm{dI} / \mathrm{dU}>0$. Como as curvas referemse às velocidades da reação global em condição aproximadamente estacionária, a janela de potencial em que se dão as oscilações claramente comprova o estabelecimento de diferentes recobrimentos superficiais e velocidades reacionais. Além disso, o amplo intervalo de potencial em que se dão essas mudanças auto-organizadas de recobrimento possibilita uma autolimpeza periódica ou oxidação de intermediários fortemente adsorvidos em baixos potenciais. Conforme menciona, o processo de limpeza auto-organizado da superfície do catalisador pode promover um considerável aumento do desempenho global de células com membrana polimérica operando em regime oscilatório e alimentadas com misturas de $\mathrm{H}_{2} / \mathrm{CO}$.

Dentre as diferentes possibilidades de se expressar a eficiência de uma célula combustível, uma delas é equacionada em termos do potencial atual $U(I):[4,5]$

$$
\text { eficiência }=\frac{U(I)}{U_{c e l}^{o}}=\frac{U_{c e l}^{o}-\left(\left|\eta_{\text {ânodo }}\right|+\left|\eta_{\text {cátodo }}\right|+I R\right)}{U_{c e l}^{o}}
$$

em que $U(I)$ é o potencial da célula em modo operatório, i.e. quando flui uma certa corrente $i$ pelo sistema, e $U^{o}{ }_{c e l}$ é o potencial termodinâmico de circuito aberto já apresentado na Tabela I, na primeira seção desta tese. O potencial da célula $U(I)$ depende da magnitude da corrente e seu menor valor em relação a $U_{c e l}^{o}$ deve-se aos sobrepotenciais catódico e anódico, e à queda ôhmica do 
sistema. Para experimentos em uma meia-célula, e desprezando todas as perdas, exceto aquela por causa do sobrepotencial da reação do ânodo, a equação (37) pode ser reescrita como:

$$
\text { eficiência }=\frac{U_{c e l}^{o}-\left[U(I)-E_{\text {ânodo }}^{o}\right]}{U_{c e l}^{o}}
$$

Utilizando-se as oscilações de potencial do eletrodo $U(t)$, pode-se fazer a mesma análise com a eficiência variando com o tempo, sob regime oscilatório. Deve-se notar que, para todos os sistemas, quanto menor for a diferença $\left(U-E_{\text {ânodo }}^{o}\right.$, maior é a eficiência global. Por meio da Figura 26 percebe-se que os menores valores de potencial alcançados durante as oscilações evidenciam uma diminuição do sobrepotencial da reação do ânodo. Diminuição importante mesmo se o potencial médio a cada ciclo (ver pontos verdes na Figura 26) for maior do que os valores estacionários sob regime regular, pois o processo de autolimpeza da superfície do eletrodo minimiza a sua desativação superficial.

A fim de ilustrar esse aumento de eficiência observado em regime oscilatório, a Figura 27 mostra um gráfico da densidade de potência $v s$. densidade de corrente para a eletro-oxidação do formaldeído em condições experimentais idênticas àquelas da Figura 26. Exceto que, diferentemente dos resultados apresentados na Figura 26 (a), que foram obtidos a corrente constante, a curva em vermelho na Figura 27 refere-se a uma galvanodinâmica, ao longo da qual o potencial do eletrodo oscila aproximadamente em todo o intervalo de corrente. Para comparação, a curva de polarização quase-estacionária também é mostrada nesta última figura. O sobrepotencial $\eta$ foi estimado em termos do potencial de equilíbrio de uma célula combustível hipotética alimentada com formaldeído no ânodo e gás oxigênio no cátodo. Portanto, $\eta=1.35-\mathrm{U}$, em que 1,35 V é o potencial de circuito aberto termodinâmico para a célula completa, c.f. Tabela I, e $U$ é o potencial da reação do ânodo, medido versus um ERH, cf. Figura 26. Assim, todas as limitações nessa situação idealizada são atribuídas à reação anódica e a redução do oxigênio é assumida ocorrer em seu valor de equilíbrio, 1,23 V. Embora reconhecidamente limitado, esse procedimento permite a comparação das densidades de potência sob regimes oscilatório e regular: a densidade de potência estimada sob regime oscilatório é mais do que duas vezes maior do que a estimada em regime regular. 
Figura 27 - Curvas de densidade de potência vs. densidade de corrente para a eletro-oxidação de farmaldeído sob regimes galvanodinâmico (vermelho) e potenciodinâmico (preto). $\mathrm{dI} / \mathrm{dt}=5 \mu \mathrm{A} \mathrm{s}^{-1}$. Demais condições são idênticas às descritas na Figure 26.

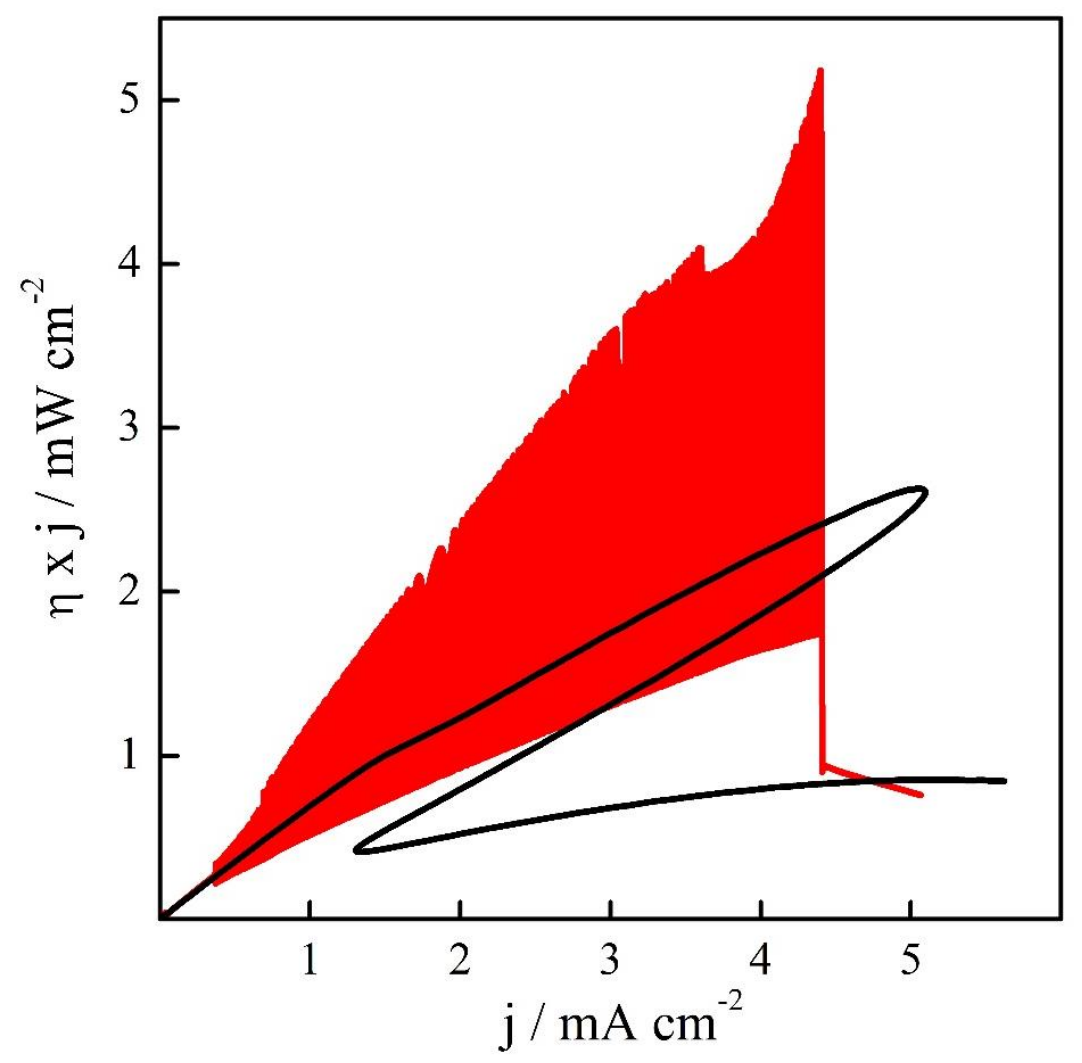

\subsubsection{Eficiência e Mecanismo Reacional}

Foi mencionado que os resultados obtidos em regime oscilatório são mais sensíveis às diferenças no mecanismo reacional do que os obtidos em condições não-oscilatória. Portanto, as oscilações de potencial podem ser utilizadas para caracterizar um sistema eletrocatalítico. Contudo, para se obter informações específicas sobre a natureza e a população das espécies superficiais, bem como sobre as reações envolvidas na dinâmica, também é indispensável o emprego de técnicas auxiliares in situ e on line, vide supra. Ainda assim, a evolução temporal auto-organizada do potencial do eletrodo pode ser usada como uma ferramenta de caracterização. Por exemplo, a velocidade de transição de baixo para alto recobrimento de espécies que bloqueiam a superfície, esquematicamente representado na Figura 1, na seção inicial, pode ser inferida a partir da 
velocidade com que o potencial $U$ aumenta em relação ao tempo. Quando a corrente aplicada é constante, o recobrimento de espécies bloqueantes aumenta com o tempo, levando a um aumento do sobrepotencial para manter o fluxo de elétrons através da interface, consequentemente, dU/dt expressa a velocidade de envenenamento superficial. A Figura 28 mostra ciclos oscilatórios, bem como a velocidade de aumento do potencial dU/dt para a eletro-oxidação das moléculas em estudo. As linhas pontilhadas horizontais e verticais indicam, respectivamente, o valor do potencial médio $\mathrm{U}_{\mathrm{m}}$ para cada ciclo e o intervalo de tempo para o qual a velocidade $\mathrm{dU} / \mathrm{dt}$ foi computada em cada caso.

Figura 28 - dU/dt versus $\mathrm{U}$ (parte inferior) e U versus tempo (parte superior) para um ciclo oscilatório. Dados extraídos da Figure 26 para (a) e (d) formaldeído, (b) e (e) ácido fórmico e, (c) e (f) metanol.
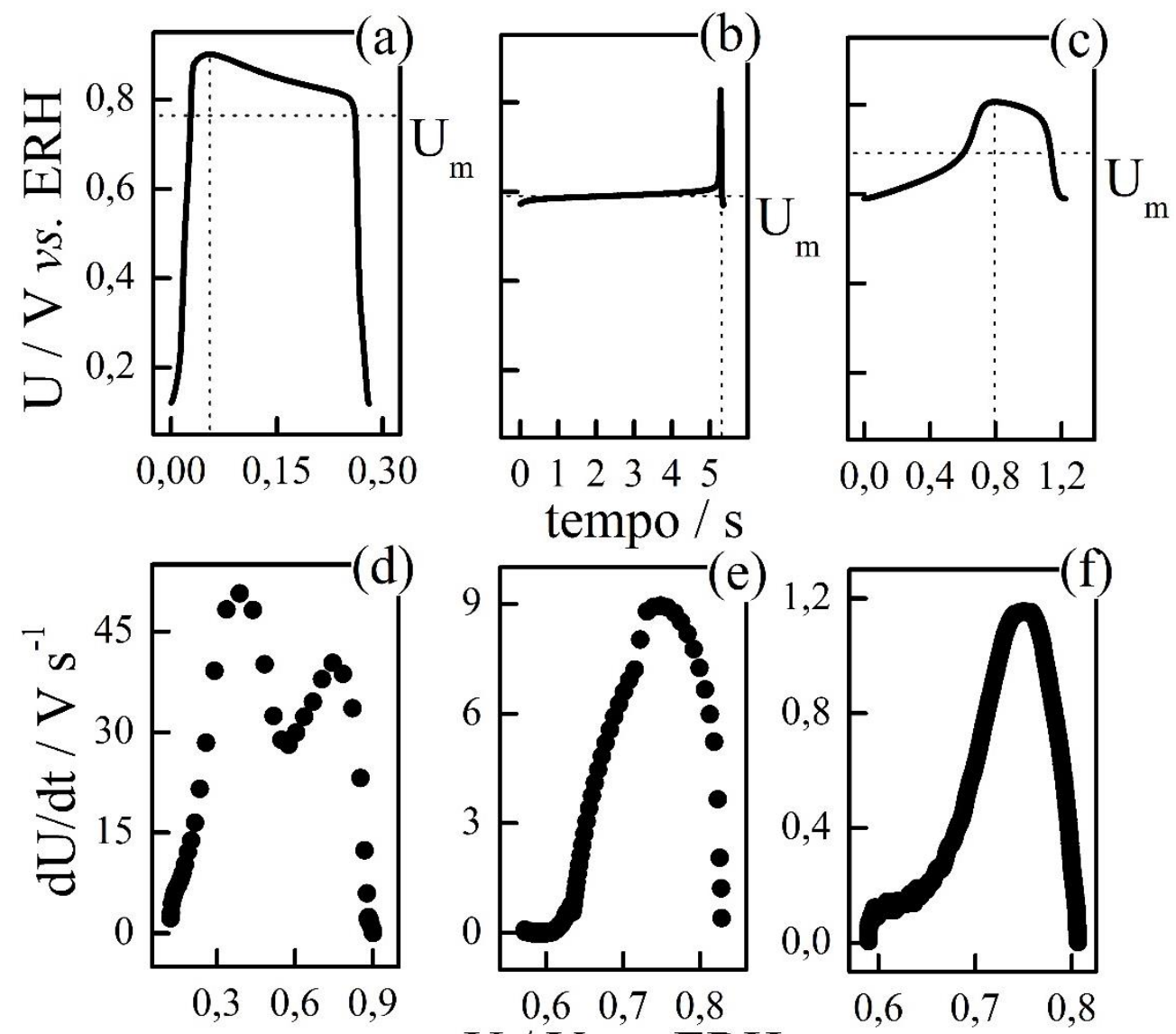
tempo / s

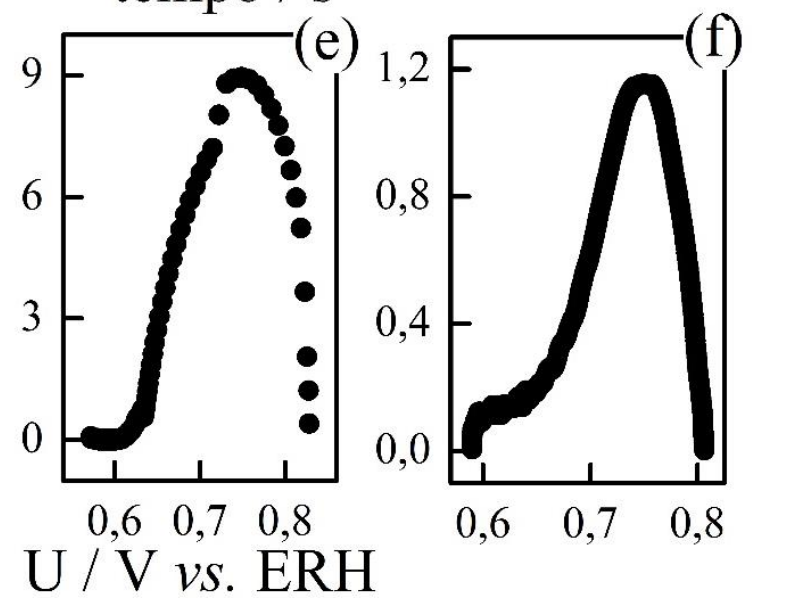


Para as três moléculas estudadas, a velocidade de envenenamento, $\mathrm{dU} / \mathrm{dt}$, é baixa quando o eletrodo está em seu menor valor, aumenta até um máximo e então diminui novamente; para formaldeído, dois máximos são observados. Em termos de valores absolutos, dU/dt diminui na sequência: formaldeído > ácido fórmico > metanol. Levando-se em conta que alta atividade eletrocatalítica implica, de certa forma, em alta susceptibilidade ao envenenamento, essa sequência é comparável com aquela dada anteriormente em termos da atividade inferida por meio das correntes de pico das curvas potenciodinâmicas. A discrepância evidente refere-se à maior velocidade de envenenamento dU/dt encontrada para formaldeído do que para ácido fórmico, enquanto que as atividades inferidas pelas curvas potenciodinâmicas são praticamente iguais.

A Tabela II mostra, para todos os casos, a máxima velocidade dU/dt e os seus correspondentes potenciais de pico $U_{p}$, a amplitude $\Delta U$ e a frequência de cada ciclo oscilatório. Também é mostrado o tempo necessário para que o potencial do eletrodo alcance o seu valor máximo durante um ciclo, $\mathrm{t}_{(\mathrm{Umax})}$.

Tabela II - máxima velocidade dU/dt e $\mathrm{U}_{\mathrm{p}}$ para um ciclo oscilatório, amplitude $(\Delta \mathrm{U})$, o tempo para o potencial atingir o seu valor máximo ( $\mathrm{t}_{\mathrm{Umax}}$ ) e frequência (f) para um ciclo oscilatório

\begin{tabular}{cccccc}
\hline Molécula & $\mathbf{d U} / \mathbf{d t}\left(\mathbf{V s}^{\mathbf{- 1}}\right)$ & $\mathbf{U} \mathbf{p}(\mathbf{V})$ & $\boldsymbol{\Delta} \mathbf{U}(\mathbf{V})$ & $\mathbf{t}_{\mathbf{U m a x}}(\mathbf{s})$ & $\mathbf{f}(\mathbf{H z})$ \\
\hline Formaldeído $^{\mathrm{a}, \mathrm{b} 1}$ & $50,7,40,3$ & $0,39,0,75$ & $0,12-0,9$ & 0,054 & 3,5 \\
\hline Formaldeído $^{\mathrm{b} 2}$ & $19,1,28,2$ & $0,37,0,75$ & $0,29-0,92$ & 0,17 & 3,3 \\
\hline Formaldeído $^{\mathrm{b} 3}$ & $6,4,8,5$ & $0,40,0,74$ & $0,37-0,94$ & 0,28 & 3,2 \\
\hline Ácido fórmico $^{\mathrm{a}}$ & 8,9 & 0,75 & $0,57-0,83$ & 5,3 & 0,19 \\
\hline Metanol $^{\mathrm{a}}$ & 1,2 & 0,75 & $0,59-0,81$ & 0,80 & 0,82 \\
\hline
\end{tabular}

${ }^{\text {a }}$ Dados extraídos de ciclos oscilatórios selecionados em regiões das séries temporais mostradas na Figura 26.

b1, b2, b3 Dados extraídos antes, em torno e depois da abrupta variação do potencial médio, respectivamente, c.f. Figure 26.

Como já mencionado, a evolução espontânea do potencial do eletrodo mostrada na Figura 28 traz mais informações sobre as reações de eletro-oxidação do que, por exemplo, as curvas potenciodinâmicas apresentadas na Figura 26. Isso deve-se ao fato de que, sob regime oscilatório, a importância de diferentes etapas reacionais muda continuamente ao longo de um ciclo oscilatório; enquanto sob regime regular, uma única etapa determinante domina o perfil observável. De fato, os parâmetros descritos na Tabela II variam drasticamente de acordo com a reação considerada. 
Esses parâmetros apresentados na Tabela II expressam: (a) a natureza e (b) a população de espécies adsorvidas, (c) suas velocidades de adsorção e (d) suas velocidades de reação envolvendo reações entre adsorbatos e/ou espécies em solução. Embora sejam parâmetros inerentes de cada sistema, é possível encontrar alguma regularidade entre eles sob a luz de alguns aspectos mecanísticos.

A correspondente curva de dU/dt na Figura 27 (a) mostra dois picos para o caso do formaldeído, um próximo a $0,4 \mathrm{~V}$, presumivelmente devido à alta velocidade de adsorção de $\mathrm{CO}$ em baixos potenciais,[62-64] e outro pico próximo de $0,75 \mathrm{~V}$, provavelmente devido à adsorção de espécies oxigenadas. Em adição, a adsorção de formiato $\mathrm{HCOO}_{\mathrm{ad}}$ deve ser considerada no segundo pico, já que sua eventual decomposição a $\mathrm{CO}_{2}$ é bastante lenta.[37, 39, 65]

O menor valor de, $\mathrm{t}_{(\text {Umax })}, 0,054 \mathrm{~s}$, encontrado para o caso do formaldeído, se comparado com aqueles obtidos para as outras moléculas, pode ser compreendido como se segue. Entre 0,12 e 0,4 V, na região do primeiro pico, a desidrogenação do formaldeído hidratado (metileno glicol) para $\mathrm{CO}_{\mathrm{ad}}$ tem uma cinética rápida,[59, 62] como sugerido pelo alto valor de $\mathrm{dU} / \mathrm{dt}$ para este pico, cf Tabela II. De todas as moléculas em estudo, o processo de desidrogenação do formaldeído é o menos susceptível à inibição causada pela adsorção de hidrogênio.[40] E ainda, nesse intervalo de potencial $\mathrm{CO}_{\mathrm{ad}}$ apenas se adsorve, já que a formação de espécies oxigenadas necessárias para a sua oxidação via uma etapa de Langmuir-Hinshelwood é desprezível.[66] Levando-se em consideração que o sucessivo acúmulo de $\mathrm{CO}_{\mathrm{ad}}$ inibe intensamente o processo de desidrogenação do formaldeído hidratado,[59] o sistema prontamente perde a sua capacidade de manter a corrente imposta através da interface nessa região de baixos valores de potencial. Devido ao aumento abrupto do sobrepotencial, um segundo processo de envenenamento envolvendo $\mathrm{HCOO}_{\mathrm{ad}}$ e espécies oxigenadas é iniciado, provocando um novo aumento abrupto do sobrepotencial.[63, 64]

Particularmente a série temporal obtida para formaldeído pode ser dividida em três regiões: a primeira localizada antes da abrupta variação do potencial médio e outras duas, em torno e depois desta variação intensa, cf. Figura 26 (a). Como os perfis de dU/dt são similares para as oscilações situadas nessas três regiões, na Figura 28 foi apresentado somente o ciclo oscilatório da primeira região e o seu correspondente perfil de dU/dt. Características específicas dos ciclos oscilatórios situados nas outras regiões são mostradas na Tabela II. O tempo de transição de baixo para alto sobrepotencial $t_{\max }$ aumenta ao longo dessas três regiões porque o potencial mímimo também aumenta, cf. $\Delta \mathrm{U}$ na Tabela II, resultando em uma cinética de adsorção de $\mathrm{CO}_{\mathrm{ad}}$ mais lenta. Da mesma forma, o valor máximo de $\mathrm{dU} / \mathrm{dt}$ relacionado com os primeiros picos diminui e a mesma 
tendência é observada para dU/dt associado com os segundos picos. Já que a velocidade de envenenamento diminui, evidentemente outras etapas reacionais devem ser favorecidas de modo a suportar a corrente aplicada, como por exemplo, a rápida oxidação via glicolato de metileno, a ácido fórmico e $\mathrm{CO}_{2}$.[59] Claro que não se pode subestimar a oxidação de $\mathrm{CO}_{\mathrm{ad}}$ a partir de 0,55 V e,[66] portanto, a organização estrutural das espécies que bloqueiam a superfície, a cinética de adsorção de espécies oxigenadas e a oxidação de $\mathrm{CO}_{\mathrm{ad}}$ devem ter um impacto nesse comportamento, mas técnicas in situ e on line são indispensáveis para se fazer inferências neste sentido.

Essa diminuição da velocidade de envenenamento e o consequente aumento da contribuição de outros caminhos para a corrente global, que não passam pela formação de $\mathrm{CO}_{\mathrm{ad}}$,[59] claramente causa uma melhora em termos de sobrepotencial, como se pode deduzir pela considerável diminuição do potencial médio ao longo da série temporal, cf. Figura 26 (a). Por outro lado, a diminuição da amplitude $\Delta \mathrm{U}$ evidencia um decréscimo da eficiência do processo de reativação da superfície.

Para ambas as moléculas, ácido fórmico e metanol, os ciclos oscilatórios começam por volta de $0,6 \mathrm{~V}$, cf. $\Delta \mathrm{U}$ na Tabela II. $\mathrm{O}$ valor de $\mathrm{dU} / \mathrm{dt}$ alcança um máximo próximo de $0,75 \mathrm{~V}$ devido ao acúmulo de espécies oxigenadas e $\mathrm{HCOO}_{\mathrm{ad}}$.[30, 67, 68] Como o processo de envenenamento para esses ciclos acontece entre 0,6 e 0,75 V, a cinética de adsorção de CO para o caso do ácido fórmico e do metanol deve ser mais lenta do que aquela apresentada pelo formaldeído.[62]

Especificamente para os ciclos oscilatórios do ácido fórmico, antes do aumento abrupto do potencial, existe uma região centrada em torno de $0,6 \mathrm{~V}$ em que o potencial é quase invariante com o tempo, cf. Figura 28 (b) e (f). Osawa e colaboradores atribuíram a quase invariância do potencial

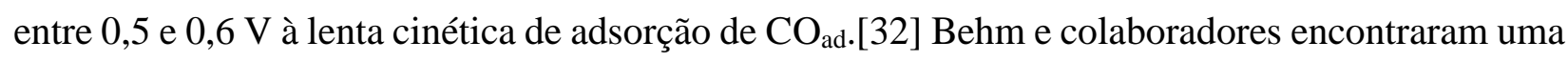
contribuição menor do que $1 \%$ da oxidação de $\mathrm{CO}_{\mathrm{ad}}$ para a corrente global, sob condições específicas, à 0,6 V.[69] Sobre o intenso aumento de potencial, com base em novas evidências de uma terceira via reacional,[39] resultados experimentais e simulações, Chen e colaboradores[37] mostraram que a supressão da corrente reacional e o consequente aumento abrupto do potencial é causado pela adsorção de espécies oxigenadas e $\mathrm{HCOO}_{\mathrm{ad}}$.

O maior valor do tempo de transição de baixo para alto sobrepotencial observado para o ciclo do ácido fórmico do que os observados para formaldeído e metanol, cf. , $\mathfrak{t}_{(\text {Umax }}$ na Tabela II, evidencia a sua maior capacidade de transferência de carga via intermediário reativo durante o 
lento processo de envenenamento superficial em torno de 0,6 V. Essa alta capacidade, aliada ao lento envenenamento, beneficia a eletro-oxidação oscilatória do ácido fórmico em termos de sobrepotencial, como se pode notar pelos seus baixíssimos valores de potencial médio na Figura 26 (b), se comparado com os valores observados para as outras moléculas.

Embora os ciclos oscilatórios de metanol e ácido fórmico aconteçam aproximadamente no mesmo intervalo de potencial, cf. $\Delta \mathrm{U}$ na Tabela 2 , o menor intervalo de tempo entre baixo e alto potencial observado para o ciclo oscilatório do metanol, $\mathrm{t}_{(\mathrm{Umax})}$, apesar do baixo valor de dU/dt, indica uma menor capacidade deste sistema em manter a corrente aplicada durante seu específico processo de envenenamento. Essa constatação é concordante com estudos teóricos que mostram que os processos de transferência de carga envolvendo a desidrogenação do metanol requer diversos sítios superficiais livres.[70, 71]

A quantidade de monóxido de carbono $\mathrm{CO}_{\mathrm{ad}}$ formado durante a eletro-oxidação de moléculas orgânicas pequenas depende criticamente da identidade da molécula. Por exemplo, Jusys e Behm relataram recobrimentos de 87,36 e $10 \%$ (em relação a uma camada saturada de CO em condições idênticas) depois da adsorção de formaldeído, ácido fórmico e metanol sobre platina, respectivamente. Além do mais, o potencial em que o $\mathrm{CO}_{\mathrm{ad}}$ é oxidado depende intensamente da estrutura e/ou de interações laterais entre espécies adsorvidas, sendo que a intensidade dessas interações criticamente depende da identidade da molécula precursora, i.e. da molécula orgânica sob consideração.[72]

Em regime oscilatório, tem sido relatado para ácido fórmico mudanças autônomas de recobrimento de monóxido de carbono $\mathrm{CO}_{\mathrm{ad}}$ e formiato coordenado em ponte $\mathrm{HCOO}_{\mathrm{ad}}$ em um intervalo de 0,20 a 0,30 monocamadas (ML) e 0,10 a 0,20 ML, respectivamente.[32] Para metanol, mudanças de recobrimento de $\mathrm{CO}_{\mathrm{ad}}$ em torno de 0,24 e 0,37 $\mathrm{ML}$ foram estimadas.[73] Essas estimativas do grau de recobrimento de $\mathrm{CO}_{\mathrm{ad}}$ e $\mathrm{HCOO}_{\mathrm{ad}}$ sugerem que a superfície não está completamente saturada por estes intermediários. Desse modo, como as oscilações de potencial ocorrem em um alto intervalo de potencial, espécies oxigenadas também podem ter um papel importante no processo de desativação superficial.

Em regime oscilatório, mudanças autônomas em $U$ expressam uma resposta interna do sistema em decorrência da aplicação de uma corrente. Em comparação com um sistema operando em regime não-oscilatório, em que intermediários parcialmente oxidados se acumulam e desativam a superfície do catalisador, sistemas sob condição oscilatória apresentam uma contínua mudança 
da quantidade de espécies adsorvidas, originando um processo de limpeza autônomo que retarda a desativação superficial. 


\section{CONCLUSÕES}

$\mathrm{Na}$ metodologia analítica desenvolvida, apoiada na premissa da máxima contribuição possível, o peso de cada contribuição faradaica, ou seja, cada parâmetro de regressão $\beta$ é determinado pela restrição imposta, pelo método dos mínimos quadrados e também pelo perfil de sua correspondente corrente iônica: para a maioria das pequenas moléculas orgânicas, o perfil da produção da espécie volátil de contribuição faradaica majoritária é o qual mais se assemelha ao da corrente faradaica total. A metodologia foi testada aplicando-a na análise de três moléculas com distintos mecanismos reacionais e cujos modelos de regressão multivariada incorporaram diferentes correntes iônicas: $m / z=44$ para ácido fórmico, $m / z=44$ e 60 para metanol e $m / z=15$, 29 e 44 para etanol. Além disso, a partir de uma dedução lógica apoiada em independentes trabalhos disponíveis na literatura, demonstrou-se que os resultados obtidos são concordantes com o mecanismo reacional de cada molécula. Por fim, a metodologia permite, qualitativamente e comparativamente, ordenar a contribuição faradaica proveniente da produção de espécies voláteis para a corrente faradaica total, bem como inferir sobre espécies solúveis parcialmente oxidadas não detectadas, tornando-a bastante útil para a comparação de diferentes conjuntos de dados, como por exemplo, para o estudo da influência de parâmetros reacionais na produção de espécies voláteis.

Com o intuito de comparar a atividade de diferentes sistemas operando em regimes convencional e oscilatório, as oxidações de formaldeído, ácido fórmico e metanol foram realizadas sob condições equivalentes sobre platina policristalina em meio ácido. As velocidades reacionais sob regime não-oscilatório foram estimadas por meio de curvas potenciodiâmicas lentas, sendo observado que a atividade inferida pela corrente de pico diminui na sequência: formaldeído ácido fórmico > metanol. Um sobrepotencial de pelo menos $500 \mathrm{mV}$ foi constatado para todos os casos estudados. Durante a eletro-oxidação oscilatória dessas moléculas, os menores potenciais alcançados durante as oscilações notadamente diminuem o sobrepotencial para a reação anódica. Isso resulta em um considerável aumento na conversão global e, portanto, no desempenho dos sistemas. Uma estimativa para uma célula hipotética alimentada com formaldeído líquido e operando sob regime oscilatório demonstrou o dobro de densidade de potência do que a mesma estimativa realizada para o regime convencional. Do ponto de vista do mecanismo reacional, as características das oscilações espontâneas de cada sistema demonstraram-se bastante diferentes umas das outras, trazendo informações adicionais sobre o mecanismo reacional. 


\section{REFERÊNCIAS BIBLIOGRÁFICAS}

${ }^{1}$ KRISCHER, K.; VARELA, H. Oscillations and other dynamic instabilities. In: VIELSTICH, W; LAMM, A.; GASTEIGER, H. A. Handbook of fuel cells: fundamentals, technology and applications. Chichester: Wiley, 2003. v. 2. p. 679-701.

${ }^{2}$ DELMONDE, M. V. F.; SALLUM, L. F.; PERINI, N.; VARELA, H. The activity of the electro-oxidation of liquid fuels under oscillatory regime. In: Ertl symposium on surface analysis and dynamics, 3., 2014, Berlin.

${ }^{3}$ NAGAO, R.; CANTANE, D. A.; LIMA, F. H. B.; VARELA, H. The dual pathway in action: decoupling parallel routes for $\mathrm{CO} 2$ production during the oscillatory electro-oxidation of methanol. Physical Chemistry Chemical Physics, v. 14, p. 8294-8298, 2012.

${ }^{4}$ CALVO, E. J. Interfacial Kinetics and Mass Transport. In: BARD, A. J.; STRATMANN, M. Encyclopedia of electrochemistry. Weinheim: Wiley-VCH, 2003. v. 2, p. 553.

${ }^{5}$ LAMY, C.; BELGSIR, E. M.; LEGER, J. M. Electrocatalytic oxidation of aliphatic alcohols: Application to the direct alcohol fuel cell (DAFC). Journal of Applied Electrochemistry, v. 31, p. 799-809, 2001.

${ }^{6}$ ZHANG, J. X.; DATTA, R. Sustained potential oscillations in proton exchange membrane fuel cells with PtRu as anode catalyst. Journal of the Electrochemical Society, v. 149, p. A1423A1431, 2002.

${ }^{7}$ LOPES, P. P.; TICIANELLI, E. A.; VARELA, H. Potential oscillations in a proton exchange membrane fuel cell with a Pd-Pt/C anode. Journal of Power Sources, v. 196, p. 84-89, 2011.

${ }^{8}$ KADYK, T.; KIRSCH, S.; HANKE-RAUSCHENBACH, R.; SUNDMACHER, K. Autonomous potential oscillations at the Pt anode of a polymer electrolyte membrane fuel cell under CO poisoning. Electrochimica Acta, v. 56, p. 10593-10602, 2011.

${ }^{9}$ EPSTEIN, I. R.; POJMAN, J. A. An introduction to nonlinear chemical dynamics. Oscillations, waves, patterns, and chaos. New York: Oxford University Press, 1998. p. 392.

${ }^{10}$ KRISCHER, K. Nonlinear dynamics in electrochemical systems. In: ALKIRE, R. C.; KOLB, D. M. Advances in Electrochemical Science and Engineering. Weinheim: Wiley, 2002. v. 8, p. 90-203.

${ }^{11}$ KOPER, M. T. M.; SLUYTERS, J. H. Electrochemical oscillatores - their description through a mathematical-model. Journal of Electroanalytical Chemistry, v. 303, p. 73-94, 1991. 
${ }^{12}$ KOPER, M. T. M. The theory of electrochemical instabilities. Electrochimica Acta, v. 37, p. 1771-1778, 1992.

${ }^{13}$ KOPER, M. T. M.; SLUYTERS, J. H. On the mathematical unification of a class of electrochemical oscillators and their design procedures. Journal of Electroanalytical Chemistry, v. 352, p. 51-64, 1993.

${ }^{14}$ ORLIK, M. Self-organization in electrochemical systems I: general principles of selforganization temporal instabilities. Berlin: Springer, 2012. p. 528.

${ }^{15}$ BARD, A. J.; FAULKNER, L. R. Electrochemical methods: fundamentals and applications. 2. New York: John Wiley \& Sons, 2001. p. 650.

${ }^{16}$ STROGATZ, S. H. Nonlinear dynamics and chaos: with applications to physics, biology, chemistry and engineering. Massachussets: Perseus, 1994. p. 498.

${ }^{17}$ KOPER, M. T. M. Non-linear phenomena in electrochemical systems. Journal of the Chemical Society-Faraday Transactions, v. 94, p. 1369-1378, 1998.

${ }^{18}$ ABELL, M. L.; BRASELTON, J. P. Differential equations with mathematica. 3. ed. San Diego: Academic Press, 2004. p. 876.

${ }^{19}$ KRISCHER, K. Principles of temporal and spatial pattern formation in electrochemical systems. In: CONWAY, K.; BOCKRIS, B. E.; WHITE, J. O. Modern aspects of electrochemistry. New York: Kluver Academic/Plenum Publishers, 1999. v. 32, p. 1-142.

${ }^{20}$ LYNCH, S. Dynamical systems with applications using Mathematica. Boston: Birkhüauser, 2007. p. 484.

${ }^{21}$ KOPER, M. T. M.; SLUYTERS, J. H. Instabilities and oscillations in simple-models of electrocatalytic surface-reactions. Journal of Electroanalytical Chemistry, v. 371, p. 149-159, 1994.

${ }^{22}$ BALTRUSCHAT, H. Differential electrochemical mass spectrometry. Journal of the American Society for Mass Spectrometry, v. 15, , p. 1693-1706, 2004.

${ }^{23}$ WOLTER, O.; HEITBAUM, J. Differential electrochemical mass-spectroscopy (DEMS) - A new method for the study of electrode processes. Berichte Der Bunsen-Gesellschaft-Physical Chemistry Chemical Physics, v. 88, p. 2-6, 1984. 
${ }^{24}$ IWASITA, T.; PASTOR, E. A DEMS and FTIR stectroscopic investigation of adsorbed ethanol on polycrystalline platinum. Electrochimica Acta, v. 39, p. 531-537, 1994.

${ }^{25}$ BITTINS-CATTANEO, B.; WILHELM, S.; CATTANEO, E.; BUSCHMANN, H. W.; VIELSTICH, W. Intermediates and products of ethanol oxidation on platinum in acid solution. Berichte der Bunsengesellschaft für physikalische chemie, v. 92, p. 1210-1218, 1988.

${ }^{26}$ JOHNSON, R. A.; WICHERN, D. W. Applied multivariate statistical analysis. 6. ed. New Jersey: Pearson, 1998. p. 800.

${ }^{27}$ NETO, B. D. B.; SCARMINIO, I. S.; BRUNS, R. E. Como fazer experimentos: pesquisa e desenvolvimento na ciência e na indústria. 2. ed. Campinas: UNICAMP, 2001. p. 412.

${ }^{28}$ OKAMOTO, H. Mechanistic studies of the potential oscillation and induction period in the oxidation of formic-acid on platinum. Electrochimica Acta, v. 37, p. 37-42, 1992.

${ }^{29}$ NAGAO, R.; EPSTEIN, I. R.; GONZALEZ, E. R.; VARELA, H. Temperature (over) compensation in an oscillatory surface reaction. Journal of Physical Chemistry A, v. 112, p. 4617-4624, 2008.

${ }^{30}$ MEI, D.; He, Z.; JIANG, D. C.; CAI, J.; CHEN, YAN-XIA. Modeling of potential oscillation during galvanostatic electrooxidation of formic acid at platinum electrode. Journal of Physical Chemistry C, v. 118, p. 6335-6343, 2014.

${ }^{31}$ MUKOUYAMA, Y.; KIKUCHI, M.; SAMJESKE, G.; OSAWA, M.; OKAMOTO, H. Potential oscillations in galvanostatic electrooxidation of formic acid on platinum: A mathematical modeling and simulation. Journal of Physical Chemistry B, v. 110, p. 1191211917, 2006.

${ }^{32}$ SAMJESKE, G.; MIKI, A.; YAMAKATA, A.; MUKOUYAMA, Y.; OKAMOTO, H.; OSAWA, M. Potential oscillations in galvanostatic electrooxidation of formic acid on platinum: A time-resolved surface-enhanced infrared study. Journal of Physical Chemistry B, v. 109, p. 23509-23516, 2005.

${ }^{33}$ ABD-EL-LATIF, A. A.; BALTRUSCHAT, H. Formation of methylformate during methanol oxidation revisited: the mechanism. Journal of Electroanalytical Chemistry, v. 662, p. 204$212,2011$.

${ }^{34}$ NAGAO, R.; CANTANE, D. A.; LIMA, F. H. B.; VARELA, H. Influence of anion adsorption on the parallel reaction pathways in the oscillatory electro-oxidation of methanol. Journal of Physical Chemistry C, v. 117, p. 15098-15105, 2013. 
${ }^{35}$ ZHANG, L. J.; XIE, Q. J.; YAO, S. Z. EQCM study on the potential oscillations during galvanostatic oxidation of glucose, galactose and ethanol. Acta Physico-Chimica Sinica, v. 21, p. 977-982, 2005.

${ }^{36}$ HAN, L.; JU, H.; XU, Y. Ethanol electro-oxidation: Cyclic voltammetry, electrochemical impedance spectroscopy and galvanostatic oscillation. International Journal of Hydrogen Energy, v. 37, p. 15156-15163, 2012.

${ }^{37}$ CHEN, Y. X.; HEINEN, M.; JUSYS, Z.; BEHM, R. J. Bridge-bonded formate: Active intermediate or spectator species in formic acid oxidation on a Pt film electrode? Langmuir, v. 22, p. 10399-10408, 2006.

${ }^{38}$ CHEN, Y. X.; HEINEN, M.; JUSYS, Z.; BEHM, R. J. Kinetics and mechanism of the electrooxidation of formic acid - Spectroelectrochemical studies in a flow cell. Angewandte Chemie-International Edition, v. 45, p. 981-985, 2006.

${ }^{39}$ JOO, J.; UCHIDA, T.; CUESTA, A.; KOPER, M. T. M.; OSAWA, M. Importance of acid-base equilibrium in electrocatalytic oxidation of formic acid on platinum. Journal of the American Chemical Society, v. 135, p. 9991-9994, 2013.

${ }^{40}$ JUSYS, Z.; KAISER, J.; BEHM, R. J. Methanol electrooxidation over Pt/C fuel cell catalysts: Dependence of product yields on catalyst loading. Langmuir, v. 19, p. 6759-6769, 2003.

${ }^{41}$ IWASITA, T.; VIELSTICH, W. Online mass-spectroscopy of volatile products during methanol oxidation at platinum acid-solutions. Journal of Electroanalytical Chemistry, v. 201, p. 403-408, 1986.

${ }^{42}$ BATISTA, E. A.; MALPASS, G. R. P.; MOTHEO, A. J.; IWASITA, T. New mechanistic aspects of methanol oxidation. Journal of Electroanalytical Chemistry, v. 571, p. 273-282, 2004.

${ }^{43}$ WANG, H.; LOFFLER, T.; BALTRUSCHAT, H. Formation of intermediates during methanol oxidation: A quantitative DEMS study. Journal of Applied Electrochemistry, v. 31, p. 759-765, 2001.

${ }^{44}$ SRIRAMULU, S.; JARVI, T. D.; STUVE, E. M. A kinetic analysis of distinct reaction pathways in methanol electrocatalysis on Pt(111). Electrochimica Acta, v. 44, p. 1127-1134, 1998. 
${ }^{45}$ PARSONS, R.; VANDERNOOT, T. The oxidation of small organic-molecules - A survey of recent fuel-cell related research. Journal of Electroanalytical Chemistry, v. 257, p. 9-45, 1988.

${ }^{46}$ IWASITA, T. Electrocatalysis of methanol oxidation. Electrochimica Acta, v. 47, p. $3663-$ 3674, 2002.

${ }^{47}$ KUNIMATSU, K.; HANAWA, H.; UCHIDA, H.; WATANABE, M. Role of adsorbed species in methanol oxidation on Pt studied by ATR-FTIRAS combined with linear potential sweep voltammetry. Journal of Electroanalytical Chemistry, v. 632, p. 109-119, 2009.

${ }^{48}$ WANG, H. S.; WINGENDER, C.; BALTRUSCHAT, H.; LOPEZ, M.; REETZ, M. T. Methanol oxidation on Pt, PtRu, and colloidal Pt electrocatalysts: a DEMS study of product formation. Journal of Electroanalytical Chemistry, v. 509, p. 163-169, 2001.

${ }^{49}$ HOUSMANS, T. H. M.; WONDERS, A. H.; KOPER, M. T. M. Structure sensitivity of methanol electrooxidation pathways on platinum: An on-line electrochemical mass spectrometry study. Journal of Physical Chemistry B, v. 110, p. 10021-10031, 2006.

${ }^{50}$ CAMARA, G. A.; IWASITA, T. Parallel pathways of ethanol oxidation: the effect of ethanol concentration. Journal of Electroanalytical Chemistry, v. 578, p. 315-321, 2005.

${ }^{51}$ ABD-EL-LATIF, A. A.; MOSTAFA, E.; HUSTER, S.; ATTARD, G.; BALTRUSCHAT, H. Electrooxidation of ethanol at polycrystalline and platinum stepped single crystals: a study by differential electrochemical mass spectrometry. Electrochimica Acta, v. 55, p. 7951-7960, 2010.

${ }^{52}$ IWASITA, T.; RASCH, B.; CATTANEO, E.; VIELSTICH, W. A SNIFTIRS study of ethanol oxidation on platinum. Electrochimica Acta, v. 34, p. 1073-1079, 1989.

${ }^{53}$ LAI, S. C. S.; KLEYN, S. E. F.; ROSCA, V.; KOPER, M. T. M. Mechanism of the dissociation and electrooxidation of ethanol and acetaldehyde on platinum as studied by SERS. Journal of Physical Chemistry C, v. 112, p. 19080-19087, 2008.

${ }^{54}$ WANG, H.; JUSYS, Z.; BEHM, R. J. Ethanol electro-oxidation on carbon-supported Pt, PtRu and Pt3Sn catalysts: A quantitative DEMS study. Journal of Power Sources, v. 154, p. 351-359, 2006.

${ }^{55}$ HITMI, H.; BELGSIR, E. M.; LEGER, J. M.; LAMY, C.; LEZNA, R. O. A kinetic, analysis of the electrooxidation of ethanol at a platinum-electrode in acid-medium. Electrochimica Acta, v. 39, p. 407-415, 1994. 
${ }^{56}$ LAI, S. C. S.; KLEIJN, S. E. F.; OZTURK, F. T. Z.; VELLINGA, V. C. V. R., KONING, J.; RODRIGUEZ, P.; KOPER, M. T. M. Effects of electrolyte $\mathrm{pH}$ and composition on the ethanol electro-oxidation reaction. Catalysis Today, v. 154, p. 92-104, 2010.

${ }^{57}$ WANG, H.; JUSYS, Z.; BEHM, R. J. Ethanol electrooxidation on a carbon-supported Pt catalyst: Reaction kinetics and product yields. Journal of Physical Chemistry B, v. 108, p. 19413-19424, 2004.

${ }^{58}$ SUN, S.; HALSEID, M. C.; HEINEN, M.; JUSYS, Z.; BEHM, R. J. Ethanol electrooxidation on a carbon-supported Pt catalyst at elevated temperature and pressure: A high-temperature/highpressure DEMS study. Journal of Power Sources, v. 190, p. 2-13, 2009.

${ }^{59}$ BATISTA, E. A.; IWASITA, T. Adsorbed intermediates of formaldehyde oxidation and their role in the reaction mechanism. Langmuir, v. 22, p. 7912-7916, 2006.

${ }^{60}$ NAGAO, R.; SITTA, E.; VARELA, H. Stabilizing nonstationary electrochemical time series. Journal of Physical Chemistry C, v. 114, p. 22262-22268, 2010.

${ }^{61}$ CABRAL, M. F.; NAGAO, R.; SITTA, E.; EISWIRTH, M.; VARELA, H. Mechanistic aspects of the linear stabilization of non-stationary electrochemical oscillations. Physical Chemistry Chemical Physics, v. 15, p. 1437-1442, 2013.

${ }^{62}$ REICHERT, R.; SCHNAIDT, J.; JUSYS, J.; BEHM, R. J. The influence of reactive side products in electrocatalytic reactions: methanol oxidation as case study. Chemphyschem, v. 14, p. 3678-3681, 2013.

${ }^{63}$ MIKI, A.; YE, S.; SENZAKI, T.; OSAWA, M. Surface-enhanced infrared study of catalytic electrooxidation of formaldehyde, methyl formate, and dimethoxymethane on platinum electrodes in acidic solution. Journal of Electroanalytical Chemistry, v. 563, p. 23-31, 2004.

${ }^{64}$ SAMJESKE, G.; MIKI, A.; OSAWA, M. Electrocatalytic oxidation of formaldehyde on platinum under galvanostatic and potential sweep conditions studied by time-resolved surfaceenhanced infrared spectroscopy. Journal of Physical Chemistry C, v. 111, p. 15074-15083, 2007.

${ }^{65}$ BRIMAUD, S.; SOLLA-GULLON, J.; WEBER, I.; FELIU, J. M.; BEHM, R. J. Formic acid electrooxidation on noble-metal electrodes: role and mechanistic implications of $\mathrm{pH}$, surface structure, and anion adsorption. Chemelectrochem, v. 1, p. 1075-1083, 2014. 
${ }^{66}$ CLIMENT, V.; GOMEZ, R.; ORTS, J. M.; FELIU, J. M. Thermodynamic analysis of the temperature dependence of $\mathrm{OH}$ adsorption on $\mathrm{Pt}(111)$ and $\mathrm{Pt}(100)$ electrodes in acidic media in the absence of specific anion adsorption. Journal of Physical Chemistry B, v. 110, n. 23, p. 11344-11351, 2006.

${ }^{67}$ CHEN, Y. X.; MIKI, A.; YE, S.; SAKAI, H.; OSAWA, M. Formate, an active intermediate for direct oxidation of methanol on Pt electrode. Journal of the American Chemical Society, v. 125, p. 3680-3681, 2003.

${ }^{68}$ SAMJESKE, G.; OSAWA, M. Current oscillations during formic acid oxidation on a Pt electrode: Insight into the mechanism by time-resolved IR spectroscopy. Angewandte ChemieInternational Edition, v. 44, p. 5840-5844, 2005.

${ }^{69}$ CHEN, Y. X.; YE, S.; HEINEN, M.; JUSYS, Z.; OSAWA, M.; BEHM, R. J. Application of insitu attenuated total reflection-Fourier transform infrared spectroscopy for the understanding of complex reaction mechanism and kinetics: Formic acid oxidation on a Pt film electrode at elevated temperatures. Journal of Physical Chemistry B, v. 110, p. 9534-9544, 2006.

${ }^{70}$ CAO, D.; LU, G. Q.; WIECKOWSKI, A.; WASILESKI, S. A.; NEUROCK, M. Mechanisms of methanol decomposition on platinum: A combined experimental and ab initio approach.

Journal of Physical Chemistry B, v. 109, p. 11622-11633, 2005.

${ }^{71}$ OKAMOTO, Y.; SUGINO, O.; MOCHIZUKI, Y; IKESHOJI, T.; MORIKAWA, Y. Comparative study of dehydrogenation at $\mathrm{Pt}(111) /$ water and $\mathrm{Pt}(111) /$ vacuum of methanol interfaces. Chemical Physics Letters, v. 377, p. 236-242, 2003.

72 JUSYS, Z.; BEHM, R. J. Methanol, formaldehyde and formic acid adsorption/oxidation on a carbon-supported Pt nanoparticules fuel cell catalyst: a comparative quantitative DEMS study. In: KOPER, M. T. M. Fuel cell catalysis: a surface science approach. New York: Wiley, 2009. v. 1, p. 411-464.

${ }^{73}$ BOSCHETO, E.; BATISTA, B. C.; LIMA, R. B.; VARELA, H. A surface-enhanced infrared absorption spectroscopic (SEIRAS) study of the oscillatory electro-oxidation of methanol on platinum. Journal of Electroanalytical Chemistry, v. 642, p. 17-21, 2010. 